Nation-Building as Necessary Effort in Fragile States 



\section{Nation-Building as Necessary Effort in Fragile States}

René Grotenhuis 
Cover illustration: Supporters of Afghan presidential candidate Dr. Abdullah Abdullah listen to his speech in Kabul, Afghanistan on 27 September 2009. Afghan Independent Election Commission announced on 26 September 2009, the preliminary results for 357 provincial lawmakers, while there was still no exact date for final results of hotly disputed presidential elections.

(c) EPA/S. Sabawoon

Cover design: Coördesign, Leiden

Lay-out: Crius Group, Hulshout

Amsterdam University Press English-language titles are distributed in the US and Canada by the University of Chicago Press.

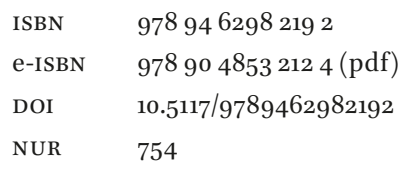

Creative Commons License CC BY NC (http://creativecommons.org/licenses/by-nc/3.o)

@ René Grotenhuis / Amsterdam University Press B.V., Amsterdam 2016

All rights reserved. Without limiting the rights under copyright reserved above, no part of this book may be reproduced, stored in or introduced into a retrieval system, or transmitted, in any form or by any means (electronic, mechanical, photocopying, recording or otherwise) without the written permission of both the copyright owner and the author of the book. 


\section{Table of contents}

1 Struggling in the world of nation-states 15

Nation-state: Self-determination ánd international acceptance $\quad 19$

The puzzling nation-state $\quad 22$

2 Nation and state $\quad 25$

The Montevideo Convention: The defined state 25

The undefined nation $\quad 26$

Nation and state intertwined $\quad 28$

Does the state presuppose a nation? $\quad 29$

Does the nation presuppose a state? 30

War and the making of the nation-state 33

An ideal model for the nation-state? $\quad 35$

The nation-state in a globalizing world 37

The changing map of the world $\quad 38$

The nation-state: A coveted object 40

The absent state 41

Vignette: From commanders to governors in South Sudan 43

3 Fragility: A donor's concept but not far from reality 45

Fragility: Definitions and reality $\quad 45$

A conceptual model for fragility 47

Fragility: Social networks, governments and hybrid political order? $5^{0}$

The New Deal for Engagement in Fragile States $\quad 5^{2}$

Vignette: Blueprints, checklists and formats: Disarmament in the DRC 56

4 Nation-building: Sovereignty and citizenship $\quad 59$

The people as sovereign 59

Republican citizenship: In-between individual and community $\quad 61$

Republican citizenship in fragile states 63

Citizenship as solid base for diversity $\quad 66$

$\begin{array}{ll}\text { Who is the citizen? } & 67\end{array}$

Citizenship under pressure in a globalizing world $\quad 69$

Vignette: Protecting the role of local organizations in Afghanistan 71 
5 Nation-building and state-building and the challenge of fragility 73

Nation-building and state-building in international political discourse $\quad 74$

The intertwined nature of nation-building and state-building $\quad 81$

Nation-building and state-building: Trust as the linking pin $\quad 84$

Why is state-building not good enough in fragile contexts? $\quad 85$

Nation-building in fragile states: History never repeats itself $\quad 89$

Vignette: Transitional Justice in Afghanistan 992

6 Peacemaking as the preliminary step towards nation-

building and state-building

Vignette: An outspoken and inclusive mediator in Colombia 100

7 The Scylla and Charybdis of nation-building 101

The Scylla of nation-building: Identity as exclusion 102

The Charybdis of nation-building: Silencing identity 102

$\begin{array}{ll}\text { Moderate patriotism } & 105\end{array}$

Vignette: NGOs blamed as allies of opposition in Burundi $\quad 107$

8 Nation-building: Identity and identification, process and content 109

The dangerous romanticism of homogeneous nation-states $\quad 109$

From identity to identification 111

Identification and fragility $\quad 113$

Heterogeneity in fragile states $\quad 115$

Nationhood and minorities $\quad 116$

Nation-building as nation-destroying $\quad 119$

$\begin{array}{ll}\text { National identity as moving target } & 121\end{array}$

Vignette: Imagination of reality in Gaza

9 National identity: A model and its content 125

$\begin{array}{ll}\text { National identity: The model of Shulman } & 127\end{array}$

Is Shulman's model applicable to fragile nation-states? $\quad 129$

A modified model for fragile nation-states $\quad 132$

Nationhood and civic identity $\quad 134$

$\begin{array}{ll}\text { Nationhood and religious identity } & 136\end{array}$ 
$\begin{array}{ll}\text { Nationhood and cultural identity } & 140\end{array}$

$\begin{array}{lr}\text { Nationhood and ethnicity } & 141\end{array}$

$\begin{array}{lr}\text { From open to ascribed identity } & 145\end{array}$

$\begin{array}{lr}\text { Case: Bangsamoro nation } & 148\end{array}$

10 A program for nation-building in fragile states 153

Content: The elements that make up national identity $\quad 154$

Process: Nation-building is a learning process $\quad 159$

Institutions: Nation-building requires an institutional setup $\quad 163$

Actors: Nation-building is a national endeavor $\quad 166$

The possibility of nation-building for different modes of state

fragility 172

Vignette: Legitimacy for development organizations in Uruzgan $\quad 178$

Case: Rwanda: Nation-building in mildly authoritarian regimes $\quad 180$

Epilogue: The challenges of fragility - and the beginning of an answer 183

$\begin{array}{lr}\text { Commit to interdisciplinarity } & 187\end{array}$

$\begin{array}{lr}\text { Build the nation-state on solid soil } & 189\end{array}$

$\begin{array}{lr}\text { Acknowledgements } & 191\end{array}$

$\begin{array}{ll}\text { Bibliography } & 193\end{array}$

$\begin{array}{lr}\text { Index } & 199\end{array}$ 



\section{Prologue: The urgency of reality}

In the Afghan presidential elections of 2014 the ethnic identity of the candidates and their running mates appeared to be the key issue in the electoral campaign. Candidate Abdullah Abdullah was perceived as someone of the Northern Alliance and candidate Zalmai Rassoul as the representative of the Pashtun. Ashraf Ghani as a Pashtun selected Abdul Dostum (an Uzbek) as his running mate to strike a balance between the south and the north, notwithstanding the history of Dostum as a warlord (or a war criminal according to the standards of the International Criminal Court). ${ }^{1}$

In South Sudan, 22 years of joint struggle to win independence from the North of the country failed to produce a feeling of South Sudanese national identity and a shared national interest. Barely two years after independence was celebrated in 2011, simmering hostilities and a leadership struggle between the Dinka and Nuer once again turned the country into a battlefield. I remember my visit to South Sudan in 2006, a year after the government of Sudan and the southern liberation army signed the Naivasha Agreement for peace. I was at the Kiir river, the border between North and South Sudan in the province of Bahr el Gazal. International organizations were discussing and planning how to organize the return of the millions of Southern Sudanese who had fled their villages and had been living in camps for the displaced and on the outskirts of Khartoum in North Sudan. Cordaid supported the operation by providing transport and medical care. But people did not wait for the organized return. They started the journey home spontaneously and with their own means. Trucks brought them to the northern banks of the river, which they crossed with improvised rafts. I spoke with a woman who, together with her four children, was returning to her home village; the place that she had fled years before when her husband was killed by the North Sudanese forces. She carried with her nothing but the longing for a safe place to call her own and the dedication to give her children a better future. There is no doubt she voted for independence in the 2011 referendum. In 2013 her hopes were shattered; the new nation that she entrusted with her future is in tatters.

In the Kenyan presidential elections of 2013, the issue was not which candidate would be best suited to lead the country, but whether Uhuru Kenyatta, from the country's largest ethnic group the Kikuyu, or Raila

1 Due to allegations of fraud the presidential elections ended in a deadlock and only after intensive mediation by the US both candidates agreed to form the government in tandem. 
Odinga, a Luo from western Kenya, would win. Both candidates organized their support on their ethnic ticket, starting among their own ethnic groups and then pulling others into their alliance. The elections were fought along ethnic lines and Kenyan politics today are still very much led by ethnic issues.

Fragile and failing states are among the most frightening realities for the international community. We all know of Syria and Iraq, Mali and Afghanistan, Somalia and Libya, South Sudan and the Democratic Republic of Congo. Their predicament is spelled out in newspaper headlines and tops the agenda of the UN Security Council. Much less visible are Chad and Cameroon, or Myanmar and Laos, countries that are equally vulnerable to fragility. In Central America, states have lost control over criminal groups that are operating unchecked and autonomously, causing more casualties among the population than many of the well-known violent conflicts. In the above-mentioned examples identity plays a dominant role in the stability of nation-states. Afghanistan is suffering from instability and constantly threatened by internal conflict; South-Sudan is suffering from internal war; Kenya (after the post-elections violence of 2007-2008) happily could avoid new ethnic driven post-elections violence.

The concepts central to this book are 'nation' - or 'nation-building' - 'fragility' and 'identity'. All three are contested concepts of which no singular, agreed definition exists. As for nation, there are different opinions on the nation as modern or historic concept, whether a nation is, or should be, congruent with a state. As for fragility, scholars dispute whether this one term can cover the diverse realities and challenges of the states that suffer the predicament. Others point at the fact that the term 'fragile state' is a derogatory label that serves no other purpose than to put people down or further alienate their governments from the world community. And identity could be approached from so many different perspectives (community, individual, ethnicity, class, religion) that it is hard to formulate a clear definition, let alone answer the question whether identity is a fixed or a flexible concept.

This book has its origin in the urgency of the reality of millions of people like the woman at the Kiir river, whose lives are marked by instability and insecurity, who are living in nation-states where identity conflicts are affecting society and who cannot count on a government to protect them against violence, hunger or disease, nor offers them a prospect of a better, more stable and more dignified future. I was confronted with this reality time and again during the ten years of my leadership of Cordaid, one of the largest Dutch development organizations. Most of my traveling in those 
years was to the complex, confusing and conflict-affected destinations that this book is about: Palestine, Afghanistan, the DRC, Colombia, South Sudan, Central African Republic.

At the time when governments signed the Paris Declaration on Aid Effectiveness in 2005 , it was already clear that fragile states posed a specific challenge to the international community. Since then the problems of instability and fragility have been high - even if arguably not high enough - on the international political agenda. In 2012, the Overseas Development Institute (ODI) in its future scenario of development cooperation, Horizon 2015, stressed that fragile states will remain the hardest nuts to crack for the international community. ${ }^{2}$

That fragile states are a special case is also illustrated by their performance on the targets of the Millennium Development Goals (MDGs). Since the launch of the MDGs in 2000, absolute poverty as a percentage of the world population has declined and the lives of many poor people have improved. However, progress on the MDGs has been very slow, if not stagnant, in fragile low-income countries. The progress noted in a recent World Bank ${ }^{3}$ report is largely due to the broad definition of fragility used, which includes countries like Bosnia-Herzegovina and Nepal. For countries like Afghanistan, the Central African Republic, the DRC and South Sudan the picture is much bleaker; few of them will meet any of the targets set for 2015. In these fragile countries, fundamental human needs continue to go unsatisfied. With the even more ambitious agenda of the Sustainable Development Goals (SDGs), recently adopted by the general assembly of the UN for the 2015-2030 era, fragile states will be even less likely to meet these ambitions.

In 2011, the $\mathrm{G}_{7}+{ }^{4}$ launched a new initiative to harness renewed awareness and support for dealing with the issue of fragile states, the International Dialogue for Peace and Stability (IDPS). ${ }^{5}$ This initiative marks the begin-

2 http://www.odi.org/sites/odi.org.uk/files/odi-assets/publications-opinion-files/7723.pdf (accessed 3 September 2014)

3 http://siteresources.worldbank.org/INTPROSPECTS/Resources/334934-1327948020811/ 8401693-1355753354515/8980448-1366123749799/GMR_2013_Full_Report.pdf (accessed 3 September 2014)

4 The $\mathrm{G}_{7+}$ is a group of 20 countries affected by conflict and in transition to stability and development: Afghanistan, Burundi, Central African Republic, Chad, Comoros, Côte d'Ivoire, DRC, Guinea, Guinea-Bissau, Haiti, Liberia, Papua New Guinea, Sao Tome Principe, Sierra Leone, Solomon Islands, Somalia, South Sudan, Timor Leste, Togo, Yemen. According to the OECD State of Fragility report 2015, 18 of them (all except Papua New Guinea and Sao Tome Principe) figure on the list and 15 of them have been continuously on the list since 2007 .

5 http://www.pbsbdialogue.org/about/origins/ (accessed 3 September 2014) 
ning of a period of new reflections on the meaning of fragility and how to tackle it. In the last fifteen years, the international community has invested billions of US dollars in the process of state-building. In Afghanistan and Iraq, the idea was to create a new and better government by joint efforts of military and civil engagement: First ousting the Taliban and Saddam Hussein by military force, then building a well-functioning and representative government to provide security, justice and basic social services to its citizens. However, the results are modest at best. Thousands of military and civilians lost their lives, billions of US dollars were spent, but stable and secure countries have not materialized. Moreover, the support of the people, their 'hearts and minds' were not won. Many citizens in Iraq and Afghanistan may have welcomed the toppling of the regimes of Saddam Hussein and the Taliban, but somewhere down the timeline their support for the international community's state-building project evaporated. A new approach is needed if we really aspire to contribute to building a more stable, secure and prosperous future for the women, men and children living in fragile states.

This book aims to offer a different perspective on how fragility can be approached and tackled: The process of nation-building should be considered an urgent issue and a complementary challenge to that of state-building. The international efforts at state and institution-building of the last decade have been underpinned by the work of scholars like Douglas North, Darren Acemoğlu and James Robinson, who all used historic evidence to prove the importance of institutions for the well-functioning of states. This book does not contest the importance of state-building and institution-building for overcoming fragility, however, it contends that these are only half of the solution. I argue that nation-building, seen as the process of building a shared identity as the basis for people to live together, to accept laws and to share resources is often overlooked in the strategies of donors to address fragility. Yet building a national identity is an indispensable element for solving the problem of fragility. The challenge of nation-building - referring basically to the shared identity of people - addresses the role that ethnicity, religion, language and culture play in overcoming, or reinforcing, fragility. In the international political discourse these issues are at best marginalized and at worst seen as spoilers: Stressing the importance of issues like religion, language, cultural identity is seen as not being constructive or are seen as creating conflicts. It is telling that the World Development Report 2011, Conflict, Security and Development, does not address issues of identity. It does stress the need to build 'inclusive enough coalitions' and the importance of including community leaders and marginalized 
groups, but solely looks at them as political or economic interests groups, ${ }^{6}$ not as identity groups per se. The international community, in its response to fragility, seems to have adopted a materialistic view on how to build a stable state: Political and economic power interests are the issues to be dealt with. I do, however, believe that we need to address the complex issues of identity (ethnic, religious, linguistic, cultural) head-on as relevant themes in and of themselves in the process of nation-building.

This book is an answer to the urgency of reality. It makes use of the academic research that has been conducted on issues of fragility, statebuilding and nation-building without having the ambition to settle scholars' disputes. This book also for a large part builds on the experiences of practitioners working in fragile areas around the world. We do not pretend to have the silver bullet for solving fragility. The reality of fragility is always messy and solutions and strategies will have to be adapted to the everchanging realities on the ground. That is not to say that we have to be satisfied beforehand with second-best solutions, however, solutions will have an eclectic character, choosing elements from different theoretical approaches and practical experiences in order to find responses that work. The complexity of the issue and the diversity of the fragile contexts require humility. I believe we need to open a new window, deepen our insights into the defining factors of fragility by including issues of identity, and invite people to look through that window at the urgent and dire realities of people living in fragile contexts - and inspire them into action.

The structure of the book is as follows. In the first chapter I present the complex reality of the nation-state as an entity that may seem self-evident in the current global world, while acknowledging that the process of building a nation-state is like walking an unpaved road. Chapter 2 to 4 take stock of the three discourses that are fundamental for our research: The nation, state and nation-state discourse, the concept of fragility and the discourse on sovereignty. We discern three dominant modes of fragility, based on a model in which authority, legitimacy and capacity are the critical factors.

With these three conceptual pillars clarified, I turn in chapter 5 to the nexus of nation-building and fragility, arguing why nation-building is needed in fragile states as a complementary effort to state-building. Chapter 6 briefly turns to the issue of peacemaking, which I consider a necessary precursor to nation-building and state-building. In chapter 7 , I elaborate on the debate on nationalism and the broad shadow hanging over the concept of identity as exclusionary and discriminatory. Chapter 8 discusses the 
concept of national identity and identification, and makes the case for considering diversity as the basis of national identity; nation-building is not about achieving homogeneity or uniformity.

Based on the foregoing, in chapter 9, I present a model for the nationbuilding concept that includes four different elements of national identity (civic, religious, cultural, ethnic).

Chapter 10 unfolds a program for nation-building: How can theory be put into practice? Nation-building is overarching and requires specific processes, specific institutions and a specific role of domestic and international actors. I explore the possibility of this nation-building program in relation to the three modes of fragility that were presented in chapter 3. Finally, in the epilogue, I will formulate two challenges: One as a conclusion of our research, one as an agenda for future multidisciplinary work for scholars, policymakers and practitioners together. 


\section{Struggling in the world of nation- states}

The date: 5 December 2001

The place: The city of Bonn in Germany

The participants: Representatives of 85 nation-states, the United Nations and fifteen International Organizations

The occasion: The celebration of the formation of a new provisional Afghan government after the toppling of the Taliban by a US-led invasion in response to the $9 / 11$ attacks. Five years earlier, in 1996, the people of Afghanistan had welcomed the Taliban, who made an end to the ongoing struggles of warlords that had devastated Kabul. But within a couple of months it was clear that the Taliban had very little idea of what it meant to govern a nation-state. Organizing the state as a theocracy, they were more occupied with chasing perpetrators of Sharia law than with providing security, comprehensive justice, basic social services and infrastructure to the Afghan people.

The relief of the Afghan community of toppling the fanatic and intransigent Taliban was widespread. The international community of nation-states was relieved too and welcomed Afghanistan as a lost son that had returned to their midst. There were high hopes and great joys at the Bonn conference, on all sides. The international community promptly started to organize its human, financial and technical expertise to build the new Afghanistan according to the 21st-century norms and standards of the community of nation-states.

In 2007-2008, the international community was deeply engaged. All provinces had an international lead-partner deploying military and civil support with a Provincial Reconstruction Team in place. At the national level, large programs in training the military, the police and the judiciary were being implemented. Basic education and basic health care programs were rolled across over the country.

In 2009, US president Obama ordered a surge in the military presence in Afghanistan in order to deal a final blow to the insurgents who had regrouped since 2001 via a 'capture, clear and hold strategy' that was meant to chase the Taliban and their allies out of their strongholds.

In 2014, the ISAF mission came to an end. The American forces were the last of the international allies to leave the country. The fragility of Afghanistan was not resolved. The presidential elections of 2013 proved 
a disappointing process with accusations of fraud, recounting and an international mediation to create a grand coalition. The Taliban have not been defeated. Ordinary Afghans are still suffering from insecurity and a lack of future prospects.

The date: 1 May 2003

The place: Aircraft carrier USS Abraham Lincoln

Participants: The 43rd President of the United States, George W. Bush and the crew of the Lincoln

The occasion: To announce 'mission accomplished': The war in Iraq is over.

The war that had started in Spring 2003 was meant to bring about regime change in Iraq. The dictatorship of Saddam Hussein had long been the eyesore of the United States and other Western nation-states. The sanctions that had been instated in response to the presumed production of weapons of mass destruction in the country had barely been successful. Iraq had to be reorganized and rebuilt to turn this rogue state into a well-respected member of the community of nation-states. It was conceived as the start of a program of democratization that would eventually elevate the entire Middle East. Starting from scratch, removing the civil servants who had been loyal members of Saddam's Baath party, the US took Iraq as a blank sheet on which a well-functioning nation-state was to be designed.

In 2007 , the US realized a surge in its military presence to counter the increasing problems of insecurity and to curb the number of casualties. At that time, all ideas about building a better and more democratic Iraq had vanished from the agenda. Security was the only issue left.

In December 2011, the last US military convoy crossed the border between Iraq and Kuwait to mark the end of the Iraq war. Its legacy is a failed project - or at best, unfinished business. Ever since, Iraq has been struggling with its internal stability compromised by the insurgencies by Sunni groups and the Islamic State.

The date: 9 January 2005

The place: Naivasha in Kenya

Participants: The government of Sudan, the Sudanese Peoples Liberation Movement and representatives of the international community

The occasion: The signing of the comprehensive peace agreement after more than twenty years (1983-2005) of civil war between the SPLM in South Sudan and the Sudanese government in Khartoum. 
The agreement opened the way for solving the deadly conflict by creating a new nation-state through the secession of South Sudan - to be decided in a 2011 referendum. There was great relief within the international community. The end was in sight of the endless stream of refugees, the large-scale humanitarian relief operations and spillover effects of this war that had caused instability in the region (Darfur, Chad). And rapidly the international community brought in their resources to build up a wellfunctioning state in poverty-stricken South Sudan. Embassies opened their offices, countless aid agencies moved in and multilateral agencies set up large multidonor trust funds to make the peace dividend happen in South Sudan. Consultants flew in and out to help set up a government structure, start training on organizational development and to turn a guerrilla movement into an ordinary government that could become a well-respected member of the international community of nation-states. In January 2011, there was a massive turnout for the referendum. 99\% of the voters voted for independence and on 9 July of that same year South Sudan became the much longed-for independent state. Representatives from all over the world gathered in Juba to celebrate the momentous occasion. The people of South Sudan were thrilled and excited about this new future, filled with hope and confidence; a page of suffering had been turned.

In December 2013, the lingering conflict between president Salva Kiir and his former deputy Riek Machar turned into an interethnic conflict between the Dinka (Kiir) and the Nuer (Machar). Since then, 100,000 South Sudanese have once again been uprooted from their homes. The hope has been dashed that the country is on its way to stability and prosperity.

The date: 8 November 2005

The place: Monrovia, Liberia

The occasion: Presidential elections in Liberia after more than 10 years of civil war and anarchy. Ellen Sirleaf Johnson takes office as the first female president in African history.

Liberia and Sierra Leone had both suffered from more than a decade of chaos, coups and counter-coups, and warlordism. Unspeakable atrocities were reported from both countries: The slaughtering of entire communities, child soldiers being forced to kill their own kin, cutting off limbs as a regular practice. The mining of 'blood diamonds' kept criminal gangs and warlords economically alive.

In 2003 , the warlord Charles Taylor was forced to leave Liberia by international pressure and by a massive movement of women for peace. In 
Sierra Leone, British troops restored order after a failed UN peacekeeping mission. Gradually Liberia got back onto its feet and the presidential elections of 2005 were judged to be the most free and fair elections in the history of the country.

In 2010, the debt cancellation program helped Liberia to reduce its huge debt (US $\$ 4,5$ billion in $2003,800 \%$ of the country's GDP) and create space for national and foreign investment and development. While the targets of most Millennium Development Goals will not be met by the end of 2015, education enrolment rates have soared and under-five mortality has declined. In 2010, Liberia's economy was among the twenty fastest growing economies in the world.

In 2014, several countries in West Africa were hit by a massive Ebola outbreak. The epidemic nearly paralyzed the Liberian economy and brought the medical infrastructure on the brink of collapse. However, the country showed great resilience in standing together to combat the Ebola-crisis.

In the first three events (Bonn, USS Lincoln, Naivasha), ordinary people were barely involved. It is a telling fact that these events happened outside of the territory of the respective countries whose history was about to change. Yet the people were assumed to welcome the events. How could the citizens of Afghanistan not be happy about the toppling of the Taliban and the conditions for peace and prosperity that the international community was committed to contribute to? Equally, so the international community assumed, the Iraqis surely welcomed this new start that promised them a better life in freedom and democracy, the end of sanctions and the prospect of taking part in the rapidly accelerating globalization that would benefit all. But in both countries, stability has not been achieved and the support for the external intervention was not as broad as expected. The least doubt existed about the happiness of the South Sudanese who, after their decades long struggle, finally were so proud of their own independent state which, with the generous support of the international community, would operate according to standards that had proved to be so effective. And even the strong support of the Sudanese for their independence was not enough to create a stable new nation-state.

Only in Liberia the combined efforts of the international community and national pressure were able to restore the government in the country and create the basis for a restart of the process of building the nation-state.

Becoming a member of the family of nation-states and complying to its standards of democracy is not an easy struggle. Foreign injections of money 
and expertise are anything but a guaranteed solution for the many challenges and problems inherent to the process of state- and nation-building.

From the perspective of the extended family of nation-states, it is no smooth ride either. In the interconnected global world the international community of nation-states struggles with the presence of dysfunctional members. If there is no globally shared system of standards, reliable governance, international security, trade, economic interests, communication, etc. are bound to suffer. The family of nation-states has huge interests in the stability of all its members.

\section{Nation-state: Self-determination ánd international acceptance}

The United Nations counts 193 members, all of them nation-states. Size - in square kilometers or number of inhabitants - does not matter: There are no criteria for the formation and existence of a nation-state. China and India with a population of more than one billion are nation-states and so are Palau and San Marino with a population of some tens of thousands. City-states like Singapore or Monaco exist side by side with Brazil and Australia. And there are no performance criteria - on economic, social or democratic performance - that can be used to allow or refuse countries membership of the community of nation-states. There is no square kilometer of landmass on this planet that does not belong to a nation-state. Some areas may be the source of dispute between countries, but the map of the world is a map of nation-states.

The nation-state as we know it is a modern phenomenon, which dates back no more than 250 years. But it is not without its history and predecessors. Empires, Kingdoms, Princedoms and Caliphates have been around for more than 4000 years, each with very different forms of governing systems, different types of leadership and different relationships between rulers and ruled. Without wanting to reduce world history to a few brush strokes, one can argue that the defining feature of most of these historical forms of governance was a clear separation between the ruling elites and the ordinary people. The latter were fully subject to the authority, the vision, decisions and whims, of those who ruled over them. Emperors and princes could, by conquests, marriages and inheritance, bring people under their rule or cut them off without people themselves having any influence.

By the end of the 18th and the beginning of the 19th century, the formation of nation-states started in Europe and the Americas (North and South). This process of profound change was initiated by new political and 
philosophical ideas, which identified the people as the source of sovereignty. Subsequently, nation-states emerged all over the world. The nation-state became the unique and exclusive form of organizing people. In Latin America and Africa, nation-states emerged when colonial powers marked new borders on the world map. In other parts of the world, for instance the Caribbean and Pacific islands, there is no clear pattern in the formation of nation-states. At other times, it was the new political arrangements (the partition of India, the former Yugoslavia, Sudan) that created new nation-states.

In the end, there are two decisive features that define a nation-state: The self-reference of people who declare themselves a nation-state - the nation-state draws its legitimacy from the people - and the acceptance of that declaration by the international community.

This book conceptualizes the nation-state as an intertwined and inseparable reality - between a people and their identity on the one hand, and the territory within the state borders where they live on the other hand. This intertwined nature is first and foremost based on the sovereignty of the people: It is they who affirmatively define themselves as the ones giving legitimacy to the nation-state. The nation-state comes into being by this affirmative act of identification. Without that basis of sovereignty the nation-state ceases to exist. And thus the nation-state is not simply a set of institutions and instruments that is organized to run a territory - it is so much more than the state apparatus. The legitimacy of state institutions and systems presupposes the affirmative action of people who identify themselves with the nation-state and who adopt this nation-state as theirs.

But this throws up the questions: Did the people of Afghanistan ever positively decide to be a nation-state? Not at the time when the borders of their country were drawn as part of the process of marking out nationstates in the late 19th and early 20 th century. And the Iraqis? They found themselves identified as a nation-state after Great Britain and France had divided the remains of the Ottoman Empire. The South Sudanese people in 2011 expressed without a trace of doubt that they wanted to be an independent nation-state. However, in view of the internal conflict that re-erupted in 2013 one wonders whether theirs was mainly a vote for separation from the North of Sudan rather than an expression of the will of all the many different ethnic groups to live together as a nation-state.

This points at the primary challenge of the nation-state: The affirmative will of the people to form the legitimate sovereignty of the state is posed as the basis without which a nation-state cannot exist. This affirmative will, however, has to be realized: It is a continuous and dynamic process of 
making and remaking. The identity of the nation-state is self-referential. Only those belonging to the nation-state can decide what their collective identity is - and whether, for example, religion, ethnicity, culture, or language, are part of that. But this self-referential aspect of the nationstate is not stable or fixed over time, nor is it shared by all in those stable nation-states, even more so in more fragile nation-states. Dutch men and women today define their Dutch identity differently than their ancestors a hundred years ago. Afghans will define their Afghan identity differently than their ancestors, even if they value their history and traditions. The 2014 referendum for Scottish independence proved that the idea of what it means to be Scottish is understood quite differently amongst the Scots themselves. The decades long conflict in the Philippines is rooted in the identity gap between the Christian/Catholic majority and the Islamic minority, who both have a different idea of what it means to be part of the Philippines nation-state.

The nation-state requires the acceptance of the international community as its second defining principle. International acceptance is the flipside of the nation-state's self-referential precondition. Nation-states that fail to be accepted by the international community are faced with an uphill battle for their existence. The current entities Puntland and Somaliland, which both came into existence following the collapse of the state of Somalia, still lack this international acceptance. Though much better organized and governed than Somalia itself, the international community does not want to accept the dissolution of the Somali nation-state. Without the international stamp of approval a political entity cannot be part of multilateral agencies, cannot conclude treaties with neighboring countries, has no recognized borders and cannot let its citizens travel as 'its' citizens.

That the two defining principles of the nation-state do not always fit together harmoniously is clear. Many people and communities have unsuccessfully claimed their self-determination as an independent nation-state. The sovereignty and with that the integrity of borders and territory are often deemed more 'sacred' by the international community than the claims of people for splitting sovereignty by secession. Again, internationally agreed principles, criteria and checklists on the basis of which this sovereignty will or will not be granted are lacking. It depends on the global power relations at the time that Papua New Guinea in 1962 was not recognized as an independent nation-state and Kosovo in 2008 was, is more the result of international political power games than of careful judgment. Although the International community has accepted and endorsed the self-determination of the Palestinians and although the majority of the members of the United 
Nations have recognized the Palestinian nation-state, that has very limited impact on its position in the world as long as the political heavy-weights (the US and most of Europe) do not recognize Palestine.

\section{The puzzling nation-state}

The fact that the world is divided into neatly interlocking nation-states - borders drawn on the world map, their surface measured, their people counted, leaving no square kilometer undefined - may give the impression that we are living in a well-organized world of nation-states. The reality is more ambiguous. The nation-state is engaged in a constant struggle to define itself and to position itself in the family of nation-states. Even well-established nation-states like Great Britain, Spain and Belgium are struggling with who they are, how they define themselves and who belongs or who does not. And the family of nation-states is constantly struggling to create a shared basis for membership, to define when a community qualifies as a nation-state and to maintain order in the family.

Within that family, states like Afghanistan, Iraq and South Sudan are only the more extreme version of the ordinary nation-state that is struggling with itself and its position. The problem of the nation-state is much more systemic and inherent to the delicate construct of the nation-state itself. The nation-state is inherently unstable due to the need for affirmative identification by its people - people who change their minds, form new alliances, create new identities - and the lack of clear criteria and indicators for who belongs and who does not.

And thus we may question: Do we need nation-states in the 21st century? Is the struggle in the family of nation-states a waste of energy and of people's lives? Can we not do without this inherently unstable construct? Perhaps we should declare it not fit for purpose. Would it not make much more sense to separate 'nation' and 'state' and focus on building strong states with technically well-functioning systems and institutions? If that succeeded, the nation-state may well prove an obsolete construct. The answer is: no. Because if all we needed was a strong and fair well-functioning state apparatus, then how do we explain why the Catalans, the Quebecois, the Scots want to become an independent nation-state? These people, aspiring to express their affirmative identification to a nation-state different from Spain, Canada and Great Britain, are living in states that are technically speaking functioning well, without discrimination, based on meritocratic principles, offering equal access to education, health care and jobs. If 
the Catalans, Quebecois and Scots would be allowed to create their own nation-states, these very likely would be, technically speaking, in terms of systems and institutions, a copy of Spain, Canada and Great Britain. These people want their nation-state to be theirs, reflecting their identity. That is, in essence, the same problem that is causing so much suffering in Afghanistan, where Pastun, Uzbeks and Tadjieks are all looking for a nation-state they can identify with and affirmatively embrace as theirs. And that is the same struggle in South Sudan, where Nuer and Dinka want to put their mark on the newly formed state, and in Iraq where Sunni and Shia want to make sure that the state reflects their identity. It is on the level of the nation-state that these identity issues have to be solved, besides issues of economic, political and power interests, majority and minority positions. The solution of the problem of fragile states requires a legitimate sovereignty that depends on and reflects the people. It is real in Catalonia, in Quebec and in Scotland with well-functioning state institutions; it is also real in these fragile nation-states.

The nation-state is an intriguing phenomenon. This book is an invitation to take the nation-state serious. Analyzing the complex reality of the nation-state, including the sensitive and confusing issue of identity will bring us some insights that will help us to come up with better analyses and better policies for nation-states that are plagued by conflicts in which identity is one of the root causes.

The nation-state is the - for now - latest step in the way people have organized themselves into larger communities to manage their economy, to secure their safety, to share their cultural and religious practices. The nation-state as successor of the preceding empires, princedoms and caliphates, is the form to organize our societies in modernity. The nation-state, however, is unlikely to be the end of history, and we should keep our minds and eyes open for the next step. But until then, it is the form of our times and we should take that form serious and do whatever we can to make the nation-state more stable to meet the high expectations of its people. 



\section{$2 \quad$ Nation and state}

Understanding the process of nation-building starts with understanding the concept of the nation. And with the nation the state comes in, at least in our modern world. This chapter discusses the different understandings of the nation and the state: What is a nation? What are the indicators to identify a nation? What are the decisive moments in the making of nations? What is the distinction between a nation and a state? And what similarities exist between nation and state? Do they mutually presuppose each other? At the end of this chapter we will discuss to what extent the process of globalization affects the nation and the state.

\section{The Montevideo Convention: The defined state}

In international relations, the term 'nation' is part of common speech, but its exact meaning remains undefined. There is no international agreement that unambiguously defines the concept of the nation. A definition of the concept 'state' does exist, and is included in the Montevideo Convention on the Rights and Duties of States (1933). ${ }^{1}$ Article 1 reads: 'The state as a person of international law should possess the following qualifications: a) a permanent population; b) a defined territory; c) government; and d) capacity to enter into relations with the other states.' These factual qualifications can quite easily be described and proven. Yet what are the roles that states must fulfill? This book focuses on the responsibilities of the state towards its citizens. After all, that is the recurrent focus of the international community's efforts at providing stability in fragile states: How can we build a state that meets the needs and aspirations of its citizens and thus take away the root causes of fragility? In this perspective of the relationship between the state and its citizens, we will refer to five basic functions:

1 creating space for participation in political decision making so that the polity becomes inclusive and open for citizens;

2 providing security for people against outside and inside aggressors and criminals;

3 providing justice so that people are treated as equals, fairly and without discrimination;

1 Original text: https://reaties.un.org/doc/Publication/UNTS/LON/Volume\%20165/v165.pdf (accessed 25 January 2016) 
4 providing basic social services that enable people to live their lives in dignity;

5 creating an infrastructure to facilitate economic life and making rules to let economic life be fair.

\section{The undefined nation}

National identity is a living, dynamic reality. The French increasingly identify themselves as a bulwark against what they consider the Americanization of Western Europe. It is a new feature of their identity triggered by the new context of US influence in the world. Protecting their culture (film, language, food) against the increasing presence of Hollywood, Anglicism and fast food became part of their national feeling since the beginning of the 1970s. But who can tell whether it will still be part of the French identity one hundred years from now? The number of English courses taught at French universities is increasing to keep up with the internationalization of education and the job-market. Over the last 30 years, the Netherlands saw itself as a progressive nation, addressing and promoting issues like abortion, euthanasia and gay marriage among the family of nation-states. ${ }^{2}$ It is part of the Dutch identity to be a frontrunner in the international debate about these moral issues and it exists side by side with older identifications as a nation that has successfully fought against the water and liberated itself from the Spanish in the Eighty Years' War.

Nation and national identity are strongly interlinked. As said, 'nation' as a concept does not have one shared and generally accepted definition, its meaning remains contested by different strands of scholarship. With this book, I position myself within the constructivist school of researchers, who contend that the nation is a construct, built and altered by people to define the identity of a political community in ever-changing circumstances. ${ }^{3}$ This construct is a mixture of old and new, of traditional elements and new inventions necessary to build a contextual story of 'we'. The constructivist approach is well aware of the historical components of national identity and the importance of historic and legendary myths and heroes serving as a foundation for that identity, without taking these historical ingredients as the fixed and decisive elements of nationhood. The constructivist position

2 In Dutch policies of development cooperation, sexual and reproductive rights (right to abortion, LGBT-rights) are one of the official priorities.

3 Jackson-Preece 2010, p. 17. 
is probably best reflected in Benedict Anderson's definition of the nation as 'an imagined political community - and imagined as both inherently limited and sovereign'. ${ }^{4}$ In this notion of 'imagined community', Anderson refers to the fact that the nation is a community of people who are connected to each other and who belong to each other without necessarily knowing each other.

By taking a constructivist position I do not mean to exclude the merits of other currents in academic thinking on nations and nationhood. My arguments also draw on important representatives of the primordial approach (Smith 1991) and the materialist position (e.g. Gellner 20065; Hobsbawm $\left.1992^{6}\right)$. Anthony D. Smith, who defends a more primordial position regarding the identity of a nation, describes a nation as 'a named human population sharing a historic territory, common myths and historical memories, a mass, public culture, a common economy and common legal rights and duties for all members'.

It is interesting to connect the definitions of the nation given by Anderson and Smith to the definition of the state in the Montevideo Convention. By using the words 'community', 'limited' and 'sovereign', Anderson succinctly refers to the first three constituting elements of the Montevideo definition: Nation is about a population in a limited physical territory and there is some sovereign authority that governs the population in that territory. Smith refers to the first two elements of the Montevideo definition by talking of a population and a territory. The third element, 'government', seems to be implied in the common legal rights and duties for all members mentioned by Smith. What is missing in both Anderson's and Smith's definitions is the notion of international relations: A nation, so their definitions suggest, does not necessarily have to enter into relations with other nations. 'Nation' is first and foremost an internal notion, referring to the sovereign community living within a certain territory. As the flipside of this, it is noted that the Montevideo Convention in its definition of a state makes no reference to identity or culture to describe the qualifications of the state. Up to today, states in their international relations are very reluctant to interfere in matters of identity and culture: these are deemed internal issues.

What the notion of the nation adds to the definition of the state in the Montevideo Convention is thus the importance of culture or identity 
- referred to by Anderson with his qualification 'imagined', by Smith through the words 'historic', 'myths', 'historical memories' and 'culture'. For both authors, the nation is more than a factual description of numbers, square kilometers and institutions. The nation is about identity, who we are in the sense of 'self-identification'. The nation has to do with something subjective, even if it is a collective subjectivity, distinct from the objective features of states. This is not just adding a new element, but fundamentally changing the notion of 'nation' compared to the notion of 'state': The state is about institutions, structures and systems, the nation is about identity; the state is about a collective objectivity, the nation is about a collective subjectivity.

The difference between the primordial and the constructivist perspective of the nation lies in the historical roots of this collective subjectivity. For Smith, the national identity has historic roots that go back to times before the modern nation-states. For constructivists like Anderson the nation is the result of a construction and invention, not the result of an process of preserving something from the past into present and future. ${ }^{8}$ The nation is not something tangible like a historical artifact, brought into light by archeologists. It is brought into existence by people who are actively pushing for a nation and are bringing together the elements to construct it. At the same time, in the process of constructing the nation, it may well be important to deliberately forget those elements in culture, history and narratives that do not help the construction of a shared, national identity. The construction of national identity is therefore a process of selection, bringing together those elements that fit well together to create an identity people can and wish to identify with and leaving out elements that could disturb a coherent picture. The efforts to trace back the nation into history, to link the existing nation to its historical roots, are deliberate actions to underpin a national identity of an actual living community with historical events, persons and narratives.

\section{Nation and state intertwined}

The nation and the state are not one and the same thing. And yet, comparing their definitions and considering the elements they share, it is clear that in modernity nation and state are strongly intertwined. This is the reality as described by Hobsbawm and Gellner: Today we can only speak of the nation in the connection 'nation-state'. It does not make sense to refer to 
them as separate entities. The nation is a modern phenomenon, to be understood within the framework of a modern world of nation-states. Nation emphasizes the (collective) subjectivity of the community that forms the nation; it is about identity, imagination and culture. The state is objective; it concerns people, territory and institutions. The peace treaties of Westphalia in 1648 laid the foundation for the intertwinedness of state and nation by deciding about the religious identity of this novelty it created, the sovereign state. The Westphalian Peace treaties built on the Augsburg settlements of 1555 , in which the principle cuius regio, eius religio was agreed. But if we cannot speak about nation and state as distinct entities, how can we understand their mutual relation? And if they really are intertwined, how can we understand the linkages in both directions?

\section{Does the state presuppose a nation?}

The Montevideo Convention defined the state without referring to the nation or to elements that are vital to the nation (culture, identity). To regulate international relations, as is the purpose of the Montevideo Convention, there is no need for states to be clear on the nationhood of another state. If national identity is an issue of internal concern, the question of nationhood is not another state's concern. The principle of non-intervention applies.

But from the perspective of the state itself, the answer to the question whether the state presupposes a nation is less clear. In a first approach to this issue, nationhood is necessary for the state to build its authority over its people (and its territory) on solid ground. Nationhood is a necessary prerequisite for the state to be able to create the sense of belonging needed for people to voluntarily accept the authority of the state - to make them pay their taxes and obey its laws and regulations. The sense of belonging that is based on nationhood makes that people can imagine being prepared to die for their country. ${ }^{9}$ Without nationhood the state is bound to resort to coercive and authoritarian measures to maintain its authority.

A second approach is less unequivocal: In the modern world that emphasizes - if not celebrates - people's individual autonomy, questions of culture and identity have become increasingly individual and less collective. Largescale migration adds to this shift. Nationhood is becoming problematic given the diversity of people and cultures that find themselves within the borders of one nation-state. One may even wonder whether it is at all still 
necessary to create nationhood and a sense of belonging. If the state is able to operate as a rational contractor to its people, providing security, justice and social services, that may be enough to build the necessary loyalty that makes people pay their taxes and obey the laws. The conflict that the immigration countries of Western Europe are faced with boils down to this issue: To what extent do we expect migrants to become part of the nation and adopt the national identity? Up to today the attitude has been that migrants must adopt the social and political system (democracy, human rights, gender equality, individual freedom) of our modern nation-states. Integration is about the systemic and institutional nation-state, adopting its laws and regulations. But the requirements go deeper. The European nation-states do not accept migrants to remain in a mere contractual and juridical relationship with the state. The notion of Leitkultur has emerged from the debates to describe the culture and identity of the host society as the dominant one - and the one that the migrant must accept - while the culture and identity of the migrant community is supposed to remain subordinate.

I argue in this book that the state needs the nation and that this notion of nationhood should be an inclusive one: The institutions of the state and its monopoly on violence and coercion require a sense of belonging and identification of the people, that is embodied in the nationhood. But that identification should be inclusive and be the result of a deliberative process of all who live in and are citizens of that nation-state. There is no historic identity to adopt. Migration and diversity do not make nationhood obsolete; they make belonging more complex and challenging. Without investing in that sense of belonging, societies run the risk of fragmentation and of decreasing legitimacy of the state.

\section{Does the nation presuppose a state?}

Can we imagine a nation to exist without the state and its institutions? Especially for those who emphasize the nation as rooted in communities and as having existed long before the modern state was created, the nation is a reality and does not need a state to exist: The legitimacy of a nation lies in a shared identity of its people, distinct from other groups. Adrian Hastings ${ }^{10}$ refers to the British identity as a reality that developed gradually from the 12th century onwards, long before the state and its institutions came into 
existence. For the scholars who adhere to a more primordial perspective on the nation, the deep historic roots of the national identity (myths, holy places, buildings, territory) are underpinnings of the claim that the nation is a reality apart from the existence of the state. Ephraïm Nimni clearly differentiates the two when he says: '... we use the term nation as transposable with the term state. This assumption is prevalent around the world but it is based on an error. A state is an apparatus of governance and a nation is a cultural community'. ${ }^{11}$ Castells refers to the example of Catalonia. ${ }^{12}$ The notion of being different from the Spanish is rooted in history and in the Catalonian language. 'Being different' is expressed through symbols like an anthem and a flag. The Unrepresented Nations and Peoples Organization $(\mathrm{UNPO})^{13}$ acts as the representative of nations that aim for international recognition. Often their ambition includes a claim to statehood in order to be able to live the identity to the full and without constraints. ${ }^{14}$ The example of the Kurds is a case in point: The promotion of the national identity (culture, language, myths) of the Kurds, who live in Iraq, Turkey and Iran, includes the ambition to form a new state. Similarly, the movements in Scotland and Catalonia aim for an independent state because they consider their national identity to be different from that of Great Britain and Spain. Federal structures and far-reaching autonomy within the nation-states of Great Britain and Spain are seen as insufficient.

A decoupling of nation and state would reduce the relation between the state and the citizen to a mere contractual and juridical one. To some extent, one could argue, this is the current reality considering today's dominant rational-economic instrumentality that translates nearly every value or relationship into economic and financial worth. However, in a purely contractual relationship, the state would not be able to build on the loyalty of citizens beyond the terms of the contract. In times of crisis and hardship, citizens may simply turn their back to any demands from the state, unless they calculate that there is a benefit in responding to the state's requests. From the calculating perspective of the citizen, s/he would create a benchmark to decide which state offers the best conditions and the best services. This is already happening, witness wealthier citizens

11 Nimni 2007, p. 55 .

12 Castells 2010, p. 45-53.

13 http://www.unpo.org/ (accessed 18 October 2014)

14 Different is the case of the indigenous people in the US and Canada, often called First Nations to identify them as the original inhabitants. Based on treaties with colonizers they have been granted rights on territories and connected resources (fishing and hunting). Building an independent state to express their national identity is not the issue. 
who deliberately choose where to live based on a cost-benefit analysis, e.g. which nation-state offers the optimal return on investment (services in return for taxes)? From the perspective of the citizen, a decoupling between nation and state would leave a person without a sense of belonging to a wider community. In contrast to the 'imagined community' of Anderson, my sense of belonging would be limited to those people that I know in person, a circle not much wider than my direct community of family, colleagues, friends and neighbors. This means that there is no emotional bond between the citizen and the wider society or state of which $\mathrm{s} /$ he is part. ${ }^{15}$ One could contend that in the highly individualized Western world the role of the nation as imagined community is no longer so important. However, I would object that the emergence of nationalist movements all over Europe confirms that the atomization of society has its limits. For the citizen a mere contractual relation without further loyalty makes him or her vulnerable. The bedrock of citizenship, that is the obligation of a state to take care of and maintain a relationship with each and every citizen even if $\mathrm{s} /$ he is a criminal or an outlaw, will come under pressure if the relationship is reduced to merely a contractual one. We could end up in a world where states take the liberty to end the contract with individual citizens who do not fulfill their obligations.

Earlier I stated that both Anderson and Smith include the first three qualifications of what defines a state according to the Montevideo Convention in their concept of the nation. The nation, therefore, is about a people, a territory and sovereignty. In modernity this intertwined reality of nation and state, of objective collectivity and subjective collectivity, has become ever more inextricable because the state fulfills certain functions that help to materialize a sense of belonging that is fundamental to nationhood, that is, it provides security, justice and social services. By virtue of being a member of the nation-state, one is entitled to these provisions. The issue of double nationality explains the importance of this membership of the nation-state as the basis for being entitled to services of the state. Unlike some scholars who contend that, based on a strict connection of nationhood to identity, nations can exist without a state, ${ }^{16}$ I believe that having a national identity without a state is problematic in the modern world. 
In our current modern world, nation and state are therefore inextricably intertwined. In the relationship between the nation-state and its people, there are four important grounds for legitimacy: ${ }^{17}$

1 as the expression of people's sovereignty in exercising political power;

2 the people as holding equal rights before the law;

3 the people as a group of obligatory solidarity for mutual support;

4 the people as community, united through a common destiny and shared culture.

These legitimacy grounds are intertwined and cannot be disentangled. An active affirmation of the sense of belonging and of togetherness with one's fellow citizens is necessary to build the relationship amongst citizens and between the citizens and the state that serves as the solid base for the state to act legitimately.

\section{War and the making of the nation-state}

The nation-state as we know it today is historically linked to the Westphalian peace treaties of 1648 that made an end to both the Thirty Years' War in the Holy Roman Empire and the Eighty Years' War between Spain and the Dutch, with Spain formally recognizing the independence of the Dutch Republic. The belligerent parties solved their long-drawn disputes about territory and religion with a novelty: Sovereign states governed by a sovereign who enjoyed full authority over his territory and who was entitled to decide which religion would be adhered to in his territory. The making of the nation-state was the result of war, reflected in Charles Tilly's famous statement: 'War makes states and states make war'. According to his research, state-making happens as the result of a process of rivaling factions vying for power by using violence, when one of the parties manages to establish its authority and power in the disputed territory. After that, the process of organizing a state, building its institutions, and acquiring legitimacy begins. In other words, the making of the nation-state was not an orderly process of design and negotiation, but one of different 'organized criminal groups' trying to seize power. ${ }^{18}$ Accordingly, Max Weber stressed that what 
defines the state first and foremost is its 'monopoly of the legitimate use of physical force.'. ${ }^{19}$

The violent origin of the nation-state is a recurrent fact in history. The independence war that led to the formation of the United States, the wars that split up the Spanish colonial power in Latin America into independent states, the liberation wars in the English and French colonies in the 1950s and 1960s, the Balkan wars in the 1990s and the liberation war in South Sudan are all testimonies of the intimate relationship between violence and the formation of nation-states.

However, in the 21st century, war is increasingly considered an illegitimate means to sort out political rivalry regarding the dominance of power in a country or territory. The idea of 'Give war a chance ${ }^{220}$ does not receive broad political support at the level of the international community. The humanitarian consequences are too dire and the destabilizing effects of civil war that spills over to neighboring countries and regions are too serious. This is an important and consequential change in attitude, which is reinforced by the Responsibility to Protect principle adopted by the United Nations in 2009, which means that sovereignty no longer exclusively protects states against foreign interference. ${ }^{21}$

There is a second important change in the process of forming nationstates, and that is the time factor. The current European nation-states developed gradually in a process that took more than three centuries since the signing of the Westphalian peace treaties. State institutions developed and rulers and ruled negotiated their relationship and created the legitimate basis for the state by an internalized acceptance of the system of domination. ${ }^{22}$ In today's fragile states, the process of nation- and statebuilding takes place in a pressure cooker environment. In a mere couple of decades they have to build a nation-state that can play its role in the international community according to internationally adopted standards (following International Human Rights Laws and democratic standards) and that performs the basic functions towards its citizens. The time to sort out internal rivalries, to find new and stable configurations in the sharing

19 Weber 2013, p. 7 .

20 In an article 'Give war a Chance' in Foreign Affairs, volume 78 (1999) no. 4, Edward Luttwark warned against premature peacemaking, contending that war is a necessary phase in the process of sorting out the tensions and rivalries in former Yugoslavia.

21 http://www.jochenhippler.de/html/ethnicity-_state-_and_nation-building.html (accessed 28 August 2014)

22 Jung 2008, p. 34. http://subweb.diis.dk/graphics/Publications/Reports\%202008/R200811_State_Formation_State-Building_Sociology.pdf (accessed 25January 2016) 
of power is very limited. There is ample evidence that this time-pressured process is a very challenging one.

\section{An ideal model for the nation-state?}

The time factor is one challenge, another more fundamental question is whether the building of nation-states in fragile contexts like Afghanistan or Mali should follow the model of Western European nation-states and take this as its benchmark. The unique historical process in terms of cultural-religious and socioeconomic circumstances that led to the Western European nation-state should be considered as non-replicable. There should thus be space for different trajectories of nation- and state-building taking place today - and different outcomes. However, three factors limit the room for difference.

First, the Western nation-states influenced nation-state making in the rest of the world, and continue to do so. The colonial rulers built state institutions in the colonies that were a blueprint of the institutions back home. Later, in the 1990s, the international development community's good governance agenda ${ }^{23}$ tied aid to building governments and state institutions according to the models of the Western European state. Development aid came with clear political and economic conditionalities. The good governance agenda was later on watered down somewhat into a goodenough-governance agenda, leaving some space for development according to national convictions and political ideas of the recipient countries.

A second influence is the notion of a global community of nation-states, a family bound together by the United Nations system. This community of states requires a set of common standards that define the entry-threshold to gain membership. A key factor for eligibility is the legitimacy of the state, which is closely linked to certain well-functioning state institutions. Common standards and institutions are also important to facilitate the relationships within the family of nation-states.

The last and most important influence comes from within non-Western countries themselves. During my ten years as chief executive director of a major Dutch development organization, I met people sharing common values across the globe: Women in Afghanistan want to have a voice in the public arena, villagers in Ghana want to decide on education, health care and infrastructure in their village, and indigenous people in Guatemala 
want to be treated as equal, not as second-class citizens. Everywhere in the world, especially in fragile states, people expect the nation-state to provide security and justice, to treat people equally, to take responsibility for providing basic social services and to build the infrastructure that is necessary for an economy to flourish. ${ }^{24}$ These strong demands and expectations are the reflection of an implicit ideal of what the nation-state should be and should do. Here expectations of citizens within countries meet ideas and designs developed by the international community.

An ideal model of the nation-state - and of what 'good governance' entails - may thus exist at a certain level, but it is very important to distinguish between the values, the norms and the forms of that ideal of a nation-state. There are broadly shared values about human rights, democracy and justice. The basic values of legitimate and effective government that citizens in Asia or Africa adhere to are not that different from what people in Western Europe expect. The communication revolution and the rapid increase in international migration have both contributed enormously to recognizing shared ideas and values across nations and continents. In international relations and development cooperation it is important to let go of the idea that the West has to teach these values to the rest of the world: values of human dignity, freedom and democracy are not foreign to the rest of the world.

However, there are differences in the norms to translate these values into laws and regulations that guide the day-to-day practice of government and the relationship between government and society. Community-oriented and religious societies in Africa and Asia will translate the shared values into different rules and regulations (norms) than the individualist and secular societies of Western Europe. The Ubuntu culture in certain African societies, which gives primacy to the interests of the community, will lead to a different outcome when translating democracy or human rights into practice. Women in Afghanistan share, on the value level, the need for women to play a role in the public sphere and wish to end the subservient position of women in society. However, the norms to implement these values are different from those that guide Western women in their fight for a stronger position in society.

In terms of the forms there are even more variations, even within Western Europe. The presidential system for democracy for instance is quite different from the Dutch system with a prime minister. The federal system of Germany is different from the federal system of Switzerland. Some African countries have reinstitutionalized traditional forms of government 
and incorporated them into their governance system in search of a new blend of 'modern' Western governance systems and 'traditional' indigenous systems. ${ }^{25}$

This distinction between values, norms and forms is very relevant for a meaningful debate on good governance and state institutions. For too long, the three were considered one and the same thing, a package that needed to be implemented indiscriminately in order to belong to the good governance community. However, as long as, for example, it is assumed that values on gender equality can only be implemented through a model that is copied from Western societies, there will be little chance for a real dialogue. ${ }^{26}$ It is my conviction that a model of an ideal nation-state exists indeed, however, only at the level of values. When translating values into norms and forms, there is no single recipe that makes the ideal nation-state a reality.

\section{The nation-state in a globalizing world}

By the mid-199os, Kenichi Ohmae predicted 'the end of the nation-state'. However, we are well into the new millennium and the nation-state has all but disappeared. It is undeniably true that, as a result of globalization, the nation-state has lost some of its weight in international and domestic issues. In the economic domain, the examples are legion. The free movement of capital and the flexibility of transnational corporations escape the regulating role of the nation-state. The financial crisis in the second half of the 1990 s and early 200os (Asia, Russia, Mexico, Argentina) showed the lack of control of nation-states. The fact that many industrial companies have transferred their production to China is something that the Western European nation-state can do little against. The World Trade Organization (WTO) has created a set of binding international trade rules that limit the economic policy space for the nation-state. At the political level, too, globalization brings about change. Regional bodies have gained in number and influence; from the African Union and Ecowas in Africa to the European Union, from Mercosur and Alba in Latin America to ASEAN in Asia, it is widely acknowledged that countries on their own have less and less

25 Boege, Brown, Clements \& Nolan 2008; http://www.berghof-foundation.org/fileadmin/ redaktion/Publications/Handbook/Articles/boege_etal_handbook.pdf (accessed 25 January 2016)

26 Cf. the receptor approach of Tom Zwart: Using local culture to further the implementation of international human rights: the receptor approach, Human Rights Quarterly, 201234 (2), p. 546-569. 
impact in the international political arena. They need to form alliances to defend and foster their interests - alliances that require a give-and-take attitude of compromises. Also in the domain of international law there is increasing space for citizens to claim their rights beyond the confines of national law. The European Court of Justice and the European Court for Human Rights are well-known examples of institutions used by citizens to challenge national jurisdiction. Finally, in the domain of security, regional arrangements (NATO, ASEAN) have been since long established to provide mutual support in case of foreign aggression.

All these realities, however, do not make the nation-state redundant. I do not believe that the role and functions of the nation-state have become obsolete or have been taken over completely by other actors. No other actor takes responsibility for providing security, justice, basic social services and infrastructure to the citizens of a nation-state. The European Union, widely seen as the most ambitious project of intergovernmental governance, continues to struggle with its domains of authority. Ever since the problematic 2005 referendum about the European constitution, member states have become increasingly reluctant to hand over more responsibilities to 'Europe'. It is telling that, while the average state budget in European countries equals $40 \%$ of GDP, the budget of the European Union is only $1 \%$ of the total European GDP. Issues that are vital to citizens, like health, education and welfare, have remained national.

\section{The changing map of the world}

There is no square kilometer of land on this planet that is not assigned to a nation-state. Even if some borders are disputed, the general consensus is that every piece of land should be governed by a state that has authority and responsibility over it. At the same time, this constellation of nationstates is not fixed, but an ever-changing reality. In the past decennia too, new borders were drawn on the world map. The breaking up of former Yugoslavia into six independent nation-states meant a major change in the map of Europe. The collapse of the Soviet Union also created a series of new nation-states. The division of Czechoslovakia into two nation-states was a smaller and less bloody event. The current ambitions in Scotland and Catalonia and the process of federalization in Belgium may lead to the creation of more new nation-states in Europe. In Africa we have seen the partition of Sudan after more than twenty years of war and the de facto creation of new countries out of the chaos of Somalia. In Asia, Timor-Leste 
was the result of an unfinished decolonization process and a subsequent violent conflict. Some of these processes were peaceful (Czechoslovakia), many of them were violent (Kaukasus) and in some cases the creation of new nation-states itself happened rather peacefully but was followed by internal wars within these newly created states (Nagorno Karabakh - Azerbaijan; Georgia - South Ossetia; Moldova - Transnistria). A new map of Palestine is still not drawn, and also the nation-building of the Western Sahara is an as yet open-ended aspiration.

What the changing world map tells us is that the process of nationbuilding is complex and volatile. Even while trying to create a feeling of togetherness and belonging, a shared identity, there is always the possibility that certain groups within society prefer to take the secession route and aim to break away to form their own nation-state. The risk of fragmentation is real, especially in fragile states where there is often little cohesion and the forces in favor of secession are stronger than those aiming for togetherness. We all know that many of today's borders were drawn arbitrarily (such as at the Berlin conference of 1884), without consultation of the people and without considering the ethnic, cultural and religious realities on the ground. The map of the world will be redrawn in some places in the future, but I do not believe that redrawing will offer a real solution for the problems of lack of social cohesion and instability within fragile states. It would be a bloody and a costly process without any guarantee that the outcome will be more stability. The war between the dominant ethnic groups (Nuer and Dinka) in South Sudan after the country won independence, is a painful reminder that redrawing is no guarantee of success. Even if redrawing the map is sometimes unavoidable (as it was in the case of Sudan), it should not be the option that we look or aim for when we are designing policies for overcoming the lack of coherence and belonging in fragile nation-states.

Partition or secession is usually motivated by the wish to create a nationstate that reflects only the shared identity of a certain group - an ethnically, culturally, religiously or otherwise homogeneous nation-state as it were. However, in today's world especially, this is bound to be an impossible aspiration. ${ }^{27}$ Ethnic and cultural diversity is today's reality. If ever there existed ethnically homogeneous societies, they have by now been broken open as the result of internal conflict, migration and globalization. At the same time, in many countries majorities claim a privileged position, turning minorities by default into second-class citizens. The challenge for nearly

27 Zajda 2009, p. 94. See also Horowitz 1985, p. 265-277, where he addresses the heterogeneity of separatist movements. 
all of today's nation-states is to build a cohesive and overlapping identity in the reality of diversity. This challenge will be discussed more at length in chapter 8 .

\section{The nation-state: A coveted object}

Why, in the face of so much internal struggle in societies, does partition not happen more often? Why do 'the powers that be' want to fight for keeping the nation-state intact rather than allowing disenfranchised groups to build their own nation-state where they can live their identity uncontested? The reason is this: In today's world where nation-states require international legitimacy, shrinking physical size and shrinking numbers of citizens mean shrinking power both at the national and international level. Size is power. And the modern nation-state remains the most important source of power and wealth in our globalized world. In Western countries, the state's national budget equals more than $40 \%$ of a country's GDP; the state is by far the single largest beneficiary of a nation's economic resources. ${ }^{28}$ Although in most developing countries and in fragile states especially, the state's share of national GDP is much smaller (between $10 \%$ and $20 \%$ ), the state is nevertheless an important and powerful actor in the economy of a country. The capacity to impose taxes and levies on citizens and companies, and the authority to give out contracts and concessions, give the state access to collect large amounts of money and economic power. In many fragile states, the issuing of concessions for oil drilling and mineral mining brings large sums of foreign exchange to the national budget. ${ }^{29}$ Furthermore, the state formally is still the sole legitimate executer of physical (military) force. From an international perspective, the nation-state has access to international networks of aid ${ }^{30}$ that is mostly channeled through bilateral and multilateral programs in close cooperation with the recipient country's government. The power position of the nation-state, both domestically and

28 Wimmer 2002, p. 92.

29 Timor Este collects US\$ 275 million per month in oil revenues for a state budget of US\$ 1,7 billion, whereas domestic resources count for not more than $5 \%$ of the budget. http:// asiafoundation.org/in-asia/2012/02/22/oil-in-timor-leste-a-kick-start-or-a-kick-back/ (accessed 9 September 2014) The case of IS in Iraq and Syria shows the importance of oil revenues for the caliphate to build its power and to be able to finance its operations. http://www.syriadeeply. org/articles/2014/07/5856/isis-3-million-day-selling-oil-analysts/(accessed 9 September 2014) 3o Afghanistan's net ODA influx was $32,6 \%$ of GNI in 2012: http://data.worldbank.org/indicator/ DT.ODA.ODAT.GN.ZS 
internationally, is further strengthened thanks to the networks that states can build with powerful allies. In short, even if the role of the state today is challenged and even if its influence has decreased due to the process of globalization, the state remains an attractive source of national and international power. Seizing power over a nation-state is therefore still far more attractive than translating one's ambition of building nationhood into the partitioning of the nation-state into smaller territories. In this regard, South Sudan is an interesting case in point. John Garang, the deceased leader of the South Sudan Liberation Movement (SPLM) for a long time held on to his aspiration of nation-wide change in Sudan that would allow the country to stay together as one. It was only when it became absolutely clear that nation-wide change in favor of the discriminated South would never materialize that he accepted the idea of secession of South Sudan.

\section{The absent state}

The nation-state remains a source of power and influence in our globalized world. And the nation-state, we established earlier, fulfills vital functions for its citizens: It creates space for political participation, provides security, justice and basic social services, organizes infrastructure and economic life. In international development cooperation, assumptions abound about the positive role that the nation-state can play in people's lives - and how this can and should be strengthened.

But we should realize that the situation in most fragile contexts is very different. There, the state at best is absent; at worst it is part of the problem and perpetrator of criminal acts. In the fragile-states discourse, policymakers often define the role of the international community as 'reconstructing the institutions', not realizing that in fragile contexts there often simply is no state to reconstruct. In many fragile contexts, a very limited number of people in the capital controls all political processes. Large segments of society, in cities as well as in rural areas, simply do not participate. Although the state has a formal authority over the country, in reality authority is exercised by local leaders, who take care - or not - of people's security and well-being. National armies are often among the warring parties, which all commit crimes against humanity against civilians. Basic social services are not delivered, there is no economy to speak of, and the elites appropriate the country's natural resources. Partly this absence is due to unwillingness of these appropriated states (i.e. under control of ruling parties or elites and lacking legitimacy) to fulfill their obligations; partly it is due to a lack of 
capacity in the absence of physical and institutional infrastructure. If we aspire to understand, or even contribute to, the process of nation-building in fragile contexts, we need to acknowledge this reality of absent or criminal states and the presence of other actors, networks, and loci of power that fill the void of the absent nation-state. 


\section{Vignette}

\section{From commanders to governors in South Sudan}

In 2006, I visited South Sudan, one year after the comprehensive peace agreement was concluded in Naivasha. At that time Cordaid's programs were more humanitarian than developmental, solving the most urgent needs of the people of South Sudan after more than twenty years of civil war. One of the programs was in Aweil in the state of Northern Bahr el Gazal on the border with (North) Sudan. Tens of thousands of returnees tried to return to their homes in a precarious process, with very limited access to food and shelter and water, unreliable transport.

I paid a visit to the new head of the local government in Aweil. It was a difficult conversation between the two of us. He was suspicious what operations this international agency, Cordaid, was going to conduct in his area and he was quite clear that he was head of the government. In fact, we as Cordaid should hand over our resources to his new local government in order to deal with the problems. He emphasized that they (SPLA/SPLM) had won the war, that they were now in command of the country and that it was up to them to decide what would happen. There was also a personal justification for his position: As the military commander he was the one who had fought a bitter war and who was the victor and therefore deserved this position as the leader of the local government.

Turning commanders into governors is one of the challenges of post-conflict development work. It seems a continuation: If a revolutionary movement has been able to forge a peace agreement recognizing its position, the leadership wants to continue and translate its success at the negotiation table into a position in the political arena. Often it is understood as a justified reward for the hardship and risks military commanders have faced during the civil war: Becoming provincial governor, cabinet minister is therefore the deserved next step.

But being able to win a military battle does not make you competent to win political battles or to run a government. The discipline an army, even a rebel army can organize and expect from its soldiers is a far-removed reality from the chaotic behavior in the political arena where a host of organizations and interests are represented and where every group fights for attention and recognition. In the military campaigns of a freedom movement there are clear and clear-cut goals and objectives, in the political arena of a government a wide variety of goals and competing claims are vying for attention and resources. 
One of the biggest challenges for a post-conflict government is to solve the problem of the ex-combatants and the military commanders. How to keep them satisfied and how to reward them and at the same time acknowledging that leading a military organization is different from running a government. Every phase deserves a different type and style of leadership. 


\section{Fragility: A donor's concept but not far from reality}

Over the last fifteen years, the media have made us familiar with the notion of fragility. Afghanistan, Sudan, the Democratic Republic of Congo ... they are among the countries that are labeled 'fragile' in newspaper articles and news bulletins. The stories about these countries evoke images of societies in conflict and chaos, where people live in poverty and lack access to the most elementary services. Security and justice are absent. Governments are at best incompetent, but more often they aggravate the volatile situation and are implicated in human rights abuses. These countries are a far cry from what 'we', living in donor countries, consider decently organized societies. These countries are dangling at the bottom of the Human Development Index. They need foreign assistance to get their house in order - if there is any hope of that at all.

In this chapter we explore to what extent this media image of fragility is justified, how it relates to policy definitions of fragility, and to what extent the latter have explanatory value to identify the problems of today's conflict-ridden countries - and seek for solutions.

\section{Fragility: Definitions and reality}

As is the case with 'nation' and 'nation-building', the term 'fragility' is not well defined, neither in academia, nor in the world of policymakers and politicians. Using the notion of fragility, or 'fragile states', implies that there is a way to measure which state is fragile and which is not, a benchmark model for assessing the performance of states. ${ }^{1}$ This is problematic because in the current policy discourse the Western model of the welfare state is implicitly taken as the benchmark. Fragility is thus not merely a descriptive term; it implies a value judgment. The notion of 'fragility' emerged as a donor's concept and is being used in two ways:

1 The measurement approach: The World Bank and the Canadian donors use the Country Policy and Institutional Assessment (CPIA) as the basis

1 Woodward 2006: http://www.fride.org/publication/97/fragile-states:-exploring-the-concept (9 September 2014) 
for their assessment. ${ }^{2}$ They have a strong focus on public institutions and their economic and financial governance. The World Bank labels any country with a score lower than 3.2 on this multidimensional scale as fragile. Since 2012, the World Bank uses the presence of a UN peacekeeping mission as an additional indicator, thereby including the issue of conflict and violence.

2 The descriptive approach: DFID and the OECD use a descriptive definition of fragility. DFID labels a state fragile when 'the government cannot or will not deliver core functions to the majority of its people, including the poor.' The core functions include service entitlements, justice and security. ${ }^{3}$ The OECD defines states as fragile when 'state structures lack the political will and/or capacity to provide for the basic functions, needed for poverty reduction, development and to safeguard the security and the human rights of their populations'. ${ }^{4}$

The countries that are defined 'fragile' by donors and policymakers have not been particularly keen on this new label. They have criticized the use of the concept because it is loaded with negative connotations (that is, stressing only what countries are lacking and their inability to perform better) and obfuscates the efforts of countries and governments to overcome the challenges of fragility. These countries responded in 2010 by initiating the $\mathrm{G}_{7+}$ group of fragile and conflict-affected states, which currently has 20 members. ${ }^{5}$ The $\mathrm{G}_{7}+$ group is one of the constituent members of the International Dialogue on Peacebuilding and Statebuilding (IDPS), an initiative to address the issues of fragility led by fragile countries. They formulated their definition of fragility as follows: 'A state of fragility can be understood as a period of time during nationhood when sustainable socioeconomic development requires greater emphasis on complementary peace-building and state-building activities

2 CPIA score is composed out of scores on 21 indicators: Building human resources, business regulatory environment, debt policy, economic management, efficiency of revenue mobilization, equity of public resource use, financial sector, fiscal policy, gender equality, macroeconomic management, policies for social inclusion/equity, policy and institutions for environmental sustainability, property rights and rule-based governance, public sector management and institutions, quality of budgetary and financial management, quality of public administration, social protection and labor rights, structural policies, trade, transparency, accountability and corruption, IDA resource allocation. All indicators are rated between 1 and 6). http://data. worldbank.org/data-catalog/CPIA (accessed 8 November 2015)

3 http://r4d.dfid.gov.uk/PDF/Outputs/Inequality/wp51.pdf p. 2 (accessed 9 September 2014)

4 OECD 2010, p. 146. http://www.oecd.org/dac/governance-peace/conflictandfragility/docs/ do\%20no\%2oharm.pdf (accessed 25 January 2016)

5 http://www.g7plus.org/en/who-were-are/member-countries, (accessed 16 September 2014) 
such as building inclusive political settlements, security, justice, jobs, good management of resources, and accountable and fair service delivery' ${ }^{6}$

The differences between this southern-based definition and the northern, donor definitions of fragility are clear:

- The G7+ definition has no assessment approach that implies a benchmark. Pejorative and judgmental notions like 'unable' or 'unwilling' are not used.

- The $\mathrm{G}_{7}+$ countries define fragility as a temporary phase in their development and focus on the challenges that need to be tackled in order to leave this phase behind. These challenges include security, justice, jobs and service.

- The $\mathrm{G}_{7}+$ countries define fragility as a phase in their process of building nationhood, while the donor definition does not refer to nationhood but only talks about states.

At the same time, the definition of the $\mathrm{G} 7+$ contains similarities with the donors' definition in stressing inclusiveness of political settlements, the need for security and jobs, the fair service delivery, the accountability and the economic components of jobs and good management of resources. In that sense this definition mirrors people's reality. During the ten years that I traveled to many fragile and conflict-affected countries, I listened to people and what they believe the state should deliver - and where it falls short. In countries like Afghanistan, Sudan or Haiti, people are looking for a state that values their voice in the political processes, that can provide security, justice and access to basic social services and that creates a physical and institutional infrastructure for a functioning economy. While I believe that the Western political, social and economic model should not be the benchmark to assess and to judge other nation-states, at the same time people across the world have shared expectations about the basic functions a state should fulfill, regardless of the forms, regulations and institutional set-up into which these functions are translated.

\section{A conceptual model for fragility}

The Norman Paterson School for International Affairs of Carlton University in Canada identifies three basic competences for the state: Authority

6 http://static.squarespace.com/static/5212dafbe4bo348bfd22a511/t/538e $366_{5} \mathrm{e}_{4} \mathrm{bo1aec} 83_{31}$ 4ebe5/140183126904o/g7+\%2oEnglish\%2oFS\%2oNote\%2oDesign.pdf (accessed 16 September 2014) 
Figure 1 The ACL fragility model

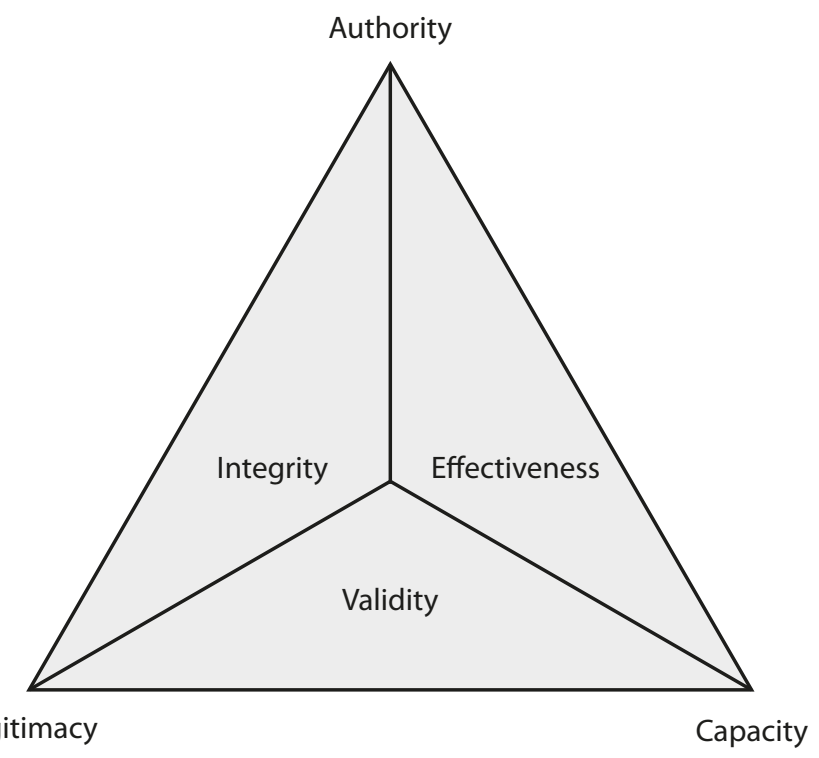

(controlling the territory and able to push through laws and regulations); legitimacy (accepted by the population as representing them and working for their interests) and; capacity (having the instruments and the means to implement policies). ${ }^{7,8}$

This framework distinguishes between three types of states, each covering two of the three basic competences:

1 States that have control over their territories and are seen as legitimate representatives of the population, but lack the capacities, means, instruments and institutions to fulfill their obligations. Fragility in these states is probably easiest to solve, that is, by securing and building the resources and institutions. Examples are Liberia, Sierra Leone, Timor-Leste.

2 States that are legitimate representatives and have capacity to fulfill their obligations, but have no full authority over their territory. Most

7 Carment, Samy \& Prest2008, p. 354.

8 The so-called ACL model has three main factors (authority, capacity and legitimacy) and three consequences when two of the three main factors are in place: effectiveness, validity and integrity. For these three consequences see http://www4.carleton.ca/cifp/app/serve.php/1144. pdf p. 37 (accessed 25 January 2016) 
of the time part of the territory is under control of rebel groups and the state is not able to get its authority established. Examples are Nigeria and Colombia.

3 States that have authority over their territory, have the power to impose laws and regulations and have the capacity to do so through the resources and institutions they control, but that lack the legitimacy to act on behalf of the population. Even if the governments of such states came into power through elections, these elections were rigged or pressures were so strong that people did not cast their votes freely (also called 'illiberal democracies'). Examples are Eritrea, Sudan and Zimbabwe.

Clearly, the three competences in the above model are interrelated. A country that has no control over its territory most often also lacks sufficient legitimacy because part of the country does not recognize the state as their representative. States that have insufficient institutional capacity will have a hard time exerting authority over their territory. And states that have no capacity will lose their legitimacy because they are unable to provide security, justice and basic social services. While most fragile states suffer from interrelated problems on all three competences, it is nevertheless helpful to distinguish between them in order to address the different aspects and to disentangle the fuzzy concept of fragility. Where does the notion of nation-building fit into this model? I believe it is located in the legitimacy corner of the triangle. Most of the legitimacy discourse is political in nature. It is about political power and about representation of people in the political process. Organizing democratic elections is considered a sine qua non for creating legitimacy for a government. However, legitimacy is not guaranteed simply by organizing democratic elections. A country that lacks a shared identity will face a legitimacy problem, regardless of elections. When there is no shared identity it means the state is not owned by part of the population, who do not feel part of the 'we'. Those who do not feel part of the nation-state are bound to contest laws and regulations and distrust institutions, as these do not reflect their identity and interests.

Fragility is a changing reality. The World Bank publishes an annual list of fragile states. Comparing the 2015 list with that of 2012, we see Mali and Madagascar are newcomers, while Angola and Georgia have left the list. Canada and the US have developed a system that reflects different phases in the process from stability to fragility (or vice versa). The Canadians have introduced fragile, weak, failing, failed, collapsed and recovering states, with each label reflecting different stages of fragility. USAID distinguishes 
within the broad category of fragile states between vulnerable states and states in crisis. These attempts to refine the notion of fragility can be seen as reflecting the changing reality and the movement of states on a continuum from outright fragility to clear and undisputed stability. ${ }^{9}$

The OECD, in its report States of Fragility $2015,{ }^{10}$ identifies 67 countries that have appeared on the fragile states list at least once between 2007 and 2015 . The list of 2015 includes 50 countries, among which the 'usual suspects' such as Afghanistan, South Sudan and Haiti, but also countries that are, even if not free from risks and threats, generally considered to be in a different league such as Rwanda, Kenya and Bangladesh. The OECD also lists 23 chronically fragile countries, that is, countries that have appeared on all lists between 2007 and 2015. ${ }^{11}$ This 'core' group of fragile states does not include, however, certain countries that have only recently been identified as fragile (e.g. Syria and Mali) or South Sudan, which only became an independent country in 2011. Some have been on the list and could easily relapse into fragility (Pakistan, Lebanon). Therefore the list will remain flexible with countries appearing and disappearing off the list.

\section{Fragility: Social networks, governments and hybrid political order?}

The most problematic aspect of the notion of fragile states is that it puts a blanket of failure on these states, as if structures and institutions are completely absent, people are incapable to act and to change anything, and are fully dependent on external interventions and aid to survive. I wish to list two caveats to this viewpoint.

9 Whereas there is differentiation in the fragility spectrum, there is no such differentiation in the stability spectrum, which underlines the criticism on the benchmark approach to fragility of donors. It seems that the benchmark is a single standard, which overlooks the differences between the Northern, Southern and Eastern member states of the EU.

10 http://www.oecd-ilibrary.org/docserver/download/4315011e.pdf?expires=1442302139\&id=i $\mathrm{d} \&$ accname $=$ guest $\&$ checksum $=\mathrm{F}_{7} \mathrm{D} 80125 \mathrm{~A} 2701786 \mathrm{FC}_{7} 675 \mathrm{FC}_{454544 \mathrm{~A}} 4$ (accessed ${ }_{15}$ September 2015)

11 The OECD 'core' list includes: Afghanistan, Burundi, Cameroon, Central African Republic, Chad, Comoros, Democratic Republic of Congo, Eritrea, Guinea-Bissau, Haiti, Kiribati, Liberia, Myanmar, Niger, Nigeria, Sierra Leone, Solomon Islands, Somalia, Sudan, Timor-Leste, Togo, Yemen, Zimbabwe. Comparing this list with the membership list of the $\mathrm{G}_{7}+$ reveals the following differences: Cameroon, Eritrea, Kiribati, Myanmar, Niger, Nigeria and Zimbabwe are no members of the $\mathrm{G}_{7+}$. The $\mathrm{G}_{7}+$ members Côte d'Ivoire, Guinea, Papua New Guinea and Sao Tome and Principe are not on the OECD list. 
Firstly, if a state is fragile, that does not mean society is not functioning. Fragile states are not a tabula rasa on which the international community can design its blueprint for reconstruction and state-building. During conflict, people survived, although on a minimal basis, thanks to the power of their social networks: Families, tribes, communities, churches. All these institutions proved to be resilient, sharing food and shelter, providing healthcare, giving spiritual support in times of suffering and loss. The power of these social institutions is an important asset in nation-building and state-building. Many state-building interventions by the international community have provoked anger and resentment exactly because they do not value, and often dismiss, these social networks as building blocks for nationhood.

The idea of hybrid political orders developed by Boege et al. ${ }^{12}$ builds on this social reality. The notion of fragile states is framed by a Western perspective about the welfare state and the division between state and civil society, each with its own functions. In many fragile states, there is a structure of social institutions that provide important basic services to the people and which operates parallel to the (non-functioning) state institutions. Security, justice and social services are provided by ethnic groups, religious communities and local networks. In such hybrid political orders the boundaries marking what is whose responsibility are not always sharp. The notion of the hybrid political order is helpful as it opens up a new perspective on the agency of people and social structures in fragile states. However, these important social structures and networks should not be taken for granted as the solution to fragility. The outreach of these social institutions is limited, and they are not always inclusive. In fact, the problem of fragility is for a large part caused by a focus on the in-group as the reference. The bonding social capital is not accompanied by bridging social capital. And even in-group cultures may not be inclusive (e.g. women).

Secondly, even if we leave aside society at large and focus on the stateapparatus, there is good reason to be more precise in our analysis of fragility. My own experience in different conflict-affected countries taught me a few things about the diversity in state institutions. Framing a generalized picture of fragile states as fully dysfunctional and not constructive is misjudging the more complex reality and the opportunities for change. I observed a clear distinction between the security-apparatus of the government (presidency, ministries of defense, security services) and other ministries. In Burundi, for instance, I met ministers of health, education, infrastructure and gender 
who were less obsessed with security, were open for new ideas and had a genuine focus on development and social improvement. Often I met civil servants who wanted to move forward, who were not corrupt, and who were really committed to the plight of the poor. The innovation in Performance Based Financing of the health sector in the Democratic Republic of Congo would not have happened without the push and power of civil servants who were creative and committed to introducing and expanding this new funding model.

Another observation is that national and regional governments can markedly differ. Representatives of the regional governments of the province of South Kivu, DRC, who live close to ordinary people and are not encapsulated in the national political coterie, genuinely wish to make a difference in the lives of the people in their province. The Cordaid program for education got a foothold in South Kivu thanks to the provincial ministry of education that wanted to bring about change and realize better results.

Those who focus on the power-holders at the state level may consider the above distinctions within governments of fragile states irrelevant because as long as these power-holders keep their position, nothing will change and processes of state-building and nation-building are bound to fail. From a perspective of social dynamics, however, these distinctions are relevant: Social and political change is always the result of processes and interactions and it is important to identify agents of change, even if at moments their impact on the power structure on nation level is limited.

\section{The New Deal for Engagement in Fragile States}

The international community's specific attention for fragile states started around 2007. Fragility affects more than 1.4 billion people worldwide and fragile countries fare significantly worse in reaching the targets of the Millennium Development Goals than the non-fragile developing countries: ${ }^{13}$

- Poverty. The 50 states and economies on the 2015 list account for only $20 \%$ of the global population but $43 \%$ of the world's poor. According to World Bank projections, nearly two thirds of currently fragile countries will fail to halve poverty by 2015. By comparison, only a third of other developing countries will fall short of this target.

- Child survival. Both fragile and non-fragile states have made impressive progress in reducing child mortality. Nonetheless, while $15 \%$ of 
non-fragile states are projected to reduce the under-five mortality rate by two thirds by 2015, only one fragile state will reach this goal.

- Education. Just one fifth of fragile states and economies are on track to achieve universal primary schooling, compared to nearly half of non-fragile developing countries.

- Water. Only $28 \%$ of fragile states are on track to halve the number of their citizens without access to safe water, while $61 \%$ of non-fragile countries have reached this target. Fragile states have also made slower progress on sanitation. ${ }^{14}$

The British Overseas Development Institute (ODI) in its report Horizon 2025 analyzes that fragile states will pose the biggest challenge to successful development cooperation. ${ }^{15}$ The ramifications of fragility on neighboring countries and the international community in general (military/security, poverty, refugees) are too big to ignore.

In response to this reality, the New Deal for Engagement in Fragile States was launched at the 4th High Level Forum on Aid Effectiveness in Busan in 2011. The New Deal is an agreement signed by more than 40 fragile and conflict-affected states, international development partners and civil society organizations to improve current development policy and practice in fragile states. The New Deal calls for five Peacebuilding and Statebuilding Goals (PSGs) to be at the forefront of all international efforts in fragile and conflict-affected countries:

1 Legitimate Politics - Foster inclusive political settlements and conflict resolution;

2 Security - Establish and strengthen people's security;

3 Justice - Address injustices and increase people's access to justice;

4 Economic Foundations-Generate employment and improve livelihoods;

5 Revenues \& Services - Manage revenue and build capacity for accountable and fair service delivery. ${ }^{16}$

Goals 2 to 5 are not different from the common goals of the international community's state-building agenda: Positioning the state as the actor that delivers security, justice, economic development and services. However, the

14 http://www.oecd.org/dac/governance-peace/publications/documentuploads/SOF2015.pdf (accessed 8 November 2015)

15 http://www.odi.org.uk/sites/odi.org.uk/files/odi-assets/publications-opinion-files/7723. pdf (accessed 8 November 2015)

16 http://www.pbsbdialogue.org/documentupload/49151944.pdf (accessed 8 November 2015) 
notion of 'people's security' in the second goal suggests a shift of focus from a state-centric security approach to an approach focused on people. In the aftermath of the 2001 attacks on the World Trade Center, the problem of security as posed by fragile states like Afghanistan and Somalia was framed from a state perspective: How to defend the nation-state against attacks from terrorists? Homeland security became a dominant frame for addressing security issues. In response to that, the concept of Human Security, already developed by the UNDP in its 1994 Human Development Report ${ }^{17}$ and adopted as the basis of the UN's Responsibility to Protect commitment, has been pushed for by the International Dialogue on Peacebuilding and Statebuilding as a much more comprehensive approach to security; not only defending the interests of the state but fostering the much broader interests of people, including a well-functioning society with access to justice and social services that create the basis for a life in dignity.

Also interesting is the first goal of 'legitimate politics', which aims for political settlements and conflict resolution. It brings in the legitimacy component of the triangle of fragility (figure 1). By identifying conflict resolution as part of legitimate politics, I conclude that the New Deal is willing to position, at least partly, conflict resolution outside the security area. I believe that this is an important step forward. Too often internal conflicts in fragile states are dealt with from an exclusively state security perspective. By pointing to 'inclusive political settlements' the New Deal acknowledges that exclusion of certain groups in society is often the reality in fragile states - both cause and consequence of fragility - and stresses the need to find inclusive solutions in a political process. Exclusion processes often have their origin in identity issues of ethnicity, religion or region. Resolution of conflicts related to exclusion takes time due to the internal dynamics and complexities of fragile states. Security and stability require the integration and non-discrimination of all groups in society, which can only happen if societies engage in a process of self-examination leading to a common purpose. International partners must adjust their interventions accordingly.

The fragile and conflict-affected countries that have come together as the $\mathrm{G}_{7+}$, made a clear statement about the nature of their countries' internal problems in an annex to the Dili Declaration that came out of their inaugural meeting in Dili, Timor-Leste in April 2010. In a paragraph on security they wrote:

17 UNDP 1994, p. 24. http://hdr.undp.org/sites/default/files/reports/255/hdr_1994_en_complete_nostats.pdf (accessed 9 September 2015) 
We have all dealt with what have often seemed intractable problems and social division. We acknowledged these problems and agreed on the approaches that are necessary to bring peace and security. This includes the need for reconciliation, social inclusion, dialogue, the institution of the rule of law, and for an honest examination of the root causes of conflict and our national mentality. There must be recognition that a change of national mentality is a long process that takes time. As we have all experienced conflict, there was agreement that we can learn from our individual and collective experiences and discuss together how we addressed our problems.

Referring to intractable problems, root causes and a nation's mentality they hint at problems and challenges of a different nature than those that can be solved by mere political, economic or institutional arrangements and interventions. Acknowledging the need for reconciliation and dialogue and recognizing the existence of root causes that have to be examined creates the space for a different approach. Acknowledging that overcoming fragility is a long process reflects the reality that quick fixes do not exist. 


\section{Vignette}

\section{Blueprints, checklists and formats: Disarmament in the DRC}

A couple of years ago the Ministry of Foreign Affairs of the Netherlands hosted an international conference on Disarmament, Demobilization and Reintegration in the Democratic Republic of Congo (DRC). These issues were high on the agenda with the civil war in the DRC coming to an end and huge amounts of money being available to finance this difficult part of the transition to peace. The Netherlands had pledged a US\$ 100 million contribution to the DDR fund for eastern Congo.

At the conference policymakers, analysts and researchers, mainly from the OECD countries, shared expertise and knowledge. Just a few participants came from the Central African region, amongst them a Congolese civil servant and his Swedish colleague based in the DRC. On the second day of the conference, after eloquent speeches and insightful presentations, they burst out in despair, mingled with anger: 'What do you expect us to do with all that is designed in ministries and think tanks in the donor countries? We have seen new and more refined checklists, formats and blueprints that tell us what to do with DDR, but nobody cares about the reality. The reality of eastern Congo is that we are satisfied if we can make sure that ex-combatants leave their weapons in their cupboard and do not threaten other citizens'.

The disconnect between the realities of conflict and fragility on the ground and the best intentions of policymakers and analysts is serious and problematic. Policymakers want to offer the best ideas and the most sophisticated tools to solve the complex problems of societies in conflict. Complex problems require complex answers to address all issues that are at stake and to make sure we do not get trapped in unexpected details. And they feel the pressure of domestic constituencies: No parliamentarian in the Western Capitals will be satisfied with a policy without strong wordings about gender, democratic oversight of the military by political actors, anti-corruption measures and reporting and monitoring formats that allow to follow the money and to define outcome and impact. Every minister of foreign affairs or development cooperation will be criticized and taunted if $s /$ he presents his or her policies without these elements. This leads to a complex system with checklists, formats and blueprints that are sent to our embassies and missions in the form of guidelines for the implementation. Accountants use these guidelines to check whether spending has been accordingly. And different research groups, think tanks and policy departments compete with each other to publish better guidelines and more sophisticated tools that are even more in line with the values and principles of good governance. 
It is a tragic disconnect. There is no reason not to bring the best we have to solve the problem of fragility and to contribute to the end of conflict and violence. We should not fob off the people in fragile situations with run-down solutions or tools that are imprecise. However, there is no need for an overkill of guidelines and rules that are designed for an ideal world. Fragile states are messy and the dynamics are unpredictable. But what is the right match between the reality on the ground and the values, principles and insights of researchers and analysts? 



\section{Nation-building: Sovereignty and citizenship}

The issue of sovereignty is pivotal in the nation-building project. If we agree that the sovereignty of people is the founding principle of the nation - without this a nation has no existential legitimacy - any theory of nation-building must start by putting people center stage. Even if those who design policies for fragile states embrace this principle, in practice their policies often transform people from subject to object.

In this chapter we start from the philosophical principle of 'people as sovereignty', or 'popular sovereignty', we subsequently turn to the notion of citizenship as the practical translation of sovereignty into rights and duties of people in a nation-state - and the dilemma's this evokes in today's world.

\section{The people as sovereign}

The very notion of the nation-state that emerged in modernity was indissolubly connected to the shift in sovereignty that occurred in the 18th century. During the 17 th and 18 th century, the absolute authority of monarchs - kings, emperors, dukes - became increasingly questioned. In France and Great Britain, sharing of power became unavoidable partly because the nobility and the emerging powerful merchant class had started challenging the monarch's decisions, and partly because the monarchs, in order to finance their wars and extravagant lifestyles, themselves became increasingly dependent on the nobility and merchants. The erosion of the monarch's autocratic power happened in tandem with the new philosophical ideas that gained ground thanks to Enlightenment philosophers like John Locke and Jean Jacques Rousseau, who stressed the ideals of liberty, reason and tolerance while questioning the religiously based legitimacy of rulers. This sovereignty of the autocratic ruler - which had often been presented as based on a divine intervention - became untenable. A fundamental shift took place: The people became the source of sovereignty. Even though the road to general suffrage was still long, the philosophical principle of people's sovereignty was established. From being the object of governance, people became the subject; from merely being governed, the people gained the double role of being both governor and governed. 
Over the last century the debate about sovereignty has moved between stressing a state-centric and a people-centric approach to sovereignty. 'Sovereignty in international relations has been ascribed to two different types of entities: states, defined in terms of territories over which institutional authorities exercise legitimate control, and nations, defined in terms of "communities of sentiment" that form the political basis on which state authority rests'. ${ }^{1}$ In their historic overview Barkin \& Cronin show that a state-centric approach was dominant after the Napoleontic wars, a nation-centric one after World War I, again a state-centric approach dominated the post-World War II world and after the end of the Cold War a renewed nation-centric approach seems to be dominant. My focus on people-centric sovereignty comes from two considerations. First, as stated above, even state sovereignty rests on the consent of the people. There is no state sovereignty that has legitimacy in itself: Dictators and the communist and fascist regimes of the 2oth century fabricated that people's legitimacy of their sovereignty. The second reason is that the focus of my research is not on the international relations of fragile states and how they behave in the international community of nation-states. Focusing on the domestic challenges of fragile states, the sovereignty of the people as legitimizing the state is the critical issue.

The famous three opening words of the United States Constitution, 'We the people ...', express this principle: The Constitution derives its power from the people, it is founded on the American people as subject. As much as this is an elegant or even moving opening phrase, it is problematic too: Who is this 'we'? Is it the sum of all the individuals or an abstract entity?

Jean Jacques Rousseau also struggled with this problem and postulated the notion of the people's 'general will' to connect concrete individual persons to each other in order to be able to act as a community: Total unanimity is necessary to make the sovereignty of the people work. The general will of the people should be the expression of each and every individual's opinions and values. ${ }^{2}$ Rousseau, in other words, stated that there should be a direct link between the concrete individual and the collective of which s/ he is part. Sovereignty should not be an abstract notion but should find ownership in the most concrete we, that each and every person can give his or her positive consent to the decisions to be taken and the policies designed. Although Rousseau tried to put his ideas into practice in elaborate proposals for the

1 Barkin \& Cronin1994, p. 110-111.

2 Rousseau 1762. 
government of Geneva, Corse and Poland, his efforts to keep the direct link between the concrete and abstract people proved far too complicated.

Anderson builds his 'imagined communities' on his understanding of the nation as a community of people who are connected to each other without knowing each other, without being familiar with each other's beliefs or traditions. ${ }^{3}$ The nation is a social construct. His idea of imagined communities reflects the problem of the abstract and the concrete within the notion of sovereignty: The nation is about concrete persons, who have impersonal relations to each other. Via this impersonal nature of the relations between people in the nation-state he can arrive at a rather abstract understanding of 'the people'. People's sovereignty in the imagined community concept is to be understood as the joint expression of people without covering each and every individual's position and opinion.

A few years before the Constitution opening with 'We the people' was ratified, the Congress in 1782 had adopted $E$ pluribus unum as motto to be included in the Great Seal of United States. E pluribus unum translates as 'out of many, one' - at the time understood as 'out of many states, or colonies, emerges a single nation'; today explained as: Out of many peoples, races, religions, languages, and ancestries has emerged a single people and nation, the United States. ${ }^{4}$ This illustrates clearly how sovereignty of the people in the modern nation-state is inherently connected to diversity. This is probably even truer than it was in the late 18th century, as the individualist culture, currently dominant in the West, stresses individuality and more than ever allows for and promotes diversity. This diversity does create a considerable challenge of finding a shared expression of people's sovereignty. For fragile states this is often a particularly hard challenge as many of them cannot build on a history of gradually forming a united nation-state and are pressured to build their sovereignty from scratch on the fragmented and often antagonistic diversity of ethnicities, religions, languages and regions. To find a solution for this diversity-in-sovereignty problem I turn to the concept of citizenship.

\section{Republican citizenship: In-between individual and community}

The French Revolution expressed itself politically in the Déclaration des droits de l'homme et du citoyen. The distinction made between 'man' and 
'citizen' is crucial for our understanding of sovereignty. If sovereignty lies with the people - 'popular sovereignty' - this means it lies with the people as citizens. Citizenship is not identical with the human person. The notion of citizenship refers to the role that a person takes as a representative of 'popular sovereignty'; it is a responsibility in the public domain that can be referred to as citizenship as office. ${ }^{5}$ The citizen understands that acting as citizen requires filtering one's personal opinions and preferences before presenting them in the public domain; acting as governor in the public domain requires reflection on one's personal opinions.

Based on this basic understanding of the citizen, the perspectives on what citizenship means vary strongly, with a strictly individual and utilitarian perspective as the one extreme and a strictly communitarian perspective as the other. The utilitarian perspective postulates that the citizen acts in the public domain with a view to maximizing his or her personal benefit, stressing the rights-bearer side of citizenship. In negotiations with other citizens and with the nation-state, s/he will put forward demands in the public domain trying to achieve the most profitable outcome. The development of the welfare state has strengthened this perspective: The many different social and economic entitlements encourage citizens to adopt an attitude of maximizing one's benefits. The growing complexity of the state, exacerbated by the processes of globalization, has increasingly left citizens with the feeling that they lack the agency to act meaningfully or be influential in the political domain and therefore concentrate on their individual rights.

At the other end of the spectrum, we find the communitarian perspective on citizenship, where the citizen fully coincides with his or her role in the community (based on ethnicity, religion, language, regional or economic interests). In this communitarian perspective there is conformity between the individual and the group. The community demarcates the space for the individual to act in the public domain. There are at least two problems with this communitarian perspective. First, it invites and encourages deeper entrenchment of community-based positioning in the nation-building debate. It encourages communities within the nation-state to push through their influence based on numbers: The larger the group, the stronger the power play. Secondly, full communitarianism is not a reality, not even in fragile states that are perceived as countries where people are fully aligning along group-lines (ethnic, religious, linguistic). Also in fragile states, people make choices based on individual preferences and interests. Like every 
other state, very few, if any, fragile states consist of homogeneous groups of people who without a qualm align themselves with 'the community'. In situations of fragility people may even be more inclined to make individual decisions distancing themselves from group interests. Some decide to flee the country and become refugees and subsequently new citizens in host countries; others seize the job and career opportunities that international actors (peace missions, international NGOs) offer, and yet others, like the young refugees in the camps in Kenya, benefitted from the opportunity for better education; yet others are prepared to die for keeping their strongmen in power or instead achieving independence of their group. Citizenship therefore is neither fully utilitarian nor exclusively communitarian. Citizenship as expression of the sovereignty of the people is republican in nature: Accepting the dual role of governor and governed, accepting responsibilities alongside rights, keeping the interest of the common good in mind while safeguarding space for individual decisions. This is not only to find a middle ground between extremes, but also to understand citizenship as an office that is more than merely interest-driven, whether that be individual or group interest. As an office, republican citizenship has always been connected to ethical qualities and virtues ${ }^{67}$ It entails that every citizen has responsibilities and can be held accountable for the way s/he fulfills his office in the nation-state. Republican citizenship deepens the social contract between the state and the individual. Rather than constituting a mere provider-client relationship, the relationship implicated by the social contract - again a philosophical notion that has its origins in the Enlightenment - is reciprocal: The nation-state has to fulfill its obligations towards the citizen and vice versa. The fundamental reciprocal relation of the social contract exists regardless of whether or not citizens or the state are limited in fulfilling their obligations due to a lack of resources or capacity.

\section{Republican citizenship in fragile states}

Is it realistic to expect an active republican citizenship in fragile states? Currently, in the debates about and policies for fragile states, there is a strong emphasis on the position of citizens as rights-holders who put their demands on the tables of the duty-bearers. Most development organizations that advocate for the position of the poor and criticize the behavior of

6 Vogelsang-Coombs \& Bakken 2003, p. 450.

7 Gunsteren ibidem, p. 45 . 
governments push for this rights-based approach to citizenship. While this may seem justified given the performance of most governments in fragile states, which more often than not exacerbates the poverty and deprivation of the people, I believe that progress in fragile states requires advocating and putting into practice the fully republican perspective on citizenship. The rights-holders/duty-bearers dichotomy as a citizen/state dichotomy tends to take a state-centric sovereignty perspective: The authority and the power is with the state and therefore the state has to deliver to meet the justified demands of the citizen. The citizen has become the client of the state, not the subject.

There is a need to change the position of the people as mere object of the governments. Citizens are more than clients, they should see themselves as subjects, as owners of the sovereignty, even if - or, exactly because - that ownership brings responsibilities. As long as citizens take a 'wait and see' position, the nation-state will end in a self-fulfilling prophecy of failure. Fragile states need an active engagement by their citizens to build up a stable society. The government and its institutions alone will not win this uphill battle.

It is true that the reality is that governments in fragile states do not have very much to offer. There is a huge problem of expectations and disappointment. Given the power differences between governments and citizens in fragile states, and the limited resources of citizens to fulfill their role as governor, the perspective of republican citizenship may well seem unrealistic. However, I believe that continuing the antagonistic perspective on the relationship between citizens and the nation-state is problematic. Creating stability in fragile states requires an active role of the citizen as the governor, who takes responsibility for decisions and contributes to creative solutions to the problems of the nation-state. Take the example of Afghanistan. The Afghan government has limited means to provide security, justice and basic social services to its citizens. The state budget depends for more than $80 \%$ on foreign donors. The donor contributions, however, will undoubtedly decrease over the coming years in response to the end of the NATO-led ISAF mission in December 2014. As long as the citizens of Afghanistan first and foremost position themselves as individual claimants for services, based on international standards of what governments are supposed to deliver, the Afghan government has no chance to be seen as the one who acts as the duty-bearer. The list of unmet needs is simply too long.

In the broad range of policy domains - education, health, livelihoods - the Afghan state will only become credible if it manages to deepen its relationship with the people beyond a mere relationship of service delivery, 
while the citizens at the same time take on a role as a responsible actor in the relationship. In 2012, the Dutch NGO Cordaid started a debate with the Afghan ministry of health, suggesting that the provision of free healthcare as included in the Afghan constitution is not feasible for a sustainable design of the health care system in the country. Cordaid advocated for performance based financing of the healthcare system, in which contributions by patients had to be considered as a realistic perspective, but was confronted with staunch criticism from the health sector (both state and civil society agencies). The reality in 2012, however, was that, in contrast to the principle of free healthcare included in the constitution, $75 \%$ of the spending for healthcare was out of pocket payments by citizens, $23 \%$ came from international donors and $2 \%$ came from the Afghan government. These figures show that people indeed do take responsibility. The solution for a well-performing healthcare system in Afghanistan does not lie in a political fiction of free healthcare, nor in a hard reality of private spending (inefficient, low quality), but in facing the reality as the basis for coming up with a realistic perspective on what the government should provide and what people should take care of themselves. In the current approach, $75 \%$ of spending is seen as 'outside the system', not taken into account as part of the overall investment of Afghans in their health. Cordaid made a plea to factoring in the reality of out of pocket spending by citizens and take it as a sign of agency. Such an inclusive approach to the financing of healthcare would offer serious space for improvement (better quality and more efficiency) of the system.

Including people as a governor, taking responsibility for the future of the nation-state, based on a people's sovereignty and people's agency, has to become part of the agenda of fragile states.

This is also to be seen in connection to the fragility model presented in chapter 3 . If effectiveness is seen as the main policy-objective in the fragility discourse, we focus our interventions in the nexus between capacity and authority. The people sovereignty discourse entails shifting the focus to the nexus of authority and legitimacy with integrity as the main outcome. If the nexus of legitimacy-authority is the focus of the fragility discourse and integrity is the main outcome, we can include citizens as agents of their own future and are able to develop a different, more inclusive discourse that does not hinge on the state-citizen relation as a provider-client relation.

If citizenship is understood as an office (taking responsibility as governor), the question remains what the connection is between 'man' and 'citizen'. Even though citizenship requires filtering one's personal preferences and opinions with a view to achieving the common good, the citizen cannot 
and will not rid him or herself completely of these personal convictions. Citizenship does thus not solve the problem of diversity. The space for citizenship is not a space where political and civil issues are discussed separated from our identities. Rather, citizenship is to keep the diversity in check: ethnic, religious, cultural and linguistic identity has to be connected to the notion of citizenship and the responsibilities connected. This also implies that republican citizenship is something that needs learning and practicing. It is like parenthood: There is no test that decides whether one is eligible to qualify as citizen (as there is not for parenthood), but being a good citizen (and a good parent) is not a competence we naturally acquire by birth. Nation-states should therefore include the subject of citizenship deliberately in the mainstream educational system and other programs. In most fragile states, civic education is part of the process of preparing for democratic elections. ${ }^{8}$ This civic education is vital in supporting people to understand the differences between parties and candidates and to make up their mind for whom to vote. Especially in remote areas, people are often hardly aware of the electoral process and what is at stake. Unfortunately, such educational programs usually end when elections are over. It is my conviction that a republican perspective on citizenship calls for a much broader and much more lasting investment in citizenship education.

\section{Citizenship as solid base for diversity}

In his groundbreaking article 'Citizenship and social class' T.H. Marshall presented the history of citizenship as a process, in which citizenship became the cornerstone of political equality. ${ }^{9}$ Although the French Déclaration du droits de l'homme et du citoyen of 1789 declared all inhabitants of France to be equal, the translation of this principle in the political realm took more than a century. The role of 'governed' was for all people; the role of 'governor' was the prerogative of those who held property. In the Netherlands, from the moment the new constitution took effect in 1848 until 1880 , the percentage of the male population that had the right to vote was not more than $12 \%$. In 1900 , just half of the male population (49\%) had access to the ballot box. In almost all European countries women were excluded

8 International actors invest in these types of civic education programs. See for example: http://www.usip.org/sites/default/files/SR 254\%20-\%2oCivic\%2oEducation\%2oand\%20 Peacebuilding.pdf (accessed 25 January 2016)

9 Marshall 1996. 
from the right to vote until the early 2 oth century. In France, women's suffrage was not realized until 1946. Only when the right to vote was granted to all men and women alike, did citizenship become a fundamental right, equally accessible for all inhabitants without taking into account class differences. Finally, acting as 'governor' was no longer the privilege of the wealthy and those who paid taxes, but a right and possibility for all. The 'one man one vote' principle prevented that differences in class would mean difference in the weight of the vote. In the course of the development of citizenship, gradually a decoupling emerged between a citizen's ownership of the nation-state (expressed in property) or a citizen's contribution to the resources of the state (expressed in taxation) and his or her right to vote, that is, his or her active participation in the polity. With this decoupling the foundation was laid for the social welfare state, which grants citizens the entitlement to benefits regardless of whether or not they contribute to the financial resources of the state.

Marshall underlines that citizenship does not eliminate differences in social class, but creates fundamental equality as citizens while maintaining the space for difference. What Marshall describes for citizenship in relation to class difference, is also applicable as a model for the relationship between citizenship and cultural, ethnic, religious and linguistic differences: Citizenship is the equal 'floor' in the debate on nationhood and belonging to the nation-state, without doing away with or wanting to obscure the existing differences. Citizenship is not in conflict with the identity differences that exist in each and every nation-state, but is the solid base for full participation of all in the polity. We will explore the reality of this possibility in chapter 8 .

\section{Who is the citizen?}

If citizenship is the basis for rights and obligations, the definition of the citizen is of utmost importance in the modern nation-state. It is the answer to the question: Who is 'in' and who is 'out'? Who is part of the people, the legitimate source of sovereignty, who can be asked to contribute to the functioning of the nation-state by voting, paying taxes and obeying the laws? Today's nation-states use two different principles to define citizenship. The first is ius solis: Those who live on the territory of the state are defined as citizens, regardless of their religious, ethnic or linguistic roots. Living on the territory is the basis for granting a person the rights and the responsibilities attached to citizenship. The second principle is ius sanguis: 
Those who are the descendants of the people who built the country and lived there for generations are entitled to citizenship. This principle has often been connected with a primordial perspective on national identity: Nations have historic roots and only those who can claim that they are part of that history, should be considered as citizens of the nation-state.

Famous examples are the French (ius solis) and German (ius sanguis) way of identifying citizenship. In reality the picture is much more complex. In the European countries that apply the ius solis principle for citizenship, migration has challenged the debate about national identity, questioning whether the ius solis principle is a sufficient basis for citizenship and whether all citizens should not at least to some extent identify with the historic and cultural roots of the nation. The Netherlands has introduced exams and tests that migrants have to pass in order to acquire Dutch citizenship. These tests include questions to ascertain that immigrants are familiar with the Dutch history, culture and values.

The German approach to citizenship, traditionally build on the of ius sanguis with an emphasis on national descend, which granted German citizenship to the descendants of Germans who had settled in other (mainly Eastern European) countries, had to be modified to create access to citizenship for second- and third-generation migrants who are themselves born in Germany but whose parents and grandparents immigrated from Turkey and other non-European countries. In both cases the reality of ongoing migration challenges the traditional principle of citizenship and has created the need for a broader perspective on citizenship.

South Sudan and Scotland present two interesting examples in the recent history of the way nation-states in the making deal with the citizenship question. In South Sudan there was a huge and complicated debate about who was entitled to vote in the 2011 referendum about independence. Who could be considered South-Sudanese and therefore be part of the 'people as sovereignty' for the new nation that was anticipated? The South Sudanese decided it was important to include all those who had been forced to flee the country due to the civil war, regardless of whether they had ended up in Khartoum or other parts of 'the North' of Sudan, in Kenya or Uganda, or even outside the African continent. A complex system for defining eligibility for voting was made part of the agreement on the referendum, in which having one's roots in South Sudan was the main principle.

In Scotland, the government took a very different approach to defining who was eligible to vote in the referendum about the independence of Scotland in September 2014. All people living in the territory, whether Scottish or citizen of any other country of the European Union were eligible 
to vote. This meant that European Union students residing in Scotland for their studies could cast their vote while people who were born and raised in Scotland but who at the time of the referendum resided elsewhere, were barred from voting. It meant that many Scots living elsewhere in the United Kingdom were not entitled to vote, while many UK citizens without Scottish roots were. The government wanted to make a clear statement that it did not aim to create a purist, primordial image of Scotland, instead, that an independent Scotland would be a country open to all those who wished to live on its territory.

\section{Citizenship under pressure in a globalizing world}

As was hinted at above, citizenship itself has become a sensitive issue over the last decades of globalization and migration. To define who is a citizen and therefore, who has the right to participate in the polity, has become a battleground in the political debate.

Citizenship is indeed under pressure from two angles. First, citizenship is becoming a confused notion due to the process of globalization, which makes that nation-states have increasingly limited authority and power on the global stage. Citizens resort to the state as their representative and the one to defend their rights in the globalizing world, but increasingly states have to acknowledge that they are unable to fulfill these expectations. ${ }^{10} \mathrm{~A}$ growing body of international conventions and treaties may appear to fill the gap and act as the successor of the nation-state, but the truth is that there is no alternative international government that people are related to as citizens and which they can hold accountable - nor does it look like this is soon to happen. All the rights delineated in international conventions and treaties, for instance the Universal Declaration of Human Rights, need to be adopted by and enshrined in national legislation: The jurisdiction of international rights goes via the nation-state. In Europe, a supranational body of rights is emerging, that is, the European Court of Justice, but this Court has limited jurisdiction. In fact, current trends in the EU are more geared towards restricting the jurisdiction of the European Court of Justice than broadening it. International NGOs actively try to influence the policies

10 In his book The Globalization Paradox, Dani Rodrik describes the problem of the incompatibility of globalization, free markets and democracy at the same time. The dominant neoliberal model of the economy democracy in the West runs the risk of being marginalized and being defeated by the globalized market forces. 
of multilateral bodies, but they lack the strong legal position of the citizen. The global citizens are not the sovereignty on which a global system of governance is based. If global citizenship remains limited to a mere moral and ethical notion, this concept of citizenship will threaten the essence of citizenship and could lead to a hollowing out of the notion of citizenship.

There is a second development that threatens to undermine the power of citizenship as laying the foundation for equality. ${ }^{11}$ Many labor-migrants in fact feel that they are second-class citizens based on how they are treated on the labor or the housing market where they experience subtle, and less subtle, forms of discrimination and selection. Those without a residence permit, 'illegals', are treated as non-citizens: They live in the country and contribute to the economy but are not entitled to civic, political or social rights. Asylum seekers are treated as halfway citizens: Allowed to reside in the country for the time being, enjoying limited social and civic rights but no political rights. In today's reality of large-scale migration, forms of citizenship are emerging that undermine the notion of citizenship as equalizer in a society marked by diversity. And at the same time, at the other end of the citizenship spectrum, we see what Kate Nash calls a supercitizen: A citizen who is fully integrated in the nation-state that is part of the globalizing world and who by virtue of that is able to maximally benefit from his or her citizenship on national and global level.

Nation-building in fragile states starts with the acknowledgement of the people as the sovereign of the fragile nation-state. Even though there seems little or no sound basis for identifying these people as sovereigns by lack of resources and lack of power, drawing people center stage as legitimate 'owners' of the nation-state is a necessary basis for a theory and practice of nation-building in fragile states. It is from this fundamental position of the people as sovereign that we can build nation-states that respond to the political and socioeconomic and identity demands of people. In such a people's sovereignty approach the focus is more on legitimacy and therefore on integrity than on effectiveness. 


\section{Vignette}

\section{Protecting the role of local organizations in Afghanistan}

During the Dutch mission in Uruzgan (2006-2010) as part of ISAF, Cordaid supported the Afghan health organization AHDS. The collaboration between Cordaid and AHDS had started in 2002, long before the Dutch military took the responsibility for the Uruzgan province. During these years there was frequent contact and exchange between Cordaid and the ISAF mission and the Provincial Reconstruction Team (PRT): In The Hague at the ministry of foreign affairs, in Kabul at the embassy and in Tarin Kowt at Camp Holland. We discussed policies and strategies, shared analyses on actors and dynamics in an atmosphere of mutual trust. However, we never conducted operations jointly: In the field, development and military remained sharply separated. AHDS had the same approach, visiting the PRT at Camp Holland, discussing the situation in Uruzgan with staff of the embassy. But also claiming their operational space as strictly theirs.

After a battle between Dutch troops and the Taliban with casualties on the Dutch side, the Dutch suspected that some of the Taliban were wounded and were hiding themselves in the hospital of AHDS. Without any contact and previous information, Dutch military entered the hospital for a search to find out whether Taliban fighters were in the hospital. Right at that moment the medical director of the hospital was at Camp Holland for a meeting. He was totally upset and felt betrayed by the Dutch for not being connected and informed about the operation. Trust and good faith were jeopardized.

Cordaid took this as a serious violation of the relationship between the military and the development partners, both Cordaid and AHDS. As the CEO of Cordaid I sent a letter of protest to the chief of operations to complain and to ask for a clear statement about the relationship between the military and the development actors. As above all a clear sign in Tarin Kowt itself about the relationship between the military and AHDS and a clear signal of respect to the position of the medical director of the hospital. At a planned ceremony for handing over of the leadership of the mission at Camp Holland, the commander took ample time to praise the collaboration with the development partners and the role of the AHDS hospital as partner in the development process in the province. 



\section{$5 \quad$ Nation-building and state-building and the challenge of fragility}

In chapter 2, I investigated the discourses about nation and state and concluded that in today's globalizing world the intertwined reality of both must be the starting point. I took position in the constructivist scientific discourse, which considers nations, even if they revert to history for identification, as social constructs open to change over time. In chapter 3 , I investigated the recent concept of fragility and chose to align myself with the definition of this concept as framed by fragile states themselves, acknowledging the challenges and problems without a judgmental bias. I pointed at the fact that also in the definition used by fragile states the attention for the sociocultural issues of belonging and identity remain too limited. Based on the above, this chapter explores the concepts of nationbuilding and state-building, the relationship between the two, and the urgency of nation-building for fragile states.

In a 2008 paper, the OECD defines nation-building as:

Actions undertaken, usually by national actors, to forge a sense of common nationhood, usually in order to overcome ethnic, sectarian or communal differences; usually to counter alternate sources of identity and loyalty; and usually to mobilise a population behind a parallel statebuilding project. May or may not contribute to peacebuilding. Confusingly equated with post-conflict stabilisation and peacebuilding in some recent scholarship and US political discourse. ${ }^{1}$

The World Bank, acknowledging that it has no formal definition for nationbuilding, describes state-building as 'the centrality of efforts to build state capacity and accountability, including strong attention to the most basic state administrative and delivery systems, complementing capacity investments with robust efforts to improve accountability, and balancing state capacitybuilding efforts with support for civil society and the private sector.'2

1 OECD 2008, p. 13. http://www.oecd.org/dac/governance-peace/conflictandfragility/ docs/41100930.pdf (accessed 9 September 2015)

2 http://siteresources.worldbank.org/PUBLICSECTORANDGOVERNANCE/Resources/285741-1343934891414/8787489-1347032641376/SBATGuidance.pdf, p. 11 (accessed 9 September 2015) 
The two definitions relate to what has been said about the nation and state discourse in previous chapters by respectively emphasizing nationhood and identity-related issues (nation-building) and the importance of building institutions and systems (state-building). A problem I find with the OECD definition is its instrumental notion of nation-building, which is defined as a 'supportive' process that has its value in mobilizing people behind the, primary, state-building objectives. In my opinion, nation-building has values in and of itself that should be explored and developed. The OECD's instrumental notion is not helpful if we wish to take, as I will argue, a genuinely intertwined approach that considers both nation-building and state-building as equal components in the process of building stable nationstates in fragile contexts. As it stands, most academic and policy discourse fails to address the challenges of an intertwined approach to nation-building and state-building.

\section{Nation-building and state-building in international political discourse}

The OECD, in its definition of nation-building, points at the confusion that has crept in over the last fifteen years, mainly since the interventions in Afghanistan and Iraq, and which means that the term nation-building is loosely used as the label for processes of building peace and stability. The overwhelming attention, at the same time, has gone to state-building. Fueled by the terrorist attacks of $9 / 11$, there was a broad consensus that addressing the problem of international terrorism was doomed to fail unless proper functioning states were created in places where terrorists were successfully hiding (Afghanistan and Somalia) or where regimes were thought to be outright supporters of international terrorism (Iraq). The acts of terrorists were considered a legitimate reason to intervene in countries to bring about regime change and to install a government and state institutions that would abide by the norms of the international community, as interpreted by the self-appointed only superpower at the time, the United States.

The international relations discourse about state-building focused on the technical and institutional aspects, following the analyses of think tanks and policy advisers based in the West. They took the model of wellestablished Western nation-states as the desired end stage of building the nation-state and asked themselves: What are the first steps that need to be taken to make this state-building process irreversible and avoid the proliferation of failed states (and the subsequent threat of international 
terrorism) in the future? It was not only Western advisers who embraced this approach. Ashraf Ghani, who took office as the new president of Afghanistan in June 2014, together with Clare Lockhart wrote the book Fixing Failed States during his time at the World Bank. The book presents a list of ten functions of the state that mirror the model of the social-capitalist state as we know it in Europe, the US, Japan and Australia. ${ }^{3}$

The politically driven focus on state- and institution-building is strongly backed by recent research. Acemoğlu \& Robinson in Why Nations Fail ${ }^{4}$ base themselves on an extensive historical overview of state-building to argue that well-functioning institutions are crucial for flourishing states and are the solution for the predicament of failing states. Their analysis is as relevant and convincing as the agenda for state- and institution-building that Ghani and Lockhart present, however, both publications fail to address the issue of nationhood: What makes people believe in the credibility of institutions as theirs, what gives the state legitimacy in the eyes of its citizens? As we saw in chapter 3 , failing states are confronted with three main challenges: The challenge of legitimacy, the challenge of authority and the challenge of capacity. From the international donor community's perspective effectiveness and legitimacy are related in a cause-effect way: Lack of effectiveness generates lack of legitimacy. And solving the problem of effectiveness will solve the problem of legitimacy. Referring to the model of chapter 3, effectiveness is the result when authority and capacity are in place. According to this model, legitimacy cannot be seen as a result of effectiveness.

Legitimacy and effectiveness are different categories. Authority, legitimacy and capacity are basic competences of the nation-state; effectiveness, integrity and validity are the result when two of the basic competencies are in place.

Legitimacy in essence has a different source: It is rooted in the affirmation of belonging by the people, as was shown in the previous chapter where the issues of citizenship and sovereignty and their pivotal role in the nation-state were discussed. A lack of effectiveness of the state undeniably exacerbates the problem of legitimacy, but it is not the root cause of failing states. A lack of effectiveness may lead to people aiming for a new government that can guarantee a better functioning of institutions of their country with which they identify. A lack of legitimacy in the fundamental sense of nationhood is more likely to lead to efforts to either break away 
from the nation-state, or to try to capture the state in order to establish the possibility of identification.

The connection of legitimacy and effectiveness in the discourse of donors is rooted in a rather materialist view on the nation-state. In Why Nations Fail Acemoğlu \& Robinson take this connection as their central pillar: 'Central to our theory is the link between inclusive economic and political institutions and prosperity'. ${ }^{5}$ What they say is that the main challenge is prosperity and the conditions for that are inclusive economic and political institutions. The problem with this and similar studies lies not with what they say but with what they do not say. The authors are right in addressing the lack of well-functioning institutions as a key element in why nations fail. The extractive policies of elites who build their wealth at the cost of the poor and who are unchecked by institutions based on justice and inclusion, are among the root causes of poverty. Most poor citizens of Afghanistan, South Sudan and the DRC will support the conclusion that well-functioning institutions are central to development and stability. They suffer on a daily basis from the lack of fairness and justice in the sharing of resources and the application of the rule of law. However, by making the building of inclusive economic and political institutions the one and only response to fragility, such research unduly keeps silent about identity matters that are behind the institutional problems of fragile states. It is from this economically and politically focused discourse that effectiveness and legitimacy are connected in the cause-effect way.

I believe that this donor perspective on fragility that focuses exclusively on institution-building mirrors the reality of donor countries more than that of developing countries. Over the last decades this prosperous part of the world has shifted its focus more and more towards the economic and financial aspects of the functioning of society. A rapid economization and financialization of public life and public discourse has taken place. Most societal issues - not only economic issues but also health and education are translated into cost-benefit analyses. It has led to a strong materialist worldview. The belief in the rational choice as the basis for the organization of society further strengthens this trend. It is my conviction that this trend in the history of the donor countries is at the basis of the current donor approach to solving fragility: If we can create the institutions that in a materialist perspective will yield the most effective (cost-benefit) results people will choose these solutions out of a rational choice attitude. That will solve the problem of fragility. This institutional/materialist approach has 
as its objective to make the issues of identity (ethnicity, religion, regional) redundant.

In this materialist view of the nation-state and the creation of economic and political institutions as the essence of the solution of fragility, and by that marginalizing issues of identity, donor countries are forgetting the history of the nation-state and are denying the current struggle on identity at home.

The historical reality that the nation-state, as it came into being after 1648 , was meant to also solve problems of identity by creating religiously coherent nation-states besides establishing political and military sovereignty, is no longer part of current discourse. Issues of identity (religion, ethnicity) are marginalized in the societal and political discourse of donors. ${ }^{6}$ Identity is a problematic concept, whether it is ethnic, religious or national. From the enlightened perspective of Western governments and policymakers it is seen as irrational, backward and troublesome. But not only history tells us a story about the relevance of identity. Currently, political parties in donor countries in Europe that profile themselves as driven by concerns about the identity of the country (UKIP in the UK; Front National in France; PVV in the Netherlands; AfD in Germany and; the Swedish Democrats) advocate closing the borders for migrants in order to preserve this identity. Immigration politics in Western Europe has increasingly focused on assimilation: How can we transform the identities of Algerians, Bangladeshi and Turks into French, British or German? Governments in Western Europe are embarrassed by identity politics. By avoiding to speak frankly about identity issues Western countries fail to organize a countervailing identity discourse and leave this subject to be hijacked by the primordialist perspective on national identity as promoted by these parties, who contend that there is an eternal Swedishness, Dutchness or Germanness that must be protected and preserved against the waves of migration. The farewell to multiculturalism as explicitly announced by leaders in Western Europe ${ }^{7}$ has strengthened the focus on assimilation. Increasingly, European governments have put themselves in an impossible contradictory position to promote identityfree materialist policies based on a silently accepted primordial view on identity. Through this position and by refusing to develop a constructivist

6 Jackson-Preece 2010, p. 22.

7 http://www.theguardian.com/world/2010/oct/17/angela-merkel-german-multiculturalismfailed (accessed 9 September 2015); http://www.elsevier.nl/Politiek/nieuws/2011/2/MaximeVerhagen-Multiculturele-samenleving-is-mislukt-ELSEVIER289371W/ (accessed 9 September 2015); http://www.bbc.com/news/uk-politics-12371994 (accessed 9 September 2015) 
perspective on identity as response to new influences like globalization and migration, these governments have paralyzed themselves politically and created the basis for increasing antagonism in the field of national identity.

There is need for critical self-reflection in order to understand the bias of the donor countries in its policies for fragile states by this marginalization of identity issues and to what extent our condescending attitude towards identity at home is part of the approach to fragility.

The one-sided focus (both in motive and design) of the international community on building the systems and institutions of the state has also obscured the perspective on the domestic reality and the domestic resources in fragile states. The international community's external interventions appear to take the fragile state as a blank slate on which a new and effective state can be built, disregarding the presence and importance of local actors that have power and influence. In this institutional approach, international actors look whether there are 'up-to-standard' state institutions and systems that fit into their framework of institution-building. If not, they go to the drawing table and start designing them from scratch. This means they miss out on local realities and power structures, be it tribal, religious or informal, which escape the state-building framework. By discarding these existing institutions international actors fail to factor in the norms, convictions and traditions like leadership culture and informal rules that prevail in these states and that carry meaning and importance - be it positive or negative - for people locally. ${ }^{8}$

Even more problematic is the way the current discourse, completely disregards the need for nation-building in state-building programs. Francis Fukuyama does not make an effort to understand the difference between the two. He writes:

Nations - that is to say communities of shared values, traditions, and historical memory - by this argument are never built, particularly by outsiders; rather, they evolve out of an unplanned historical-evolutionary process. What Americans refer to as nation-building is rather statebuilding - that is, constructing political institutions, or else promoting economic development. This argument is largely true: ...9

By conceptualizing nation-building as a process that happens outside of any influence or control, Fukuyama legitimizes the neglect of it and equals it to 
state-building. ${ }^{10}$ I fully acknowledge that nation-building escapes the current planning culture of interventionism in international relations (see also chapter 10, p. 166). And then there is also the reference issue: Nation-building is self-referential. National cohesion and a sense of belonging cannot be defined outside of the involved community and there is no template with indicators to measure (see table 1). But it would be an error to think that it is a process that cannot be consciously worked on. The histories of the European nation-states show that strong policies (education, language) have been critical in forging nationhood and building a national sense of belonging. Fortunately there are quite a few authors and organizations that do acknowledge that there is more to be done than only building the institutions of a well-functioning state. Sonja Grimm ${ }^{11}$ acknowledges the need to create a sense of belonging and to build trust in order to overcome ethnic cleavages. She deems this process, labeled as creating a political community, 'a long-term process traversing several generations'. Seth Kaplan refers to the need to work on social cohesion as a necessary component within the overarching efforts of state-building. ${ }^{12}$ The Dutch organization PAX, focusing its efforts on peace-building in fragile and conflict-ridden countries, points at the need for a social contract between state and people, identifying the lack of trust between both as one of the key elements causing fragility. ${ }^{13}$

My intention is not to belittle the efforts of the international community to build the capacities of the state in countries like Afghanistan, Somalia, the Democratic Republic of Congo, Haiti or the Central African Republic, nor to delegitimize their involvement and interventions in this domain. In a globalizing world where persons, goods and services move around almost unhindered, the international community has to be able to count on the capacity of the state to take responsibility for what goes on within the borders of its country. States have to fulfill minimal internationally shared functions in the globalized world, but that does not mean that states can be built by imposing an outside design. The challenge is to build states using domestic capacities, knowledge and traditions. That will make the institutions of the state more legitimate, better rooted in society and therefore

10 Another example is the Beginners Guide for Nation Building, published by the Rand Corporation of which one hopes no beginner will ever read it.

11 Grimm 2008, p. 525-549.

12 Kaplan 2008.

13 IKV Pax Christi 2009. 
stronger and more robust - and it will corroborate identification with and ownership of the nation-state and thus legitimacy.

The international community and most of the recent publications underestimate the need for nation-building. At best they consider nation-building an instrument for state-building: To make state-building effective, a certain level of nation-building (often defined as social cohesion, societal trust) is needed. I believe, however, that nation-building has to be an integrated part of the agenda for effective state-building. The relation between the two cannot be described as instrumental: They are intertwined while both processes have their own logic and dynamic.

Table 1 The differences between nation-building and state-building

\begin{tabular}{|c|c|c|}
\hline & Nation-building & State-building \\
\hline Leading actors & $\begin{array}{l}\text { Community and group } \\
\text { leaders, representing } \\
\text { identity groups. }\end{array}$ & $\begin{array}{l}\text { Political representatives, } \\
\text { elected by the population. }\end{array}$ \\
\hline Instruments & $\begin{array}{l}\text { Stories. Myths, statues, } \\
\text { heroes, cultural traditions. }\end{array}$ & Laws, state organizations. \\
\hline Process & $\begin{array}{l}\text { Building commitment and } \\
\text { mutual understanding; } \\
\text { adding and enriching. }\end{array}$ & $\begin{array}{l}\text { Offering solutions by } \\
\text { setting rules, regulations and } \\
\text { policies: Codifying. }\end{array}$ \\
\hline Results & $\begin{array}{l}\text { Mutual understanding } \\
\text { between different groups, } \\
\text { a shared sense of belong- } \\
\text { ing: The 'we'-feeling. }\end{array}$ & $\begin{array}{l}\text { Well-organized state institu- } \\
\text { tions that deliver without } \\
\text { discrimination security, } \\
\text { justice and social services. }\end{array}$ \\
\hline Time frame & $\begin{array}{l}\text { Open-ended, constantly } \\
\text { evolving. }\end{array}$ & $\begin{array}{l}\text { Results within time frame of } \\
\text { political election cycle }\end{array}$ \\
\hline Reference & $\begin{array}{l}\text { Self-referential: Internal } \\
\text { domestic process of } \\
\text { selecting and forgetting. }\end{array}$ & $\begin{array}{l}\text { Reference found in } \\
\text { international community of } \\
\text { states, international laws, } \\
\text { treaties, conventions. }\end{array}$ \\
\hline
\end{tabular}

Nation-building is an open process that does not have a predefined result and therefore there is no straight way forward to attain that result. The open-ended character of nation-building requires a mindset different from state-building for domestic people and international partners: Nationbuilding is process-led, not results-led. The process of nation-building is self-referential: Only the people involved in the process can decide what the meaning is of their sense of belonging and their shared identity. Although they are intertwined and complementary, they are different in nature and dynamics. 
I fully acknowledge the challenges of nation-building and the fact that nation-building lies largely outside the framework of development cooperation and international interventions. Different authors have referred to the problematic nature of nation-building: It is difficult to plan, it lies beyond the planning and control mode of development agencies or military forces; it is a long-term historical process, implicating that it takes generations; it concerns very subjective issues like ethnic identity, religion, or the feelings and aspirations of minorities. The nation-building process of the European nation-states is seen as the benchmark model. Compared to that centurieslong process of nation-building in Europe, it seems unrealistic to think about nation-building in fragile states as a doable process. In a globalized world states like Afghanistan or Somalia are not granted centuries to gradually build their identity in an iterative process. Nation-states have to be present in the international community and they have to take responsibility for security, justice and basic social services for their citizens and in their relation to other states. That reality blocks the possibility of emulating the European nation-state process and presents us with the challenge to find truly new answers and concepts that fit today's reality of the fragile states of the global South.

In chapter 10, I will present a program of nation-building with interventions that can be supported also by the international community. Even though I emphasize that national actors should lead the process of nationbuilding, the reality of today's globalizing world is that no nation-state is built in isolation. International actors, even if they do not lead the nationbuilding process by intervening in the domestic reality, do have options to stimulate and facilitate this process. At the same time, domestic actors will be looking for international support to build their nation-state as part of the globalizing world.

\section{The intertwined nature of nation-building and state-building}

Against this backdrop, the question of the intertwined relation between nation-building and state-building needs to be answered: Are they inextricable in the same way that nation and state are? And if they are indeed interlinked, closely related but not the same, how can we describe and define their distinct dynamics? Is there a hierarchical relation between nation-building and state-building in importance or in time? I will discuss two perspectives. The first, defended by Hippler, considers nation-building the primary and overarching process. The 
second perspective, presented by Hobsbawm and Gellner, sees nationbuilding and state-building in the modern reality of the nation-state as inextricably linked processes.

Hippler identifies three interrelated aspects in the overarching process of nation-building:

1 creation of an integrating ideology: A 'nation' as one of the preconditions of nation-building requires some form of ideology that legitimizes and justifies a 'national' self-interpretation of the respective community;

2 creation of an integrated society: Besides a common identity and ideology, nation-building requires many practical preconditions, requires the integration of society on a practical level (communication, of economic exchange, of traffic, public debate);

3 creation of a functioning state apparatus.

According to Hippler, who defends an integrated approach, the process of state-building must correspond to the above-mentioned processes of identity building and societal integration. State-building in this context has two interconnected aspects: Firstly, it means that the respective society has constituted itself (or has been constituted by a dominant actor, including the state itself) as a political entity, or even as the key political entity. Secondly, this implies many very practical and often organizational needs: The state has not just to be proclaimed, but it has to be functional. ${ }^{14}$

Hippler sees nation-building as the overarching framework and considers state-building one of the three constituting elements of this overarching framework. State-building will lead to a sense of belonging and to a shared narrative only if it is accompanied by the two other processes. By claiming nation-building as the overarching process, Hippler suggests that the nation is the aspired end result of that process, which in effect puts nation-building and state-building in a hierarchical relation. One could even say that the relation between the two becomes instrumental: Realizing state-building is an instrument in order to contribute to the end result, nation-building.

Hobsbawm and Gellner both argue that the nation is a modern construct that can only be understood in its intertwined relationship with the state. They coined the 'nation-state' as the term to be used to understand this recent phenomenon. The authors convincingly argue that the nation can only originate in a situation where the state is able to establish its authority and power over the citizens and the territory: There is no nation without a

14 http://www.jochenhippler.de/html/ethnicity-_state-_and_nation-building.html (accessed 14 November 2014) 
state. The opposite is equally true: To build a stable and sustainable state, a sense of belonging, a collective identity of being Kenyans or Afghans, is a necessary condition. I follow Hobsbawm and Gellner in their nation-state theory and will approach the problem of nation-building and state-building as two interrelated processes that have no hierarchical relation to each other.

The international community in the last fifteen years has not taken this approach. Instead, it has focused on state-building as the key issue to solve the problem of fragility and to provide stability. After ousting the Taliban in 2001, the strategy of the international community was to build the Afghan state as the institution that will deliver security, justice and social services to the Afghan people. In this way the Afghan state would create the legitimacy and credibility necessary to be accepted by the people as the sovereign authority in the country. Based on this approach, the international community invested in building the Afghan National Army, the Afghan National Police, the judiciary and the ministries of health, education and rural development. Policy makers assumed - even if unspoken - that building effective state institutions would create the feeling of nationhood and togetherness that could serve as the basis for solving the problems of ethnic division and competition. The same strategy was deployed in Iraq and in South Sudan. There too, the focus was on building institutions, organizing structures and drawing organigrams for efficient and effective policies and public services. It is telling that the notion of 'fixing the state' became a label for this type of programs. It is as if the international community believed that by bringing in technical experts to repair and/or build a state that is broken or non-existent, in the same way that a home owner may call on a plumber or carpenter, all problems would be solved. Considering what has happened in Afghanistan, Iraq and other countries in the past decade, it seems to me that this belief in external, technical solutions for failed or fragile states is problematic - even more so if there is no sense of ownership or appropriation of such a state-building program on the part of the people and their leaders who are the alleged beneficiaries.

The prevalent state-building strategy of the past fifteen years strongly reflects the good governance strategy of the World Bank as designed since the early 1990 s. $^{1516}$ This strategy focuses on the effectiveness of public institutions in order to make them respond better to the needs of people

15 Reforming public institutions and strengthening governance, A World Bank strategy http:// www1.worldbank.org/publicsector/Reforming.pdf (accessed 25 January 2016)

16 Santiso 2001. 
in poverty-ridden countries. In countries like Iraq, Afghanistan and South Sudan, the problem of ethnic division was acknowledged ${ }^{17}$ and identified as a serious threat to stability, but it was not addressed as such in the intervention logic. By creating a strong and well-functioning government the international community sought to solve the problem of ethnic tensions by bypassing the issue. Making all ethnic groups dependent on and satisfied with a delivering state was to create the necessary sense of togetherness. As we know, in all three countries the results of this state-building strategy have been mixed at best. Iraq is plagued by an ongoing conflict between the Shia and the Sunni Muslims. In the newly independent state of South Sudan a violent ethnic conflict was reignited between the Nuer and the Dinka in 2013. In Afghanistan, issues of both religion and ethnicity-Muslim fundamentalism by the Taliban and ethnic tensions between Pashtun and other ethnic groups - have created an ongoing situation of conflict with major insecurity problems.

\section{Nation-building and state-building: Trust as the linking pin}

The linking pin between nation-building and state-building is trust. Trust is the outcome of the intertwined processes of nation-building and statebuilding. Trust is not a luxury good, it is indispensable for a viable nationstate. The sense of belonging and the recognition of the other as part of the definition of a broader 'us' will breed trust. Peacemaking, nation-building and state-building start out from the recognition of a shared interest, even if this shared aspect is minimal or even negatively formulated: Sometimes there is no more basis than the acknowledgement that it is impossible to defeat the other groups and that therefore one has to find a solution for living together. But for a state to become viable and flourishing, shared interests have to transform into trust.

The state needs the nation to be able to define the 'us' in an inclusive way as covering all the different groups and communities living on the territory. Identification at the level of the nation-state is the process that makes it possible to recognize others as belonging to the broader 'us'. This broader 'us' refers to the 'imagined community' of Anderson (see chapter 2). Creating this imagined community makes it possible to have a 'pre-reflective' sense of belonging that one can count on. It is the experience of meeting a fellow

17 The Dutch PRT in the province of Uruzgan employed a 'tribal adviser' to make the Dutch PRT and the military forces sensitive to the ethnic divisions in the province. 
countryman/woman in a foreign country. There is a pre-reflective sense of relationship that gives the confidence to ask a question or try to solve a problem: We understand each other by language but also by culture, values, accepted behavior.

But the nation also needs the state to let this trust grow. Trust needs to be nurtured by deeds and acts. Trust is more than a feeling or an emotion. Being part of the imagined community as an emotional quality requires policies in which one recognizes the shared interest of this 'us'. Here the state comes in as an important actor in the nation-building process: It makes the trust real and tangible by underpinning it with policies and laws that convince each group that it is part of the broader 'us' of the nation-state. Nation-building without state-building will make the imagined community a short-lived community.

\section{Why is state-building not good enough in fragile contexts?}

Over the years I have had many discussions with policymakers, members of think tanks and practitioners who felt that building the state is a challenge tricky enough to not want to take the open-ended, hard to manage, nationbuilding process as an additional issue on the agenda. I heard them argue over and again: Are the problems of Afghanistan, Sudan and the DRC not first and foremost due to 'not good enough' policies, the malfunctioning of governments, the judiciary and the military - and is therefore strengthening these systems not the best answer? Is the building and strengthening of institutions not the most realistic and achievable goal - and moreover one that the populations of these fragile countries crave for? Would it not be wise to leave the complex identity/culture/history stuff aside, at least for now? Should we not take the identity issue out of the political arena and leave it in the private domain? It may be important for people, but should it really interfere with public political life?

My answer to all these questions is 'no'. I strongly believe that nationbuilding, or forging 'a common sense of nationhood', should be an essential element in all of our efforts in fragile states. There are four main reasons why nation-building should be on the agenda.

First, a viable state needs a national identity as a framework that holds people and communities together despite the religious, cultural and regional differences. It would be risky to build exclusively on the power (military, economic, political) of the state as the basic foundation to keep people together. What is more, it is exactly because of the power of the 
state that a sense of nationhood is necessary: Without a national identity as shared togetherness and as a sense of belonging for all groups (religious, ethnic, linguistic, cultural), the power of the state will easily become the focus of rivaling communities that will want to capture the state to seize power and dominate others. If power is the sole mechanism to make the state function, without having an inclusive legitimacy, the state with power (authority) and capacities will fail on legitimacy and is very likely to remain fragile or to relapse into fragility. This dynamic was perhaps never better illustrated than in the battle for Kabul in the mid-1990s. ${ }^{18}$ Different factions fought fiercely against each other from different parts and neighborhoods of the city in an attempt to seize the capital as symbol and source of power. Rather than withdrawing to their respective regional heartlands, the different groups (Pashtun, Usbeks, Tadjieks and others) all were set on ruling the country. It shows the awareness of each group that they were sure to be marginalized if one of the others was to prevail. The battle was fierce and fanatic. None was willing to give, knowing the consequence of losing or winning Kabul for the division of power relations at the national level.

In short, even power-sharing arrangements in a newly formed or rebuilt state are usually not good enough, at least not in the long term. More will be said about this in the next chapter where I discuss the relation between peace-building, nation-building and state-building. Here it suffices to say that power-sharing agreements are always compromises, seen as political agreements of give and take that reflect the current power balances of the different groups involved. This means that rivaling groups will always continue to create opportunities to change the power-sharing compromise to their advantage. Power-sharing is always a strategic outcome and strategic agreements in general only last as long as they are beneficial to the involved parties. A viable state can therefore never depend on power relations and power-sharing agreements alone. The nation-state requires a framework that is more solid. Nation-building, a shared identity and a sense of belonging that surpass ethnic, religious, linguistic and cultural boundaries is the necessary complementary framework to hold people together in a sustainable relationship.

The second reason for including nationhood is the issue of loyalty. In fragile contexts especially, loyalty is organized along identity lines. Often the state is absent or, worse, contributes to conflict and insecurity. It makes sense that people organize their loyalty along ethnic, religious or regional 
identity lines: No one and no institution takes care of their security and the basic necessities except their own identity group. Why should they shift their loyalty from their identity group to the state if there is no shared feeling of belonging? Loyalty and trust are based on more than a contractual relationship, they reflect Anderson's 'imagined community' (see chapter 2) where I recognize the other, even if I do not know him, as someone belonging to my community, as someone for whom I'm willing to take responsibility.

Even if one could imagine a nation-state that is viable purely due to the contractual relation with its citizens, this is certainly not feasible in fragile states. In such contexts, building a state that is able to deliver and live up to the expectations of its people will never happen in a short period of time. The Afghanistan experience has shown that even with an enormous amount of money and external support the ability of the state to deliver is still only partial and limited. Given this reality of limited capacities and resources of fragile states, it is an illusion to expect that a mere contractual approach of state-building will be enough to build a stable nation-state. Without the presence of an 'imagined community' disillusionment with the state is always just around the corner. The reality of limited capacities requires a strong legitimacy and nation-building as building the sense of cohesion and a shared narrative is therefore indispensable.

Thirdly, a well-organized and just state is not enough to let a community flourish. In her recent book Political emotions Nussbaum argues that, besides well-organized institutions that provide justice, the sense of belonging, and based on that an emotional commitment, is necessary. She defends her wellknown position of advocate for a just society where respect for rights and equality is the basis, but adds the need for a deeper, emotional relationship that binds people together. By doing so she makes an important connection between political philosophy and psychology: The human psychology has to be factored into the political discourse. Nussbaum puts forward love for the nation as an important political emotion, the reality that ' $(w)$ e grieve for people we care about, not for total strangers'. ${ }^{19}$ She calls this the 'eudaimonistic thought': ${ }^{20}$ the reality that we cannot have equal love for all human persons, and that our emotional connectedness to the nation runs deeper. Nussbaum clearly states that eudaimonism is not egoism and does not exclude solidarity on a global scale, however, global solidarity has a different emotional basis. We don't necessarily fall victim to blind patriotism if we accept that our commitment to our own group, whether it is the family, the 
tribe or the nation, is stronger than our connectedness to those outside our group. Love for the nation, Nussbaum argues, is a necessary complementary element for a just society. ${ }^{21}$ The contractual relationship between state and citizens is based on a theoretical premise of mutual self-interest. Especially in fragile states, where crises occur frequently, a commitment deeper than that of the contractual relation between people and the state is necessary. Building a state requires people who feel responsible for the development of the nation-state even if they cannot pinpoint their immediate self-interest. Solidarity and sacrifice are necessary ingredients of the process of building a viable nation-state. When the sun is out, focusing merely on state-building perhaps can do, but this is most certainly insufficient when the weather gets rough.

Fourthly, the reality of fragility in a globalizing context also prompts the need to invest in nation-building. In some ways, the presentation of fragile states today resembles the imaging of indigenous people during the colonial era: Powerless, incapable of solving their own problems, needing to be taught how to organize themselves and behave in the modern world. The definition of fragility used by most donors, which as we saw in chapter 3 is highly judgmental and stresses the deficiencies of fragile states, resembles - even if not consciously - that colonial picture. The problem of fragile states is the new 'White Man's Burden'. Following the theory of dominance, as developed by Edward Said in his groundbreaking book Orientalism ${ }^{22}$, people of these fragile states run the risk of internalizing the idea of being not good enough to participate in the world and having a culture that is not up to modern standards. Therefore, in today's world, nation-building is a necessary process for fragile states to become self-confident and create autonomous space and power for people to position themselves in this globalizing world. Building a culture of being proud of the history, the culture, the language, and the social systems of society is necessary to take a self-confident position in the globalizing world. With an internalized negative self-image, fragile states will remain at the lower end of the supply chain, the providers of cheap labor and raw materials for the globalized economy. Nation-building makes nation-states able to be a countervailing power to strong and powerful nation-states and to global corporations.

21 This basic position of Nussbaum is also reflected in the 2005 encyclical of Pope Benedict XVI 'Deus caritas est' in which he states that even the most just society needs love (Deus caritas est, par 28b).

22 Said 1978. 
The challenges faced by fragile states will not be resolved if we are not prepared to address the issue of nation-building that can foster a shared love for the nation as the community of people living together. It goes without saying that this is a complex process. The core elements implicated in nation-building (identity, togetherness, loyalty, belonging, love) are more elusive, less concrete and much more difficult to grasp in a logical framework or an intervention logic than constructing state institutions. A process of nation-building cannot be designed in a 'fixing-the-nation' approach and implemented by external technical support and knowledge. Nor does this process have a clear and fixed timeframe. But these difficulties should not keep us from trying - instead they should challenge us in a positive way to come up with new approaches to nation-building (see chapter 10).

\section{Nation-building in fragile states: History never repeats itself}

Much of the research on nation-building and nationalism has concentrated on Europe. The centuries-long process of building the nation-state in Europe is a fascinating one for historians and political theorists. The differences in how these processes evolved in England, France and Germany have yielded libraries. The dissolution of the Habsburg Empire and the emergence of the Eastern European states, the process of nation-building in Poland, squeezed in history between the German, Russian and Austrian powers, are all generously documented. It is of course tempting to look at nation-building in the fragile states of Asia and Africa with the European perspective in mind, using the European nation-states as learning examples. The colonial imprint on the formation of the new states in Asia and Africa and their institutions has corroborated this Eurocentric perspective. However, there are four important elements that should make us cautious in doing so.

Time. The process of nation-building in Europe took several centuries. By the end of the 19th century, people in many parts of France were still not speaking the common French language. In Germany it took several not very successful processes to get a nation-state by the end of the 19th century. The comment allegedly made in 1861 by one of the pioneers in the unification of Italy, 'we have created Italy, now we have to create Italians', reflects the time-consuming process of establishing a shared national identity. In most of Europe, building a state and building a nation were parallel processes that in the end resulted in a rather consistent nation-state, where a common institutional setup matched with a common identity. Fragile states today 
cannot indulge in such a long-term process. The state is already there by sheer virtue of the international order that has left no part of our planet's landmass undefined. In most fragile states, one or more groups actively aspire to get hold of this state and establish their power over the territory. At the same time, the international community expects states to act as a responsible member of that community. Both internally and externally the pressures are too high to allow fragile states a centuries or decades-long process of forming a national identity in a more or less organic way.

Violence. The formation of the nation-state in Europe has not been a peaceful process. From military violence to cultural oppression to forced adoption of a common language and forced conscription of soldiers, the nation-building process was rife with violence committed by the powerful majority group or the ruling elite to bring minorities and the less powerful into the nation-building process. There was little romance in this process and little democracy, too, for that matter. However, in the post-World War II world, violence is no longer an accepted way of solving conflicts, at least not in the moral rhetoric of the international community. Despite the ongoing violent conflicts all over the world, violence has come to be seen as morally wrong. Ever since the creation of the United Nations and the adoption of the Universal Declaration of Human Rights and subsequent treaties and conventions to regulate the international and national behavior of states, the legitimacy of violence has been reduced to the case of self-defense and a number of other strictly delineated instances. Negotiations and mediation are seen as the default approach to solve conflicts, whether internal or external. An entire 'industry' of institutions and professionals has sprung up, busy offering their services to solve internal and cross-border conflicts in and between countries. The non-acceptance of violence is not limited to military or physical violence. Also cultural violence, for instance forcefully imposing a national language, will spark international condemnation based on the general acceptance of people's right to self-determination. And so it seems that the European road to nation-building, paved as it was by violence, is not a very feasible road for fragile states today.

Homogeneity. The process of nation-building in Europe was based on forming homogeneous nation-states. Internal differences were wiped out by strong pressure and often violence (see above). Induced by the Westphalian peace treaty the idea of homogeneity was at the basis of the European nation-building. In the 19th century the emergence of mass education and mass media created the opportunity to mold the national identity. And the 
emergence of the manufacturing industry strongly triggered this process. As I will discuss in chapter 9 , homogeneity will not be the outcome of the process of nation-building in fragile states. Here it suffices to say that in the modern globalizing world homogeneity can no longer be a goal of the process, simply because it cannot be achieved. Nation-building has to be realized in a fundamentally diverse reality.

Modernity. In 18th- and 19th-century Europe building a nation-state was part of the process of modernity. Fighting for the nation-state was a way of revolting against autocratic rulers (dukes, princes, kings, emperors) and promoting the sovereignty of the people. It was part of the promotion of the vernacular: Granting ordinary people access to education and public debate. Currently, fragile states that want to foster nationhood and construct a national narrative and national identity, addressing and incorporating culture, religion, traditional language, will fight an uphill battle. The dominant discourse is that we need a modern state in the modern world, and that focusing on nation-building is tantamount to pulling us back into the darkness of identity-discourses that are connected to those who embrace a primordial concept of identity.

Following the European road of building a nation-state is not feasible for current fragile states. We need to find an fundamentally new concept of and approach to nation-building that is less time-consuming, that does not seek refuge in violence, that accomodates diversity and that includes dealing with the modern world. Part of that modern world is today's global interconnectedness. At the time when the European nation-states evolved, only political and intellectual/cultural elites and merchants took part in international exchange - the ordinary people were much more isolated than they are today. Communication and migration create an interconnectedness that is no longer the privilege of elites. Nation-building therefore takes place in an unprecedented international reality, that creates challenges and pressures, but also offers opportunities. In chapter 10, we will elaborate on the influence of globalization on nation-building. 


\section{Vignette}

\section{Transitional Justice in Afghanistan}

Building a justice system is one of the three cornerstones of state-building, besides providing security and basic social services. When the ISAF mission started in Afghanistan in 2002, after ousting the Taliban, justice was one of the key components of the efforts of the international community.

A couple of years later, in 2010, I paid a visit to Tarin Kowt, the capital of the province of Uruzgan. Due to the security provided by the Dutch military, it was safe to be in the city. During my first visit to Tarin Kowt in 2007 the intelligence of the Dutch mission strongly advised me not to visit the hospital of AHDS, supported by Cordaid, because of information that the Taliban targeted the NGOs that manifested themselves too visibly in the province. But in 2010, I could stay in the Cordaid guesthouse in Tarin Kowt. An Australian soldier at the entrance of Camp Holland was flabbergasted when he saw me leaving the compound without military protection to sleep outside the camp.

During that visit I had a conversation with a group of local leaders about the development in the province. And we touched the subject of justice. I knew that there was a large program of ISAF, under the leadership of the Italians, to roll out a modern system of justice with attorneys, judges and lawyers, which was meant to create justice in a lawless land. It is exactly this idea of lawlessness that hampers international organizations to be effective, that hampers them to see what is already in place. If one thinks that there is nothing, that no systems are in place, so that people are suffering from injustice, one can pretend that one is making a huge step in offering a sophisticated system that has proven to be reliable in the Western world. But reality in Afghanistan was different. The image in the outside world was primed by the atrocities of the Taliban regime with stoning-to-death adultery cases. But reality in the communities was different: Local elders and imams, known and trusted by the community, were approached to get justice.

The local leaders explained to me that ordinary people had no confidence in the new system. They did not approach the newly established juridical system, but still put their juridical problems forward to the traditional mediators like the imam and local elders. They had the experience that a trial in the new system could take months before a verdict was out, whereas in their traditional system they got a decision within days or weeks. And they knew that bribes are part of the process: If their adversary paid more to the judge, he would win. Why should they trust the new system? 


\section{Peacemaking as the preliminary step towards nation-building and state- building}

Having argued the importance of nation-building as complementary to state-building in fragile states, the question remains how to connect the processes of nation-building and state-building to conflict and peacemaking. To answer this question we need to look at the development of the peace agenda over the last 25 years.

It was only three years since the fall of the Berlin Wall when UN Secretary General Boutros-Ghali presented his Agenda for Peace in 1992. ${ }^{1}$ There was great optimism worldwide about the possibility of lasting peace and there was confidence that the peace dividend would shift resources from weaponry to efforts of peace and development. The Agenda for Peace became the UN umbrella for a broad, comprehensive strategy consisting of five pillars:

1. Preventive diplomacy, which seeks to reduce the danger of violence and increase the prospects of peaceful settlement.

2. Peace enforcement, authorizing the UN to act with or without the consent of the warring parties involved in order to ensure compliance with a ceasefire mandated by the Security Council acting under the authority of Chapter VII of the UN Charter.

3. Peacemaking, designed 'to bring hostile parties to agreement' through peaceful means such as those found in Chapter VI of the UN Charter.

4. Peacekeeping, established to deploy a 'United Nations presence in the field, hitherto with the consent of all the parties concerned,' as a confidence-building measure to monitor a truce between the parties while diplomats strive to negotiate a comprehensive peace or officials to implement an agreed peace.

5. Post-conflict reconstruction, organized to foster economic and social cooperation with the purpose of building confidence among previously warring parties, developing the social, political, and economic infrastructure to prevent future violence, and laying the foundations for a durable peace. ${ }^{2}$

1 http://www.cfr.org/peacekeeping/report-un-secretary-general-agenda-peace/p23439 (accessed 15 July 2015)

2 Doyle \& Sambanis 2006. 
This commitment to global peace was reinforced in 2005 by the adoption of a new international security and human rights norm called the Responsibility to Protect $\left(\mathrm{R}_{2} \mathrm{P}\right)$. This $\mathrm{R}_{2} \mathrm{P}$ project was pushed for in the wake of the genocide in Rwanda where the world was watching without intervening and after $9 / 11$ when the cross-border impact of insurgency created a new understanding of the global reality of terrorism. With the $\mathrm{R}_{2} \mathrm{P}$ the international community commits itself to intervene - first by diplomatic and peaceful means, but if necessary through the collective use of force through the Security Council - in cases of mass atrocities committed against populations whose national governments are unable and/or unwilling to protect them. ${ }^{3}$ The commitments of the international community were underpinned by the concept of human security, which had first been introduced in the Human Development report of 1994. This concept reflects that human security is universal (for each and every person in the world), interdependent (affecting all aspects of life), people-centered, and best addressed through prevention. ${ }^{4}$

The great appeal of the broad and inclusive Peace Agenda and the concept of human security is their holistic approach: Peace and security are not understood merely as the absence of war; the ambition is to let people flourish and prosper. ${ }^{5}$ However, an agenda for peace that spans everything from preventive diplomacy to post-conflict reconstruction suggests that this is one on-going and coherent process, with one overall strategy and interventions implemented by a group of actors whose mandate and role do not change during the this process. Though it serves a purpose as a political agenda and for fostering public support, this holistic conceptualization is not easily translated into effective practice. It does not allow for clear distinctions in processes, intervention logics and actors.

The difficulty is illustrated by what happened with the implementation of the $3 \mathrm{D}^{6}$ (Diplomacy, Defense and Development) approach as implemented during the ISAF intervention in Afghanistan. This 3-D strategy, developed in Canada, was another holistic and integrated concept to tackle the problems of conflict and fragility. There is no doubt that the three components play

3 Evans 2009, p. 7-13; see also http://www.responsibilitytoprotect.org/index.php/about-rtop (accessed 15 July 2015)

4 Human Development Report 1994, p. 22-23. http:/hdr.undp.org/sites/default/files/ reports/255/hdr_1994_en_complete_nostats.pdf (accessed 15July 2015)

5 Doyle \& Sambanis (p. 335) make the distinction between negative and positive peace. By this language they delegitimize a restraint concept of peace: Who could be satisfied with negative peace and not be in favor of positive peace?

6 http://www.iss.europa.eu/uploads/media/ChaillotPaper13o_Peacebuilding.pdf for an overview of the \#-D approach as part of the peace building agenda (accessed 20 June 2016) 
a complementary role in processes of stabilization, but the $3^{\mathrm{D}}$ strategy became an unbalanced strategy because the military logic collided with the logic of development and diplomacy. As CEO of Cordaid (2003 to 2013) I was deeply engaged with the Afghanistan case and witnessed the tensions in this $3 \mathrm{D}$ strategy. The military proved to be a far too heavy system with its strict rules and intervention logic, admittedly quite rational from their combat perspective, to be able to deal with development issues. The 'hard'security perspective of the military easily instrumentalizes development efforts as merely serving the military intervention logic. When military commanders spend money on development projects and at the same time ask the population to come forward with information about insurgents, one cannot expect people to consider this engagement a sign of genuine interest in their well-being. It is an illusion to think that the military can bring social cohesion and interethnic understanding. Having a tea ceremony with tribal leaders may well be appreciated by them, but they are well aware that their counterparts are foreign military with a heavy and lethal capacity. Instructing military patrols to address Afghans without wearing sunglasses and with guns pointing downwards is not the same as establishing good relations with locals: It is merely part of respectfully and therefore effectively executing the military role of bringing security. The $3 \mathrm{D}$ approach as practiced in Afghanistan was the result of a rapidly constructed and not well thought-through answer to the pressing and multifaceted problems of Afghanistan. Diplomacy, development and defense are all needed in conflict areas, but the intersections and tensions between the three must be carefully analyzed. On an abstract level, an integrated approach is useful to understand the different interrelated aspects of conflict and peace, but such an abstract concept does not translate straightforwardly into a concrete practice. Only an approach that understands the differences between the components of such an integrated approach, which interventions are needed and who bears responsibility to act can hope to be successful.

It is against this backdrop that I choose to make a distinction between peacemaking as the process that is necessary to end conflict and forge peace agreements on the one hand and nation-building and state-building on the other hand. I consciously use the term peacemaking instead of peace-building, because I believe that the latter is used to promote a much too broad range of interventions, which creates confusion because it overlaps with activities that really belong to the nation-building and state-building process. The UN defines peace-building as 'A range of measures targeted to reduce the risk of lapsing into conflict by strengthening national capacities at all levels for conflict management and to lay the foundation for sustainable peace and 
development. (...) [it] should comprise a carefully prioritized, sequenced and relatively narrow set of activities aimed at achieving the above objectives. ${ }^{7}$ In line with this definition, the 2009 report of the Secretary General on peace-building identified five priority areas: 1 . Support to basic safety and security; 2 . Political processes; 3 . Provision of basic services; 4 . Restoration of core government functions; and 5 . Economic revitalization. ${ }^{8}$ These priority areas clearly overlap with the state-building agenda. The UN notion of peace-building gives the impression that it is a continuation of peacemaking, using the same conceptual framework and the same analysis of roles and responsibilities. However, I believe that a clear distinction must be made between peacemaking, nation-building and state-building.

There is a huge need in fragile contexts for effective peacemaking in the limited sense of ending conflicts. In a background study for the World Development Report of 2010 Barbara Walter found that all civil wars that had started since 2003 were in fact continuations of earlier conflicts. ${ }^{9}$ Paul Collier has done extensive research on the patterns of conflict in fragile states and coined the problem of the conflict trap: Once a country has experienced a civil war, there is a more than $50 \%$ chance that it will face one or more consecutive episodes of conflict. Peacemaking in terms of ending the conflict is a prerequisite for any form of state-building or nation-building to begin. As long as conflict and war continue, neither process will be effective. A negotiated peace agreement that ends the active conflict however, is just the first and limited step in this process. Official peace agreements are political outcomes of negotiations by parties who each were unable to defeat the other. In peace agreements many issues remain unresolved, are postponed or only solved in procedural terms. Politics, in terms of political negotiations for peace, really is - using an inversion of Clausewitz' famous statement - the continuation of war with other means: During peace negotiations and in the subsequent political process former warring parties continue to try to maximize their benefits and strengthen their position. State-building and nation-building are the necessary next processes to carry forward the unresolved issues of by definition limited and unsatisfactory peace agreements that have ended hostilities.

Peacemaking requires a strong role by an external party (or parties) that has convening power to bring the different warring groups to the

7 http://www.unpbf.org/application-guidelines/what-is-peacebuilding/ (accessed 28 October 2015)

8 ibidem.

9 http://web.worldbank.org/archive/websiteo1306/web/pdf/wdr\%2obackground\%2o paper_walter_o.pdf (accessed 28 October 2015) 
negotiation table. The need for this external leadership in itself illustrates that peacemaking is a different process than nation-building, as the latter requires national leadership as essential for success. Peacemaking is also different from state-building: In state-building the national political leadership takes the lead in organizing and financing institutions and systems, be it with strong support from international actors.

The process of nation-building can never replace the importance of peacemaking, because nation-building in itself does not solve or end conflicts. This is confirmed by research done by Paffenholz, who analyzed the relevance of different types of interventions during an entire conflict period. Her research shows that social relations and social capital are insignificant during both the conflict and peace negotiations phase. During this time, social relations are under high pressure, cleavages in society are deep and mutual trust between different warring groups does not exist. She criticizes NGOs that during crisis and conflict invest in social relations and social capital because there simply is no fertile soil for this. It is untimely, too early. Interventions for building social relations and social capital only become relevant in the post-conflict phase. ${ }^{10}$

My proposed distinction between the processes of peacemaking, statebuilding and nation-building supports this viewpoint. The process of fostering meaningful social relations and social capital based on trust is part of a nationbuilding strategy. Peace negotiations only represent the very first moments that warring groups are beginning to explore the bridging capacities of social capital within their communities. Until then, the social capital of communities has only focused on building the internal bonding and solidarity needed to survive in times of crisis and war. This is a normal psychosocial response to acute threats and danger. What is more, those who try to reach out to the other side are often seen as traitors, who are undermining the coherence, stability and survival of the community. In peace processes the first steps are taken in building the bridging side of social capital. Different groups meet each other, acknowledge the need to find ways for solving their problems other than war and are willing to listen to each other, even if they are still focused on how best to push their agenda through. Mistrust has not vanished but there is a platform for conversation. This groundwork of bridging has to be present in order for the processes of nation-building to take off and become successful.

Nation-building, as said above, is not a solution for conflict, it is a protective factor for countries to prevent relapse into conflict over and over again. There is an urgent need to invest in interventions that break the

10 Paffenholz, https://www.sfcg.org/events/pdf/CCDP_Working_Paper_4-1\%2oa.pdf(accessed 15 July 2015) 
vicious cycle of such relapses that was illustrated in Collier's research. Nation-building is no log-frame intervention with a predicted output and outcome within a predicted timeframe. It does much more: It builds trust and social relations, but these are not results that can be planned for. Nation-building builds on the peacemaking efforts. Its purpose is to make the initial steps of a peace agreement more robust by transforming them from agreements-out-of-necessity and based on political calculations to a fundament of understanding and mutual respect that will come to underpin the sense of belonging and the social relations of the different groups.

The table below, which adds peacemaking to the table about nationbuilding and state-building presented in chapter 5 , summarizes the differences between the three processes.

Table 2 Differences between peacemaking, nation-building and state-building

\begin{tabular}{|c|c|c|c|}
\hline & Peacemaking & Nation-building & State-building \\
\hline $\begin{array}{l}\text { Leading } \\
\text { actors }\end{array}$ & Interest-free third parties & $\begin{array}{l}\text { Leaders of communi- } \\
\text { ties and identity } \\
\text { groups }\end{array}$ & $\begin{array}{l}\text { Political representa- } \\
\text { tives, elected by the } \\
\text { population }\end{array}$ \\
\hline Instruments & $\begin{array}{l}\text { Negotiations, shuttle } \\
\text { diplomacy }\end{array}$ & $\begin{array}{l}\text { Stories, myths, } \\
\text { statues, heroes, } \\
\text { cultural traditions }\end{array}$ & $\begin{array}{l}\text { Laws, state } \\
\text { organizations }\end{array}$ \\
\hline Process & $\begin{array}{l}\text { Mediation, talks, drafting and } \\
\text { redrafting of agreements }\end{array}$ & $\begin{array}{l}\text { Building commit- } \\
\text { ment and mutual un- } \\
\text { derstanding: Adding } \\
\text { and enriching }\end{array}$ & $\begin{array}{l}\text { Offering solutions } \\
\text { by setting rules, } \\
\text { regulations and } \\
\text { policies: Codifying }\end{array}$ \\
\hline Results & $\begin{array}{l}\text { Agreement with compro- } \\
\text { mises: Give and take by all } \\
\text { parties }\end{array}$ & $\begin{array}{l}\text { Mutual understand- } \\
\text { ing between } \\
\text { different groups, } \\
\text { a shared sense of } \\
\text { belonging: The } \\
\text { 'we'-feeling }\end{array}$ & $\begin{array}{l}\text { Well-organized state } \\
\text { institutions that } \\
\text { deliver }\end{array}$ \\
\hline Time frame & $\begin{array}{l}\text { Limited in order to avoid the } \\
\text { resurgence of the conflict }\end{array}$ & $\begin{array}{l}\text { Open-ended, } \\
\text { constantly evolving, }\end{array}$ & $\begin{array}{l}\text { Results within time } \\
\text { frame of political } \\
\text { election cycle }\end{array}$ \\
\hline Referents & $\begin{array}{l}\text { Customizing examples from } \\
\text { other conflicts }\end{array}$ & $\begin{array}{l}\text { Self-referential: } \\
\text { Internal domestic } \\
\text { process of selecting } \\
\text { and forgetting }\end{array}$ & $\begin{array}{l}\text { Reference found } \\
\text { in international } \\
\text { community of states, } \\
\text { international laws, } \\
\text { treaties, conventions }\end{array}$ \\
\hline
\end{tabular}

Conceptualizing the notion of peace-building as overlapping with nationbuilding and state-building, as the international community tends to do, means blurring the lines between the different processes. This confused 
conceptualization is responsible for the large role that international actors claim in fragile situations. It legitimizes that they continue their external role from peacemaking, where they indeed are indispensable to bring warring factions to the table to force a compromise, to an uninterrupted leading role in state-building and in nation-building. This leads to claims for international engagement without limitations: The only limitation is the final solution; building a peaceful, well-functioning democracy and an economy where all are living a life in dignity above the poverty line. In this approach there are no limits to the financial commitments or the military involvement of the international community. ${ }^{11}$ It falsely suggests that the international community is able to solve the basic problems and root causes of fragility. Whereas an unlimited international involvement (financially, military and technically) was possible in small countries like Timor-Leste and Kosovo, it was and will be almost impossible in larger fragile countries. During the crisis in Darfur (2003-2004) when millions of Darfurians were uprooted and the ethnic cleansing by the Janjaweed was happening, the international community was well aware that an effective intervention in that part of Sudan required the deployment of such a high number of troops that it would be impossible, not to mention the logistic nightmares attached to such an intervention and the lacking political/ electoral support for such an undertaking. The same goes for many other fragile countries, like Somalia, the Democratic Republic of Congo, South Sudan, the Central African Republic. The history of Afghanistan is proof of the limitations of the international community in the domain of 'peacebuilding'. Although the cited UN definition of peace-building acknowledges the limitations by referring to a 'relatively narrow set of activities', I contend that the nation-building and state-building terminology offers a much better framework to define what has to be done and to define the roles, authorities and responsibilities of both national and international actors in efforts to build viable states in fragile contexts.

11 Doyle \& Sambanis calculate that Iraq would have needed three times as much foreign military to have the same per capita ratio as Kosovo, p. 339. 


\section{Vignette}

\section{An outspoken and inclusive mediator in Colombia}

One of my teachers in conflict resolution was Francisco 'Pacho' de Roux, a Jesuit priest in Colombia who I had the privilege to meet several times. He took me with him during one of his visits to Magdalena Medio, the region in Colombia where military forces, revolutionary movements (FARC, ELN) and paramilitary groups were terrorizing the population. For decades these military forces had waged a dirty war against each other and economic interests (landowners, mining companies) added to the suffering by using private armies and killing community leaders and trade unionists.

Pacho taught me two principles. The first is that you have to be inclusive and to speak to all parties, even those who have committed horrible crimes. Pacho had a very special way to address them. He always invited them as citizens of Colombia. By that he created, at least from his side, the common ground for sitting together and speaking to each other: We are all citizens of this country, we are all living in this territory, regardless of who we are and what ideology we adhere to. And he always made sure that the people were represented: In talking to each other the warring parties should always be confronted with the reality of ordinary women and men who had to bear the brunt of the fighting. Making peace does not happen behind closed doors where warring parties solve their internal fights and share the power amongst themselves. It is only in responsibility and accountability to the people that we can solve conflict and violence.

And the second principle I learned from Pacho was that he did not let there be any doubt as to what he stood for. In his commitment to human dignity and to ending human suffering no one could misunderstand him. He had no sympathy for the army, nor for the guerrillas, nor the paramilitary. Reaching out to warring parties, I learned from him, does not mean to present yourself as a neutral blank sheet without convictions and commitments. The army, the paramilitaries and the guerrillas were well aware that he condemned their violence but that he accepted them because they were Colombians and had to be involved for a solution. You do not, Pacho taught me, need to become friends with these warring parties, you do not need to respect their strategies.

Going around in the world of fragile states I saw so many times how in the political arena exclusion is the basis: We don't talk to the Taliban, we don't talk to Hamas. Politicians often confound talking to opponents with accepting or condoning their behavior. Making peace does not happen on the basis of defining first who is right and wrong, who is the good, the bad and the ugly, and then positioning yourself on the moral high grounds of talking exclusively to the right and the good.

Learn from Pacho de Roux what it takes to solve conflict and war. 


\section{The Scylla and Charybdis of nation- building}

In the previous chapter we argued that nation-building is a necessity to create viable states that are strong enough to both meet the demands of their citizens and play a self-confident role in the global community. Fragile states, too, are forced to take up this challenge of playing their role in the world of nation-states. However, there is a serious caveat here. Twentiethcentury history tells us that building strong states has its downsides. The idea of the nation-state went awfully wrong when nationalism pulled Europe into two devastating wars with the battlefields of Northern France and the Holocaust. The nation-state became tainted by nationalist, exclusionary discourse. Instead of serving as the flag for change and modernity as it was meant to be during the 19th century, nationalism became a dark ideology. These events of the 2oth century in the name of the nation-state mean that we cannot afford to entertain a romantic approach to or notion of nation-building. There will always be the risk of falling prey to fiercely nationalist movements that try to hijack the nation-building process to establish ethnic, religious or regional dominance. It would be naïve to close our eyes to that dark side of the nation.

Some would argue that nation-building is becoming ever more redundant in the world of diversity in which we live today. Processes of globalization and migration, ongoing interaction and interconnectedness make the idea of a national identity something of the past. Homogeneous societies no longer exist and it may thus be a chimera to think that we can create a meaningful national identity. In our dealings with the nation-state, I believe, we find ourselves in the classical story of Odysseus who has to sail between two mythical sea monsters (Scylla and Charibdis) to pass the Strait of Messina between Sicily and the Italian mainland. The dilemma of having to sail between two hazards is what we are confronted with. The Scylla of nationbuilding is the nationalist, exclusionary process, in which rivaling groups try to establish their specific identity as the dominant one and subsequently deem others inferior and second-class. The Charybdis of nation-building is to completely sideline the importance of building a sense of belonging and shared identity for holding a society together. The Charybdis is to believe that all we need is a state without a nation, because we are, with our differences in ideas, beliefs and convictions, all equal citizens in an ever more globalizing world. The only obligation the state bears is to deliver to its citizens. 


\section{The Scylla of nation-building: Identity as exclusion}

The titles of the publications Nation Impossible ${ }^{1}$ and Patriotism is like Racism ${ }^{2}$ reflect the perspective that nation-building inescapably leads to either exclusion and the denial of full citizenship to parts of the population of a country, or to conflict and war with people of another country. In the domestic politics of nation-building the identity adopted and proclaimed as 'the' national identity will by default exclude elements of identity of some of the groups in society. Language is a common example: The ambition of national leaders to build a national identity on a common language makes all other languages second-class and marginalizes them to the status of 'dialect'. The same goes for religious ceremonies and celebrations. In international politics, national interests or even national pride can be taken as the legitimizing ground for dominating other countries. Some nations see themselves as superior to others, believing their nation is special, chosen, more advanced, or fulfilling a historic mission. That feeling of superiority is considered to legitimize the confiscation of territory or natural resources and the bullying of other societies in the international arena. History is rife with examples of this. Feelings of superiority marked the colonial era and more recently the horrible events in Rwanda and the former Yugoslavia were also based on exclusionary politics. When the Hutus started to talk about Tutsis as cockroaches the path was leveled for the slaughter of hundreds of thousands of Tutsis. Mass killings similarly ensued when the Serbs started to spread the idea of their historic mission (battle on the Field of the Blackbirds -1389 ), designating the Kosovars, Croats and Bosnians as their enemies.

Nationalism and the strengthening of national identity are therefore strongly criticized from the perspective of moral universalism, which has the equality of people and therefore universal rights as its cornerstone. From the perspective of moral universalism, nation-building is laying the fundaments for exclusionary politics. We definitively need to round this Scylla.

\section{The Charybdis of nation-building: Silencing identity}

Turning our back to the national identity issue and merely promoting the notion of the new man in the globalizing world would be tantamount to the Charybdis of nation-building. It would mean that we push the globalization

1 Pandian 2009.

2 Gomberg 1990, p. 144-150. 
of economies and markets further by claiming that we are global citizens and that our differences in culture, religion and language are historically or locally contingent. It means claiming that in essence we are unique individuals and that identity is an individual not a collective issue. I believe that such a claim presents a serious misunderstanding of our social nature and moreover denies the reality of the origins of conflict. Identity conflicts are dominant in the conflicts the world is facing today. The Islamic State and its agenda to establish a pure, untainted caliphate is the most urgent of the current identity conflicts. But there are so many more examples. The civil war in the Ukraine revolves around issues of national identity, with the eastern part of the country identifying itself as Russian. In the Central African Republic religion plays a dominant role in the internal conflict, even if some will argue that this is just a pretext for other conflicting interests. The political crisis in Pakistan is the product of a religious and regional identity conflict and in neighboring Afghanistan the traditional divide between the Pashtun south of the country and the Northern Alliance, dominated by Tadjieks and Uzbeks continues to destabilize the country. The Israeli-Palestinian conflict has been deliberately framed by the Israeli government as a religious-identity conflict by emphasizing the Jewish identity of the state of Israel. The problem of the Kurds in Turkey, of conflicts in the Caucasus (Abghazia, Nagorno Karabach), the mounting problems of China in Xinjian blaming the Uigurs, the Abu Sayyaf group in the Philippines ... all are examples of identity-driven conflicts. In his recent book Moïsi analyzed the actual geopolitical development from the perspective of emotions and the way we are perceived by ourselves and the rest of the world. ${ }^{3}$ His thoughts on emotions as part of the crisis in the Arab world urge us to integrate this aspect into political analysis instead of keeping it outside the political equation, supposedly for being irrational and dysfunctional. Emotions are real and legitimate even if they do not fit into a rational policy discourse.

These examples come from non-Western countries. But in Europe, too, identity issues increasingly play a divisive role. Indeed, the actual political crisis in Europe revolves around identity issues. The Front National in France (founded in 1972) and the Vlaams Blok in Belgium (founded in 1978) are increasingly joined by many other parties in Europe, which all exploit people's fear that their national identities are threatened by Europeanization and globalization and by the influx of migrants from non-European countries. Rhetoric about the Russian soul, the unique French culture or 
the British identity (see the 2016-Brexit referendum) touch a nerve among the population and the mainstream political parties on the right and the left seem unable to find proper answers to this identity agenda.

The European embarrassment with identity deserves a closer look. If one would expect identity to become redundant in states that have a wellfunctioning economic and juridical system that guarantees justice and prosperity to citizens, why then is identity such a charged issue in Europe? I believe the explanation lies in Europe's history of the first half of the 2oth century. Fierce nationalism not only resulted in the loss of millions of lives and physical devastation, but also brought moral devastation: The senseless slaughter of World War I and the Holocaust of World War II put Europe on the path of denouncing the promotion of national identity as a risk to avoid at any costs. The founders of the European Union were eager to build a framework that would be able to keep the beast of nationalism in check. The successful reconstruction of Europe after 1945 convinced European leaders that their policies to make identity redundant by constructing wellorganized societies based on prosperity and justice made perfect sense. However, the backlash of the developments of the last fifteen years with the emergence of nationalist, identity-driven political parties shows the void in the mainstream political agenda. Politicians have been pushing the European unification process as the answer to the traditional nationalist rivalries, but at the same time they blocked the process of developing a European identity. It shows a discomfort with the issue of identity as a dangerous issue that is best left untouched.

This attitude is proving counterproductive. I share Horowitz' position: '(I) $t$ is, as I shall suggest, both fruitless and undesirable to attempt to abolish ethnic affiliation, but not at all fruitless to attempt to limit their impact'. ${ }^{4}$ The challenge for mainstream politics, I believe, is to put their notions about culture and identity as social constructs into practice and make it the basis of their strategies to invest in the construction of national and/or European identity in an interconnected world that is marked by diversity. At the moment, European politicians of mainstream parties are seriously foregoing their responsibility not only to lead their societies in economic and financial issues, but also to develop clear identity policies that are responsive to and factoring in the reality of migration and globalization.

In fragile states, the challenge of diversity and therefore the challenge to construct identity out of diversity is not a recent one. It is the essence of their nation-state, most of which were artificially constructed in colonial times 
and contain a rich diversity of identity groups. The above argument is not meant to deny that inequalities in power and resources are an important source of conflict. However, there is a strong correlation between unequal power relations (political and economic) and identity. From the African Americans, the Indigenous peoples in Latin America, the Muslims in the Philippines and the Pygmies in Central Africa to the Algerians in France and the Moroccans in the Netherlands, the correlation between power and identity is strong. ${ }^{5}$

We have to round Charybdis by addressing the national identity issue as a relevant and pressing issue.

\section{Moderate patriotism}

Is there a way out of the Scylla and Charybdis dilemma of nation-building? Can promoting moral universalism and building a national identity be reconciled? Can we adhere to universalist concepts like human dignity and equality and at the same time invest in the specific adherence to and love for the nation? In his Lindley lecture at Kansas University in 1984 Alasdair MacIntyre formulated that debate as between universalism and patriotism. ${ }^{6}$ Natanson further developed the idea that universal ethics and patriotism are not inherently irreconcilable. ' Moderate patriotism', as Natanson calls it, sharply distinguished from what I would call blind patriotism, can include universal ethics. Patriotism does not necessarily have to put the nation first at all cost; finding a balance between universal ethics and the love of the nation is possible. Nussbaum defends this idea of the compatibility of patriotism and universal ethics (see also the previous chapter). She refers to the importance of great humanists like the Indian Rabindranath Tagore and Martin Luther King, who have contributed to the development of the national identity from a humanist perspective. Being connected to our specific 'imagined community' does not exclude the possibility of engaging with and caring for others outside that community. The engagement will be different in emotional intensity, but both can be

5 The notion of correlation presupposes a mutual relationship, regardless of the direction of cause and effect, which is a different subject not touched upon here. I believe that both issues have to be addressed simultaneously.

6 MacIntyre, Alysdair, Is Patriotism a virtue?, Linley lecture at Kansas University 1984.

$7 \quad$ Natanson 1989, p. 535-552. 
governed by universal ethical principles. It is in this direction that the Scylla and Charybdis dilemma of nation-building will have to be resolved.

The moderate patriotism approach resembles the approach developed by Rogers Brubaker when he addressed the civic-ethnic distinction in the nationalism debate. ${ }^{8}$ Civic stands for open, universal and inclusive; ethnic stands for parochial and exclusive. Brubaker rightly argues that, if one would apply this typology in a strict way, the reality is that most nations find themselves in the middle ground between civic and ethnic and that pure ethnic or civic nations hardly exist. It is on this middle ground that I position the efforts of a nation-building program that complements state-building.

This approach makes it possible to put into practice the widely shared theory that identities, also national identities, are social constructs, which are open to change and development. The Netherlands nowadays likes to present itself as the champion of libertarianism in social-ethical issues: Abortion, gay marriage, euthanasia. Many Dutch citizens are proud of that identity, but they may not realize that only sixty years ago the Dutch identity was very much that of a traditional society based on conventional family values. We would belie our history if we pretended that our current values are part of our historic heritage.

Sound historical analysis will prove for almost all countries that national identities are ever changing and very capable to integrate new elements that were not there before. Exclusion of others (other ideas, others persons, other groups) is not the unavoidable fate of a national identity. And while it is not an easy process, it is part of social and political leadership to take the changing identity issue seriously and to actively address it in order to keep our societies healthy and stable. This is a challenge for every country, but probably most urgent in fragile states in order to realize the stability that both the people living there and the international community want to achieve. 


\section{Vignette}

\section{NGOs blamed as allies of opposition in Burundi}

When I visited Burundi in 2011, I met representatives of NGOs who informed me about the mounting pressure by the incumbent government on their organizations. Because they had expressed themselves critically about the government they were perceived as supporters of the political opposition. The government tried to clamp down on them with legislation to shrink their space and by intimidation to silence them. The executive of one of the independent radio stations received death threats, which urged Cordaid to get him out of the country for a couple of months. Being blamed for supporting the political opposition put them under constant pressure to prove that they are promoters of justice, transparency and accountability, regardless of the incumbent political powers.

It is a battle many NGOs have to fight in fragile states (and sadly also in stable states). Promoting good governance and human rights puts you in the corner of the opposition and makes you a target for intimidation. Sometimes opposition parties cleverly use the rhetoric of good governance and human rights to profile themselves even though, once in power, they would most likely not behave any better than the incumbent. And if it is not for party politics, NGOs are deemed to be agents of Western organizations and Western agendas that try to model the country according to their own systems. Mugabe in Zimbabwe and Museveni in Uganda have played that game often and profiled themselves as the defenders of authentic African culture and identity. By creating this cleavage between African and Western values they delegitimize international concern for certain developments in their countries.

During my frequent visits to fragile states I observed that values of good governance and human rights are universal. People do not like governments that squeeze citizens and entrepreneurs only to enrich themselves. They do not like to pay extras for every permit or registration paper. People do not like governments and security forces that beat up those who protest against injustices or put them in jail. People suffer all over the world from a culture of terror and fear that is created by security forces to crack down on opposition forces.

NGOs are in the front line of that battle. Like in Burundi they have a difficult task to balance in the polarized political arena, to uphold their message as an authentic agenda of people who demand a government that cares about people. 



\section{Nation-building: Identity and identification, process and content}

The Dutch Scientific Council for Government Policy (WRR) in 2007 published the report 'Identification with the Netherlands'. ${ }^{1}$ At the public presentation of the report, (then) princess Máxima, as a non-native Dutch woman, reflected on the issue of identity and stated: 'But, "the" Dutch identity? No, I haven't found it'; and: “The Dutchman” doesn't exist'. ${ }^{2}$ These statements were fully in line with the report's conclusions that in today's globalizing world, it is not very productive to speak about the Dutch identity. The council preferred to speak about 'processes of identification' (functional, normative, emotional) as open processes with different meanings and different outcomes for different parts of the Dutch population, based on the reality of the diverse Dutch society. Máxima's speech triggered strong reactions. Nationalist-leaning individuals and organizations fiercely criticized her for doing away with the Netherlands: Who we are, our common history and what has made us proud to be Dutch. On the other hand, she was wholeheartedly embraced by the cosmopolitans for acknowledging the new reality of the global world and discarding in the dustbin of history old concepts of identity that hold us hostage in tradition. And there were also lukewarm 'Yes..., but...' reactions from those who did not want to touch on this sensitive subject to either spare the princess or those who felt offended. The WRR report, the speech by princess Máxima and the ensuing debate show the problem of the national identity discourse: Is it about process, about content, or about both - and if so, in what relationship?

\section{The dangerous romanticism of homogeneous nation-states}

In the previous chapter the exclusionary nature of national identity was identified as the Scylla in all discourse about nation, nation-building, nationhood and nationalism. As was briefly pointed at in chapter 5 , most of the discourse about nation-building and national identity builds on the notion of homogeneity: Nation-states emerged as the result of a process of

\footnotetext{
$1 \quad$ WRR 2007(only in Dutch).

2 http://www.koninklijkhuis.nl/nieuws/toespraken/2007/september/toespraak-van-prinsesmaxima-24-september-2007/ (accessed 25 March 2015), translation by the author
} 
homogenization in terms of language and culture. Homogeneity here is understood as adopting a shared mainstream identity while leaving a particular identity behind. That is what happened in most European countries, where existing regional, ethnic and linguistic identities were crowded out in a zero-sum game by dominant identities that were proclaimed as being national identities and therefore the standard for all those living within the territory of the nation-state.

Many studies about the nation-building processes in Europe highlight the process of homogenization as it occurred in, for example, Italy or France. The seminal study by Weber about the transformation of the peasants living in the French countryside into French citizens ${ }^{3}$ and the statement 'we have created Italy, now we have to create Italians', point in the same direction: Nation-building is the process by which people converge to a common identity in language, culture, social and political systems, celebrate the same heroes, visit the same historic places and where a dominant religion is considered an important marker of the nation. It seems to me that a poor understanding of nation-building and biased research frameworks are due to the conventional study of nation-building processes in Europe. The more recent host of articles and books about the repercussions for national identity in Europe as a result of large-scale immigration confirm this, as they focus on how to maintain that homogeneous, shared identity in the face of the ever-increasing diversity. Homogeneity is the standard and diversity is a deviation that has to be resolved by assimilating or integrating migrants into the mainstream identity. This approach treats social and cultural diversity in the same way that religious diversity is tackled in European nation-states: People are allowed to practice their identity in the private sphere, but in the public sphere the national identity should be maintained and seen by all as the standard. A short flirtation with multiculturalism to accommodate migration and the subsequent diversity during the $1990 \mathrm{~s}$ was quickly rejected in the first decade of the new millennium. Muslim extremism created feelings of fear, which were answered by postulating a strong national identity. What happened with the notion of Leitkultur is a telling example in this respect. First introduced by Tibi to describe a European core culture, based on values of modernity (democracy, secularism, the Enlightenment, human rights and civil society $\left.{ }^{4}\right)$, the political and public discourse transformed the meaning of Leitkultur into a notion that refers to traditional national (German, Dutch) culture as that which 
everyone who wants to be a German/Dutch citizen must adhere to. Instead of providing basic values that can accommodate a diversity of cultures and religions, Leitkultur came to be used as an instrument in a cultural war about national identity.

Homogeneity as the end result of nation-building today is an unrealistic and even dangerous aspiration. ${ }^{6}$ Homogeneity is the Scylla of exclusionary politics of a dominant identity. The European process of nation-building should not be used as the template for nation-building in fragile states. The European process was a child of the 19th-century historical context. History does not repeat itself and there is no reason to expect that nationbuilding in fragile states today will follow similar patterns and generate similar outcomes. The homogeneity that is currently so much under stress in Europe, should certainly not be the reference for nation-building in fragile states. However, homogeneity continues to be a (perhaps hidden) reference for policymakers in development cooperation and especially in fragile states. The reason may be that research shows a relationship between (ethnic) homogeneity and economic progress, or negatively stated, ethnic diversity slows down growth and makes it more difficult to reach consensus on growth-enhancing public goods policies. ${ }^{7}$ Especially in fragile states the rent-seeking behavior of identity groups at the cost of others is squeezing the economy beyond its limits and therefore reduces the overall positive results at nation-state level. The challenge for fragile states today is to foster a sense of belonging and togetherness that is strong enough to build a stable and secure society, but that avoids the goal of homogenization as a zero-sum game in the competition between different groups on the identity battleground. How this can be achieved will be discussed in chapter 10.

\section{From identity to identification}

The language of 'identification' is rather recent in the discourse on national identity and responds to the problematic nature of the identity discourse. Brubaker \& Cooper $^{8}$ argue that even though the social sciences have

5 http://www.welt.de/print-welt/article540438/Einwanderung-und-Identitaet.html (accessed 24June 2015)

6 http://www.ndtv.com/india-news/the-idea-of-a-homogeneous-nation-state-is-problematichamid-ansari-719346 (accessed 24 June 2015)

7 Easterly\& Levine 1997, p. 1207. See also for more theoretical background Alesina, Baqir \& Easterly 1999, p. 1243-1284. The latter article refers to ethnic divisions in the US.

8 Brubaker \& Cooper 2000, p. 1-47. 
adopted a constructivist approach to identity, the use of identity in social and political practice continues to be rather essentialist. Especially politicians refer to identity as something real and tangible, a definable essential quality that should be maintained, protected, defended. In the political discourse, (national) identity is seen as trumping all other identities (sex, race, gender, profession, language, religion) and becomes a 'thick'-loaded issue. The conflation of the use of identity as a practical category (with an essential meaning) in the public and political discourse with its use as an analytical category (with a constructivist perspective) in scientific discourse has rendered the term problematic. Influenced by psychology and sociology the term became hard and soft at the same time: Hard as referring to something essential and substantial, something important and basic in the life of individuals and groups; soft as referring to something that is fluid, influenced by social and societal developments.

To solve this problem, Brubaker \& Cooper propose a couple of terms to break down the notion of identity into different parts, referring to different aspects of identities, which bring about a different practice:

- Identification and categorization. Identification is a willful, internal act by people to identify oneself with a certain quality or aspect: I identify myself as a medical doctor, a woman, a Muslim, a Hispanic person. But identification is also an external act in that others attribute certain identities or categories to people: I am identified by others as ... The state is a powerful force in this identification process. It formulates categories for people - based on sex, race, gender, religion, criminal status, property/tax status - in order to be able to govern them, to relate to them and to control them. ${ }^{9}$

- Self-understanding, social location. This term refers to the agency of people to define who they are in their own terms and within their own context. Whereas identification and categorization refer to categories used in society, self-identification creates space for people to define the content themselves. As an auto-referential term self-identification has its limitations in the social reality. Self-identification offers people the opportunity to redefine themselves, to escape identification conferred upon them by others and imposed identities (understood as realities).

- Commonality, connectedness, groupness. These terms bring in the issue of collectivity as they are about sharing a common attribute, about relational ties that link people to one another and about the sense of belonging to a distinctive group. In this way there is also the reference 
to the felt difference from outsiders and the possibility to make social distinctions.

Brubaker \& Cooper's contribution to the identity discourse is useful as it helps to do away with the thick identity discourse and creates a discourse that much better reflects the constructivist approach to identity. Identification, unlike identity, refers to a process, to something-in-the-making. The term therefore avoids the danger of reification that is inherent to identity understood as a separately existing object. As a process, identification is something that can be influenced, it is contextual and situational. With this framework the authors address the external and internal, the individual and collective aspects of the process of identity formation. However, I do not think that bringing in the term 'identification' will prove to be the magic wand that solves the identity problem. Especially when referring to identification conferred by the state, their approach does not escape the problem of predefined categories that are attributed to citizens. During apartheid in South Africa, the racial identification (white, black, colored) was crucial for a person's position in society, her/his rights and entitlements. In Romania and Slovakia still today the identification of belonging to Hungarian ethnicity is important for one's cultural and social position. Censuses have shown all sorts of classifications (racial, ethnic, religious) by the state to categorize people. ${ }^{10}$ By attributing categories like asylum seeker, migrant, catholic, or lesbian, the state put labels on its citizens that can serve as the basis for policies and regulations. Even if there is a form of self-identification by which people can choose to identify themselves, the state uses the results of censuses and registration to identify issues for which policies and regulations are developed.

\section{Identification and fragility}

Even though the language of identification is not the magic wand for the discourse on national identity, the identification concept offers valuable contribution for the process of building nationhood in fragile states: There is not yet a national identity, there is not yet an understanding of a common sense of belonging and it has to be built in the reality of multiple

$10 \mathrm{http}: / /$ www.pewsocialtrends.org/interactives/multiracial-timeline/ (accessed og September 2015) This website contains a dataset which offers a historic perspective on the categories used in the censuses of the US. 
self-understandings, differences and commonalities. It is a construction and design process. Nationhood in fragile states is often perceived as either a void or it is defined by usurpation by the dominant and most powerful ethnic group. In the latter case the national identity is a copy of the ethnic identity of a dominant (most of the time ethnic) group that tries to impose its identity onto all people living in the territory of the state and/or uses the national identity as a pretext to exclude minorities from equal participation in society.

Fragile states are faced with the problem of dysfunctional institutions and systems, which implies the need for state-building, and with a lack of social cohesion, which necessitates nation-building. As we established earlier, nation-building in today's fragile states cannot follow the organic path of gradual development over decades or even centuries. In order to make the state stable, there has to be some conscious design and construction process. Just leaving it to the vicissitudes of life means accepting the processes of usurpation and imposition of the most powerful identities. Nation-building in the current world has to be a more or less organized process of discovering, building and appropriating nationhood: The sense of belonging to a nationstate. It should provide an answer to the question: What makes Pashtuns, Uzbeks and Tadjieks consider themselves Afghans, what makes Nuer and Dinka into South Sudanese, what makes Toeareg, Peul and Bambara into Malinese without the need to discard their ethnic or tribal identity?

It is true that processes of usurpation and imposition played an important part in the process of building nationhood in the European countries. That explains why the Basks in France, the Catalans in Spain and the Scottish people in Great Britain continue to contest the nationhood, which fails to reflect the diversity of the country, and wish to claim autonomy. However, over time, minority groups in European countries have been able to establish influence on the national identity. In the Netherlands, following the insurrection against the Spanish in the second half of the 16th century, Catholics became a minority. It took nearly three centuries (1850) until the Catholic Church was allowed to restore its hierarchic structure. Since then this minority was able to regain its position in society and the Catholic culture has had an unmistakable influence on Dutch society. In Belgium, the dominance of the French-speaking Walloons was redressed by the Flemish after World War II, and in Germany the Bavarians managed to position themselves as a powerful counterinfluence against Berlin and the Rhineland. All examples underline that national identity is flexible, contextual and malleable.

Nation-building in fragile states in the 21st century cannot accept in advance the dominance of nationhood by the majority group: Ideas about the self-rule of people and respect for diversity that have taken root in the 
international community make a zero-sum power play no longer acceptable. And if it is not political ideology or international law, it is the power of minority groups to destabilize a country that adds ineffectiveness to the illegitimacy of nation-building that is based on the dominance of the majority group. One illustration is the state-building and nation-building efforts of the United States in Iraq. Due to the political choice of the US to rely on the Shiites as the dominant group, these efforts have derailed since 2003. As Saddam Hussein had built his power on the support of the Sunnis, the US marginalized this minority group and built their strategy for a new Iraq on the Shia population. While the Americans hoped that building on this dominant group ( $60 \%$ of the population) would create stability and a center of gravity, this strategy instead led to a deep-felt resentment among the Sunnis and the Kurds, which resulted in the fragmentation of Iraq.

Building a sense of belonging will have to start from the reality that a collective and shared nationhood is not yet defined and that a process of identification is necessary. Defining the nationhood will have to be a collective process engaging all ethnic, religious, cultural, linguistic and regional groups, whether they are small or large, dominant or marginal.

\section{Heterogeneity in fragile states}

Fragile states are marked by heterogeneity, which makes homogeneity all the more unlikely as the outcome of a process of nation-building. This heterogeneity is manifest at both the national and subnational level. All fragile states, seen from a national perspective, contain a rich variety of cultures, languages, religions and ethnicities. This diversity repeats itself in the different regions and provinces of most fragile states. Plagued by civil war, most of these countries have experienced large-scale migration of people inside the country, to neighboring countries and overseas. Forty years of civil war and external interventions in Afghanistan have permanently changed the social and demographic pattern of the country. Internal displacement has forever altered the previously homogeneous regions of Uzbeks, Pashtun, Hazara, Tadjieks. The bigger cities have become melting pots of ethnic groups, none of which has the power to dominate the culture and way of life and who are therefore forced to live together side by side. Refugees from Afghanistan who fled to neighboring countries or to the West (North America, Europe) influence their families and clans in their home country with new ideas and new opportunities. The presence of the international community, providing security (ISAF) and aid, has shaped 
new realities, attracting some and repelling others. This Afghanistan, where ethnic groups and tribes each had their own home area where they maintained their traditions and culture, is no longer there. And it will not return, neither by force nor by voluntary social and political processes.

A similar dynamic happened as a result of the decades-long civil war in Sudan. Communities broke apart and were dispersed within and outside $\mathrm{Su}-$ dan. Social structures were turned upside down. I remember a visit to a small village in the southern state of Bahr El Gazal two years after the Naivasha agreements of 2005, when people started to return to their places of origin. In that village a sensitive dispute broke out between those who had stayed on their ancestral land during the war, those who had fled to Khartoum and built their own communities in the outskirts of the capital, and some of the younger generation who had fled to the refugee camps in Kenya and had been given the opportunity to study at university. Each of these three groups made their own claims for leadership. Those who had stayed and suffered the hardship of the war felt marginalized by the 'newcomers', who brought with them new ideas that challenged their traditions. All people in that village originated from the same place, but they experienced the impact of migration and the reality of new connections to the outside world very differently.

The same story can be told about the Democratic Republic of Congo, about the Central African Republic, Timor-Leste, Colombia, Guatemala. As a consequence of war and displacement, whatever homogeneity existed in those states is no longer there. The traditional stability of homogenous communities living side-by-side, respecting each other and with agreed ways of dealing with 'trans-border' issues, is gone. The new reality means that a process of nation-building can only hope to be successful if it takes into account the diversity and heterogeneity of fragile states. There is no identity that can function as 'center of gravity'. There is no identity that can serve as the basic national identity to which new elements can be added. Any such claims, which have for instance been made by the Pashtun in Afghanistan or the Dinka in South Sudan, immediately stir up protest and conflict by those who feel marginalized and fear to become second-class citizens.

\section{Nationhood and minorities}

If restoring previous regional homogeneity is no longer an option in fragile states, if we will not accept nationhood as being imposed by the dominant group, if we cannot wait until the organic process of history has produced a broadly shared sense of belonging, and if we do not believe in redrawing 
borders (see chapter 2), then there is only one option: Nation-building will have to be an open and inclusive design and construction process that takes heterogeneity in its stride, and starts from the reality of the current territory of the state.

Nation-building is a process led by a collection of minority groups that together will have to create a common understanding of who they are and that need to develop a sense of belonging (in the emotional sense) that allows for and creates a culture of sharing. Although in most fragile states, there are groups that claim a dominant position and want to impose their culture on others, in reality they are all minorities. The Shia in Iraq, the Pashtun in Afghanistan, the Dinka in South Sudan all claim a dominant position but in fact they are (albeit large) minorities. Here one sees a clear distinction with the national identity debate in the Western world: The debate in Great Britain with the Scottish, in Spain with the Catalans and in Canada with the Quebecois is about an (assumed) majority identity that is challenged by the (regional, linguistic, cultural) minority. In fragile states, there is no established national (majority) identity or national sense of belonging. The challenge in fragile states is to build an overarching national identity out of a range of minority identities.

True, even most fragile states have national symbols, a flag, an anthem and national holidays, but that is not enough to build nationhood in terms of a sense of belonging. The challenge of nation-building is to create deeper roots for this sense of belonging in order to make it more resilient and robust for the challenges these countries are faced with. Three basic attitudes are important to make this process successful:

1 The actual process of nation-building (see chapter 10) should not be seen as a zero-sum game, neither between rivaling minority identities nor between a national identity and a minority identity. The issue of nationhood is not the next battlefield for groups that have been competing for power. Building a national identity does not mean elevating one group's identity to become the national one. Neither does the national identity replace the group identities. The approach to nation-building should be based on the capacity of people to handle multiple identities that are not necessarily contradictory but reflect the complexity of the contexts that they live in. It is not even always necessary that national identities trump other identities. There is no preordered hierarchy in the multiple identities we live with. Tribal, family or religious identities can remain important and dominant in one's day-to-day life, if at the same time people are identifying with and emotionally investing in the nation as their overarching, shared identity and, based on their 
national identification, are accountable when it comes to obeying the law, paying taxes, or solving conflicts.

2 There can be no 'winner-takes-it-all' outcome of the process. If we look at nation-building as a process in which only minorities are involved, the outcome can never be that a dominant group imposes its identity, changing the 'we-are-all-minorities' reality into a 'dominant-minority' one. All groups will have to accept at the beginning of the process that the outcome will not be a copy of their minority identity. The outcome will be a mix of replacing and copying. Therefore, creating a national identity will always happen at some cost, or, creating coherence and a sense of belonging will never be realized if the premise is that everything about the minorities' own identity needs to be preserved in a national identity (see also the next paragraph on nation-destroying). Language is a clear example. A national sense of belonging will be difficult if there is no common language. Communication requires a language that is shared by the population of a nation-state. Political deliberations about the common interests and the sharing of resources will not have a level playing field if there is no common language. Without a common language, language power will be an important factor in political decision-making. It is in the interest of all minorities to have a shared language in order to create that level playing field. That should not rule out the possibility of more than one official language. But a nation needs clarity on what the common language(s) is (are) in order to create the basis for communication and decision-making. Using the language of the former colonial power, which is foreign to all minority groups, as the shared language has been the default option. In many former colonies (the whole of Latin America, large parts of Africa and Asia) the colonial language has survived as a common language for the official state communication, even if only a small percentage of the population can speak and write in this colonial language. In many countries, a vernacular has been chosen as the leading national language parallel to the former colonial language: Kiswahili in Kenya, Hindi in India, Bambara in Mali. In reality, in many African and Asian countries people are true polyglots. Many people in the DRC speak French (the official state language), one of the four national languages (Lingala, Kikongo, Tshiluba, Swahili) and one or more of the more than 200 tribal languages. A limited number of official languages is indispensable to communicate in the government, at the market or in the hospital or the school system. This polyglot reality offers opportunities to solve the problem of language, but it is unavoidable that a 
layered system will be the result of such a process: A limited number of official national languages and many dialects. Groups that will not see their group-language elevated to become an official national language, should see other elements of their identity integrated into a common national identity.

3 The acceptance of difference. Processes of nation-building by minorities are processes of groups that are fundamentally equal, but practically different. Each group can contribute and can put demands on the table, but it is unavoidable that in the decision-making process practical considerations will often be decisive. Languages with a large constituency of speakers are more likely to become national languages than 'small languages'. Historic places that become important in the national identity - either as seats of government or in more symbolic ways - will be located within the territories of some communities and not others. Nevertheless, to avoid a 'winner-takes-it-all' outcome, groups need to deliberately include symbols, festivals, heroes and cultures from small minorities in order to make sure that all groups are part of the nation-building process.

\section{Nation-building as nation-destroying}

Political scientist Walker Connor famously defined nation-building as nation-destroying ${ }^{11}$ : By accepting the nation-state as the framework for international relations, we are in fact accepting that the rich diversity of identities is destroyed and that people are deprived of who they are. There is no doubt that nation-building changes identities and one could classify that change as destruction. Problematic in this approach to the nation-building issue is that it tends to see identity in an essentialist, primordial sense, as something that should be preserved and safeguarded against interventions from outside. But identities are never fixed and stable and there is no culture or identity that is immune to outside interventions. So the more relevant question is: Which kinds of outside interventions or interactions are legitimate and is nation-building an acceptable intervention in the identities of groups?

Earlier in this book I posited the intertwined reality of nation and state, rejecting the usefulness of a concept of nation separate from the state. That is not meant to deny the importance that people and communities attribute 
to identities that do not coincide with the state. Over the years the reality of diversity in identities has led political scientists to develop a theory of the nation separate from the state. The Canadian political philosopher Will Kymlicka has done extensive work on the position of Quebec within the Canadian federal state. He argues that there is a distinct national identity in Quebec and that this national identity deserves to be recognized. The Quebecois should be given the power to organize their community based on their sociopolitical ideas and policies. In other words, nations on substate level should have the possibility to decide on, for instance, the use and exploitation of resources found on their territories or immigration policies in order to be able to preserve and defend their nationhood. Kymlicka defends the national identity of communities within the nation-state and therefore delinks the nation and the state. Or does he? By granting power to these nations within the nation-state to decide about resources, territory and immigration, he de facto allows for the creation of a nation-state within the nation-state. But where will this process of granting executive and legislative power of these nations-within-the-nation-state end? Theoretically, there is no limit to this process of devolution and therefore it can effectively lead to the creation of nation-states within nation-states. These nation-states can decide to organize some functions of the state collectively (e.g. defense, currency) but that will be based on agreements, it is not an intrinsic necessity of the concept.

A clear example is the peace process in the Philippines between the Philippine government and the Moro Islamic Liberation Front (MILF) (see the case study on pp.148-151). The peace agreement that both parties signed and which provides for an autonomous government for the Bangsamoro has so many devolved powers (lawmaking, taxation, police, natural resource management) that it almost resembles an independent state. For the MILF an independent state has long been the objective of their struggle. Because of the unwillingness of the Philippines government to negotiate independence, MILF accepted autonomy as the next-best option and tried to maximize this autonomy to get as close to independence as possible.

Accepting the substate nation as a viable option will only fuel the ambition of these nations to govern themselves. Inevitably this will lead to new nation-states. It is like a matryoshka doll: Any group that wishes to declare itself a nation of its own with its own identity, has the right to do so, and subsequently to demand for autonomy in issues that they regard critical for their identity. And there is no conceptual definition or objective benchmark to decide when a nation-state is viable, neither in terms of geographical size nor in numbers of inhabitants. The republic of San Marino has a surface of 61 
km2 and 31.000 inhabitants; Liechtenstein $160 \mathrm{~km} 2$ and 37.000 inhabitants. In the globalizing interconnected world small states are viable entities.

Fragmentation of nation-states into smaller entities to allow minority groups to exert the self-governance is always possible and history has shown the viability, but it is never a solution: even the smallest political entity has to solve the problem of diversity and has to build a sense of belonging, bridging identity-differences.

There is space for many identities to exist side by side within a nationstate. However, defining these identities as national will make it unavoidable in our world of nation-states that these nations will aspire to become a nation-state on and of its own. The challenge for nation-building is to accept diversity of identities and create space to live these identities, within one nation-state. By making the distinction between identities of communities (ethnic, religious, linguistic) and the national identity as identities on different levels and as identities with different institutions, there is space for both to exist alongside each other and there is the possibility of creating the sense of belonging and emotional commitment that is necessary to make fragile nation-states viable.

\section{National identity as moving target}

National identity is never fixed, instead it is a 'moving target'. Processes of reification of national identity are the projects of romantics who are looking for something with deep historical roots, something not susceptible to shocks and changes. Or they are the projects of dangerous nationalists who want to use national identity as a yardstick to make distinctions between the genuine, reliable nationals and the foreign, unreliable outsiders. Reification, fixation of national identity serves as the way to make national identity inaccessible to outsiders and at the same time maintain that it is threatened by them. ${ }^{12}$

The most important step to take is to abandon this reified idea of national identity, to abandon the romanticism of identity as a historic precious artifact that needs to be protected against contamination and fragmentation. National identity is an ongoing process of change and adaptation. As a social construct it is the expression of how and with which features citizens identify themselves and how the interaction between national citizens and 
outsiders takes place. Changes in the population as a result of migration will have an influence on the national identity and so will new social and political ideas.

What is at stake is the question who has the legitimate right to influence and change the national identity. Is this right exclusively granted to those who have relations of ancestry, or do we accept that the entire national community in all its diversity may contribute to that social construct we call national identity?

Saint Augustine said it already: The times they are changing, but we are the times. If national identity is ever changing, this is because we, the citizens of the nation-states, are ever changing. The question is: How inclusive or exclusive do we define the 'we' of Saint Augustine? 


\section{Vignette}

\section{Imagination of reality in Gaza}

I have been to Gaza on numerous occasions. The last time was in April 2015, eight months after the Gaza war of the summer of 2014, during which more than 2,000 civilians were killed. The first time I visited Gaza was in 2004, with the occupation and the settlements still there and the area cut into compartments. I believe I have never visited such a desolate place as Gaza in 2004. In 2006, I visited the strip after the dismantling of the settlements and after the Palestinian elections, won by Hamas. And again in 2009, and 2011, during the blockade of Gaza.

Every time I visited the Gaza strip, I paid a visit to Theatre Day Productions, a theater NGO that gives a cultural expression to life in that area. In April 2015, I attended a new series of plays that TDP had prepared in the aftermath of the war that had uprooted so many people and which had had a deep impact on the mental and emotional well-being of children. Schoolchildren and professional actors together expressed the reality and the way they built their resilience. Touring the schools of Gaza, TDP gave children the possibility to look in the mirror, to recognize themselves in the stories and performances on stage. During the summer holidays of 2015, TDP organized a tour for the UNWRA-Unicef facilities in schools and refugee camps.

By providing a theater school in annex to the theater company, TDP offers young men and women the opportunity to develop themselves into actors and directors who are able to reinterpret and transform reality and to offer their fellow Gazans a liberating perspective on their harsh day-to-day reality.

Theater for TDP is not a moment to forget the reality of war, oppression and blockade. TDP transforms these realities into a different level of personal reflection, social relationship and spiritual interpretation. The reality remains horrible and unjust but it is not the disempowering reality of powers far away that put people in dependency. TDP invites children to express their agency, to be empowered as agents who are part of the reality, not bystanders. TDP makes the case that reality is always multidimensional, even in conflict and war. Life is unbearable if it is just war, violence and conflict. Only if we are able to develop a layered perspective on reality, through which we can see new perspectives, we are able to escape the depressing reality. It is one of the examples that have shown me that the reality of conflict and fragility has more dimensions than just political, economic or military and that in these dimensions ordinary people are able to act in a meaningful and transformative way. 



\section{$9 \quad$ National identity: A model and its content}

The process of nation-building boils down to 'forging a sense of common nationhood'. ${ }^{1}$ How can we make sure that Luos and Kikuyus identify themselves as Kenyans and that the Kenyan nationhood is an important aspect of their identity? The same challenge goes for people of different ethnic and tribal affiliations in Afghanistan and the Democratic Republic of Congo, in Pakistan and Mali, in Sri Lanka and the Central African Republic.

As stated earlier, in many fragile contexts the state is absent or, worse, a perpetrator of acts of violence. In such a reality, people look towards their family, tribe, clan or religious community to find protection and to access basic needs like food, shelter and medical care. In times of real crisis even international NGOs and multilateral agencies tend to withdraw their staff from dangerous areas. People living out of their reach are left to rely on their traditional networks. In South Sudan and Eastern Congo, the churches have played an important role in times of acute crisis in maintaining social networks that were able to provide the bare minimum of basic needs. In Afghanistan, tribal and ethnic communities have oftentimes served as the cornerstones for people to survive. These realities make that issues of ethnicity, religion, language, region, etc. are important and often strong markers of people's identities. This also means that the process of forging a sense of common nationhood is any thing but straightforward: The contours of a national identity are not drawn on a blank sheet of paper. Actively trying to create a national identity can even be perceived as a threat to existing networks that provide security and livelihoods. This is reinforced when different markers of identity come together, as was the case in Sudan where the southern part of the country had a different ethnic identity (Dinka, Nuer, etc.) from the North, a different linguistic identity ( they did not speak the Arab language), and had a different religious identity (they were predominantly Christian) and felt that, as a region, they were different from and marginalized by Khartoum and the dominant Arab/ Muslim groups. In many fragile situations at least two identity-aspects

1 OECD 2008, p. 13. http://www.oecd.org/dac/governance-peace/conflictandfragility/ docs/41100930.pdf (accessed 9 September 2015) 
come together, as is the case in Afghanistan (ethnicity, region) and Mali (religion, ethnicity, culture).

Most sociologists and political theorists in the 196os to 1980 s expected that identity markers such as ethnicity or region would lose their salience. The process of modernization, bolstered by growing migration, international relations and communications, was to make people open to relations outside their traditional circles of tribe, church and country. Economic processes were expected to create new group structures through which people would organize their joint political and economic interests, sidestepping traditional divides. However, even though all kinds of new relationships have indeed been created, it is evident that in our 21st century identity markers such as ethnicity and religion are still very present and significant in people's lives, perhaps most strongly so in fragile states. They will thus have to be taken into account in the process of building a national identity, or the complementary process of nation-building that this book argues is essential for building stable, viable states in fragile contexts. In this chapter we present a model for understanding national identity and the elements that constitute this identity.

A better understanding of national identity may help to take away the reluctance among policymakers and politicians to tackle this issue in their programs for fragile states. It is true that identity is a sensitive and tricky issue, an ever-changing reality in people's lives that can hardly be managed or controlled. And yet I believe that the issue of forging a national identity should be tackled head-on in any fragile-states strategy. We should stop mystifying national identity as something mysterious that shows up without us understanding how it developed. Globalization does not and will not offer a replacement for national identity. I am even inclined to posit that globalization has enhanced the prominence of identity discourses by creating a confusing world, where people have lost their sense of belonging and identification. Pretending that national identity is irrelevant and empty means cutting out part of people's identity without offering something tangible and meaningful in return. And lastly, we should stop hiding ourselves behind the argument that national identity is a domestic issue that lies outside the competence of international actors (bilateral, multilateral, NGOs). Yes, it is a domestic issue, but so are many other issues in stabilization and development programs. Making an artificial distinction between domestic and international issues, it seems to me, is most of all an alibi for not wanting to attempt to understand the complex reality of how national identity can contribute to stability. 


\section{National identity: The model of Shulman}

Developing a model for national identity starts, as stated above, with carefully avoiding a zero-sum debate and accepting that many building blocks complement each other to construct the national identity. As the title of this book indicates, our aim is to broaden the scope of what needs to be done to bring stability to fragile states by complementing the state-building efforts with new initiatives that support nation-building. In this complementary approach we perceive the intertwined relation of state-building and nationbuilding as two sides of the same coin. We start our approach from the model developed by the American political scientist Stephen Shulman, ${ }^{2}$ who identified three key elements in the national identity (civic identity, cultural identity and ethnicity) and a couple of constituting components for each of the three:

Table 3 Shulman's Elements and components of national identity

\begin{tabular}{ll}
\hline Elements of national identity & Components \\
\hline Civic identity & Citizenship \\
& Territory \\
& Will and consent \\
& Political ideology \\
& Political institutions and laws \\
Cultural identity & Religion \\
& Language \\
Ethnicity & Tradition \\
& Ancestry \\
& Race \\
\hline
\end{tabular}

Shulman developed this model in response to the civic/ethnic dichotomy introduced by Hans Kohn in his research and publications of the $1940 \mathrm{~s}$ about European nationalism. Kohn distinguished a civic national identity in Western Europe and an ethnic national identity in Eastern Europe. His model presents civic and ethnic as opposed frameworks with the tacit connotations attached of modern versus traditional, liberal versus illiberal, or civilized versus non-civilized. This covert judgment is still often present in the public and political identity discourse. In programs for fragile states, especially, this judgment brings in a bias in program design: Everybody 
wants to be perceived as modern and as trying to make also fragile states fit for modernity. ${ }^{3}$

Shulman criticized Kohn's dichotomy not only conceptually (like Brubaker, see p. 106), he also referred to the International Social Survey Program (ISSP) of 1995-1996 that conducted a survey in 23 countries of Europe and Northern America to explore the constituting elements of national identity. ${ }^{4}$ He found a clear and consistent pattern that confirms the dichotomy East/ West as ethnic/civic was not evident. Civic elements were highly valued in both regions of Europe, and in some issues certain Eastern European citizens emphasized the civic components of national identity more than people in Western Europe.

Shulman then developed a new model, which presents national identity as explicitly multifaceted. People have multiple identities that are dear to them and that play a role in the building of their national identity. The model, developed through his reflections on the European and NorthAmerican nation discourse, makes space for notions that are very salient in the nation-building discourse of fragile states, like ethnicity, language, traditions, religion, ancestry. It brings together the elements of civic identity that the international community promotes in its state-building programs with the cultural and ethnic elements that define many of the identity struggles in fragile states. Shulman's three main elements (civic identity, cultural identity, ethnicity) and their underlying components are the building blocks of a national identity, but their relative importance of weight is not defined in advance. It is an open model that leaves space for a contextual and diverse understanding of national identity.

It is important to stress that I adopt this model because our central question is: How do people define their national identity? What is at stake is not the objective truth about the different elements and components and their relative importance, but the extent to which people actually use these labels to define their national identity. The question of national identity in fragile states is not an 'expert problem' that can be solved by policymakers or scientists, but a problem for communities to solve. If, in line with the identification discourse of Brubaker (see chapter 8) national identity is about identification, self-understanding and commonality, the essence is how people identify each other and themselves in social relations and how

3 N.A.M.E. Grotenhuis, Modernity and Tradition: Time for Change, master thesis St Andrews University 2014.

4 https://dbk.gesis.org/dbksearch/sdesc2.asp?no=2880 (accessed 29 October 2014) 
they shape their communities. If we want to build a national identity, this will have to be a bottom-up process.

\section{Is Shulman's model applicable to fragile nation-states?}

Shulman developed his model based on his research about national identity in Europe and the United States. That the same model is also applicable to fragile states is therefore not self-evident. In fragile states, cultural and ethnic identities are often strongly developed, while a civic identity is generally weak. We will look at the relevance of the three elements in more detail below.

Civic identity is a crucial element in national identity because, even if in fragile states this civic identity is not strongly developed, it will always have to be the basis of the nation-state. Fragile nation-states, too, are built on the people as their sovereign and their source of legitimacy. There certainly are indications that people in fragile states are well aware of their power as legitimate basis of the nation-state. The high turnout at elections in countries like Afghanistan (2004) and the DRC (2006) are one example. It shows that people see elections as an important opportunity to express themselves about national politics. It reflects their belief in an elementary form of citizenship. Territory, the second component of civic identity in Shulman's model, is a more complex issue. Most fragile states have experienced large-scale forced migration. Millions of Afghans, Somalis, Rwandans and Syrians live outside their country of origin, their home territory. Do they still see themselves as belonging to that territory, and what about those who stayed behind, do they still view their compatriots who fled and migrated as fellow citizens? The component of consent and will is relevant to building national identity in fragile states because there, as anywhere, identifying oneself with the national identity of the country requires a positive expression of will: Identifying with an Afghan national identity is not a default consequence of living within the borders of Afghanistan.

Regarding the fourth and fifth components of civic identity, political ideology and political institutions and laws, the question is which lenses we apply. Most state-building programs, from the time of decolonization onwards, have been built on the political ideology and political institutions of European/Western nation-states: Parliamentary systems, electoral codes, and the division of powers. Often, a critical reflection on whether these models are an adequate response to the political reality of non-western 
(fragile) nation-states has been entirely lacking. The Western political ideology of individual rights, equality and freedom is often not part of the traditional political systems in fragile countries, where the interests of the community are dominant over the individual, and where equality and freedom are limited by different systems of authority (men-women; parents-children; clan leaders-clan members, religious leaders-believers, etc.). The extent to which Western-style political institutions are rooted in society is questionable, and the same holds for political ideology that often lacks broad support. While the high turnout at elections (especially after a peace agreement [DRC and South Sudan] or the toppling of an oppressive regime [Afghanistan, Iraq ${ }^{5}$ ]) reflects, as said, some notion of citizenship, I doubt that it can be interpreted as an embracing of Western-style liberal democracy. To my knowledge no research as yet has focused on how to interpret the large turnout of voters at these occasions. Perhaps it is an expression of people's eagerness to be heard and accepted as members of the polity after times of oppression. Or perhaps the large turnout shows that people, encouraged by community leaders, used the elections as a means to ensure that their specific group interest would be safeguarded. And then there is the steep decline in voter turnout in Afghanistan. The presidential elections of 2004 brought $83 \%$ of the population to the ballot box; the elections of 2014 only $38 \%{ }^{6}$ Does this show that the adherence to the political institutions and systems is not overwhelming? Or did people want to express their disappointment about what Western-style democracy had done for them? When we look at other political institutions like the judiciary, the Afghan example does not appear very promising. The ordinary Afghans continue to put much more trust in their traditional and customary systems that give powers to religious and community leaders to resolve disputes, than in the official Western-style judicial system that has been established with help from the international community. Widespread corruption within this official judicial system only reinforces this trend. In brief, given the current weaknesses of public political institutions, they can hardly serve as the litmus test for people's sense of civic identity.

What about alternative political ideologies and political institutions? In Africa, the Ubuntu philosophy can be considered as a basis for a political ideology: the 'I am because we are' principle is an important source of

5 Voter turnout at elections in Iraq in 2005 was 79\%, http://www.idea.int/vt/countryview. cfm?id=107; in the DRC turnout at the 2006 parliamentary elections was $70 \%$, http://www.idea. int/vt/countryview.cfm?id=39 (accessed 16 January 2015)

6 http://www.idea.int/vt/countryview.cfm?CountryCode=AF (accessed 16 January 2015) 
ethical positions. The current South African judicial system has provisions that are derived from the Ubuntu philosophy, ${ }^{7}$ but it has not been developed into a full political theoretical system. ${ }^{8}$ The Gacaca system in Rwanda, loosely translated as 'justice on the grass', that was set up to deal with the perpetrators of the 1994 genocide is another example of an institution built on the Ubuntu philosophy, which sees the individual always as part of the community. In Afghanistan, the Loya Jirga as the national gathering of representatives of (ethnic) communities is a political institution that does not fit the representational democracy model. In African countries, hybrid models exist where traditional hereditary systems of leadership go hand-in-hand with modern election-based models. ${ }^{9}$ In Islam, leadership inspired and bound by the faith in Allah has a much more central role in the political system..$^{10}$ All these political philosophies and institutions, even if they have not been developed as alternatives to the Western-style political ideologies or institutions, play a role in people's lives and the organization of their communities. To suppose that the political ideology and institutions as developed in the western world, are fit for purpose in fragile states and that they are to fill the void is showing a lack of understanding of the diverse reality of political ideologies and institutions.

British citizens in the ISSP survey about political institutions were asked whether they endorsed the statement: 'To be truly British it is important to respect British institutions and laws.' Given the reality of ineffective, corrupt and generally weak political institutions in most fragile countries, this question would be difficult to answer for, for example, Afghans or Congolese. Their answers would be even more difficult to interpret because they may well be referring not to the official 'modern' state institutions, but to the informal, customary institutions that are still very present and important in their daily lives.

Cultural identity, the second element in the Shulman model is relevant in the process of building a national identity in fragile states. The components of language and tradition are indeed important pillars of cultural identity, however, I question whether the component religion is also best placed there. The connection between culture and religion is very applicable to the European

$7 \quad$ Metz 2011, p. 523-559.

8 See also this master's thesis by Katherine Elizabeth Furman: Exploring the Possibilities of an Ubuntu-based Political Philosophy, http://philpapers.org/rec/FURETP (10 October 2015)

9 Logan 2009, p. 101-128.

10 Haider Naqvi, Ahziz, Haider Zaidi \& Rehman 2011, p. 10984-10992. 
context due to the specific history of European state formation (cuius regio, eius et religio). In Afghanistan, nearly $100 \%$ of the population is Muslim (with an important Sunni/Shia divide), while the cultural diversity in the country is enormous. And although the religious practices can differ between different ethnic groups, there certainly is a strong sense that the Islamic religion is a shared identity for all people living in Afghanistan. The same goes for Christianity in the Democratic Republic of Congo: Religion is not part of the cultural diversity. People of different cultural identities (language, traditions) are very likely to all answer that the Christian religion is important for the national identity of the DRC. For these reasons, I suggest to include religion as a separate element in an adjusted version of Shulman's model (see below).

Ethnicity, the third element in Shulman's model, and its two components ancestry and race are both relevant categories that are applicable to fragile states. As we will see below, they are complex issues too, given the reality of diversity in fragile states that is partly caused by large-scale migration.

\section{A modified model for fragile nation-states}

Based on the above, I propose a slightly adjusted version of the Shulman model that I believe better reflects the reality of fragile states and the way people living there identify themselves. I limit the components of civic identity to citizenship, territory, will and consent, leaving out political ideology and political institutions and laws. Instead, I add the issue of rights and obligations to the component of citizenship. It is important to analyze to which extend people in their civic identification, include the rights and responsibilities towards the nation-state. Secondly, I introduce religion as a separate constituting element of national identity, rather than grouping it under cultural identity.

In addition to these adjustments, and based on the notion that identity is an ever-changing social construct, I moreover consider one component with two new elements that may possibly be relevant to the forging of national identity. I would call the component 'nature \& resources' covering the idea that the physical reality of a country is shaping its identity in two ways.

The first way is that of geography. Geographical circumstances to a certain extent shape the national identity. As a citizen of the Netherlands, for instance, I am aware of the important role that our geographical reality has played in defining our identity. The continuous struggle against the threatening water and our efforts to reclaim land from the sea are defining aspects of who we are. Part of the Dutch institutions came out 
of this struggle against the water and so did the famous Dutch consensus decision-making culture referred to as 'polderen'. The identity of Bangladesh is shaped by its delta structure, which results in frequent flooding of large parts of the country. The national identity of the small island states in the Pacific is defined by their geography and the same goes for the Sahel countries that are perpetually challenged to live with drought and dust.

Economy is a second possible new element constituting national identity. All nation-states today are challenged to define their position vis-à-vis other states in response to globalization and the fact that global trade is the prevailing avenue for the relations between nation-states. Given that identity is about social boundaries, it may be worthwhile to explore to what extent the position of a nation-state in the global economic order of comparative advantages shapes its national identity. Some countries have had a rather constant position in the economic world order: Germany has a long history of cutting-edge manufacturing, the Netherlands and Brazil have both long been agricultural giants, Great Britain prides itself on its long tradition of trade and financial services. Some countries deliberately choose an economic strategy that gives them a distinct profile in their region or globally. Rwanda's strategy to become a digital hub in Africa is first and foremost an economic strategy, but the identity-shaping power of this strategy could prove to become important. At the same time, economic identities may either be too volatile or too much infused by opportunism to be considered long-lasting elements of national identity. However, it is not unthinkable that in the long run more stable patterns of economic identity and comparative advantages will emerge globally.

I conclude that, though it is certainly worthwhile to keep exploring the relevance of both geography and economy to shape national identities, it is too early to include these elements in an adjusted model for the nationhood of fragile states. The adjusted model of Shulman that I present here thus looks as shown in the table. I will discuss its elements and components below.

Table 4 Elements and components of national identity in fragile states

\begin{tabular}{ll}
\hline Elements of national identity & Components \\
\hline Civic identity & Citizenship: Rights and obligations \\
& Territory \\
& Will and consent \\
Religion & Religion as social practice \\
& Religious belief \\
Cultural identity & Language
\end{tabular}




\section{Nationhood and civic identity}

The importance of civic identity as one of the pillars of a national identity is without dispute: The nation-state needs an identification of people with the basic components of this civic identity. In fragile states, the components of civic identity are often 'under construction' rather than an already solid part of people's identity.

Citizenship. Civic identity is first and foremost based on the concept of citizenship, which dates back to ancient Greece, where the relationship between the citizens and the polis and belonging to the polity was the essence of political identity. The nation-state that gradually developed in Europe since the mid-17th century and presented itself in full force with the French Revolution, became a partner of the citizens. Le citoyen became a powerful label for people who carried both rights and duties towards the state.

Many people in fragile states do not feel that they are citizens in the modern sense of the word. Due to the absence of the nation-state in their lived reality, they do not feel a relationship with the state, nor accountability towards that state. At the same time, there is an increasing awareness that citizenship is the necessary entry ticket to hold the state accountable for providing protection, security, basic social services and investing in economic development, thus creating the basis for people's welfare. The Indian government has started to provide all its citizens with an identity card to confirm their status of citizen, which gives specific entitlements. ${ }^{11}$ In Western countries, too, citizenship is crucial for getting access to services and entitlements as can be seen in the situation of migrants without legal permits of residence. Citizens are in, non-citizens are out. There clearly is a reason why the green card in the US is such a coveted object and why the citizenship issue of migrants in Europe causes such heated debates. One would expect that the notion of citizenship will become more important to people in fragile states when these states start to take the responsibility for

11 http://www.ndtv.com/article/india/indian-citizen-id-card-what-you-may-need-to-getit-570641 (accessed 16 January 2015) 
delivering basic goods and services to their citizens. A specific challenge is the double-nationality issue: People who are accepted as citizens of more than one state. Some countries like Morocco stipulate that people can never lose their Moroccan citizenship and even second- and third-generation migrants remain citizens. Attempts by second- or third-generation Moroccan migrants to become exclusively Dutch, or German or French citizens failed: By international agreements civil authorities have to maintain the double nationality in its civil registration. Turkish second- and third-generation migrants have to fulfill their military service, based on their double nationality. Fragile states with a large number of citizens as migrants outside the country, have still to address this issue.

Territory. Is identifying national identity with territory a tautology? The definitions of nation and state after all are based on the notion of sovereignty over a certain territory. However, how people define their national identity does not necessarily coincide with where they live. Labor migrants often identify themselves as belonging to their nation of origin even though they are fully integrated into their host country. For refugees, who were forced to leave their home country due to war and insecurity, this identification may be even stronger. The recent history in the eastern part of Ukraine illustrates the problematic relationship between territory and national identity: People who are officially citizens of the Ukraine, presented themselves as Russians aiming for secession to connect their territory with Russia. For people in fragile states where the sovereignty of the state over a certain area is not self-evident, the issue of territory is real: Do they see their territory as part of the nation-state?

Regional identities are a factor to take into account when considering civic identity in fragile states, as regional identity is often very relevant to people who feel marginalized and excluded. Regional identity is a rather modern phenomenon provoked by the borders drawn during colonial rule (Berlin Conference, 1884/1885) and the subsequent formation of nation-states within these colonial borders. Combined with other identity components (ethnicity, language, religion) territorial identity can be quite powerful. The Touaregs who live in the northern part of Mali, for instance feel excluded not only as an ethnic group with their herdsman culture, but they also feel marginalized in geographical terms by the central government in Bamako.

Will and consent. National identity is more than a mere administrative or juridical act of registration in the civil administration. It requires a positive commitment by the people to identify themselves as citizens. Republican 
citizenship (see chapter 4) belongs here: The citizen affirms his or her role as the sovereign who legitimates the nation-state s/he belongs to. This declaration of belonging entails responsibilities. In immigration countries, migrants can experience a feeling of 'living in-between': No longer in their home country, their sense of belonging to the new country has to be appropriated in a process of identification that may take generations. First, second and third generations of migrants show different levels of identification and affirmation with the new nation-state that they belong to.

\section{Nationhood and religious identity}

Religion is often identified as a source of fragility and therefore a thorny matter in the building of the nation-state. Religion as source of fragility is manifest in either religious extremism (e.g. Taliban, Islamic State) or religious intransigence (e.g. the conflicts between Christians and Muslims in the Central African Republic). Discussing the role of religion in nationstates and nation-building must start from the acknowledgement that for people in the global South, where most fragile states are located, religion is highly important. $84 \%$ of the world population defines itself as religious. ${ }^{12}$ If we would correct that figure for (mostly) secular Europe and communist China it would reach more than 9o\%. For religious people, life has a meaning - often its most important meaning - beyond the material world and beyond a physical understanding of space and time. To them, the spiritual world is real (and interacts with the physical world) and there is a future beyond earthly time.

For most people in the secular world, life has no meaning outside itself: People are challenged to get the most out of the time they are granted in this world. The marginalization of religion in public life that has happened in most donor countries, has positioned religion outside the development discourse. If there is attention for religion at all in the fragility discourse, this is mostly instrumental: how can religious communities or leaders be helpful in solving the problem of fragility? An in-depth understanding of religious identity as of fundamental importance for people's sense of belonging is unduly lacking. 
Religion as social practice. In our modern world, the relation between religion and nation is generally seen as problematic. In history, their connection has been very prevalent. In the Old Testament, David is the King of the Jews but also the religious leader, anointed by Samuel in the name of God. The spread of Christianity was often a top-down process: If the ruler of the community converted to Christianity, large parts of the population followed. The Westphalian Peace Treaties strongly connected religion and the formation of nations (cuius regio, eius et religio) in order to create stability within and peace between nations.

The connection between religion and leadership was, before Enlightenment and the French Revolution, also politically important in order to legitimize the authority of the ruler. By invoking God as the basis for their powers, Kings, Emperor and Dukes created a legitimate basis for their decisions. When through the process of democratization the legitimacy of the state was transferred from God to the people, the relation between religion and the nation-state weakened, but the connection has not disappeared, even in modern society. Still today, the king of the Netherlands is officially 'King by the grace of God' and promulgation of all laws and regulations starts with that announcement ${ }^{13}$. The Queen of England is the head of the Anglican Church and the same goes for Denmark. In Sweden and Norway the direct relation between the church and the king or queen was only dissolved in 2000 and 2012. Different but also relevant examples are Italy and Russia. The Italian government carefully takes into account the opposition of the church to gay marriage. In its strategy to strengthen the Russian identity, Putin's government links itself in tandem to the Russian Orthodox Church. The recent history of Russia since the collapse of the communist USSR shows how, after more than 70 years of a secular ideology, religion resurged as an important pillar of the national identity. Of course, governments and leaders will often use religion in a very instrumental way, which should be judged critically, but this does not negate its continued importance in people's and nations' identities. In the debate on migration politicians in Western Europe refer to the judeo-christian foundations of the nation-state as underpinning for the cultural and social identity of their countries.

Religious belief. For religious people, their relation to the divine (irrespectively of how this is described, labeled or named) is a fundamental aspect of

13 In 2016 the Dutch social liberal party D'66 presented a proposal to the parliament to delete this sentence in the promulgation of laws 
their identity. Their ultimate destination is in the divine and is created by the divine. Religion touches the essence of who we are and influences how we position ourselves in the world. From a religious perspective the state is always a temporary destination. This attitude puts the commitment to the concept of the nation-state and national identity in perspective.

Both Christianity and Islam merit a closer look where it concerns potential conflicts between religious and national identities. Unlike other large religions like Buddhism and Confucianism, both Christianity and Islam have a global mission: It is their ambition to convert all people of the world and make them believers of God or Allah. This ambition can easily be at odds with the concept of, and identification with, the nation-state. This may explain why Christianity and Islam are involved in cases where religion is a source of fragility. The rivalry between Christians and Muslims was one defining feature of the civil war in Sudan and currently plays a role in the Central African Republic, Côte d'Ivoire and Nigeria. Muslim extremism is at play in Mali, Somalia, Afghanistan and the Caliphate, recently proclaimed in Iraq/Syria and in Nigeria.

Both Christianity and Islam have a tradition of merging spiritual and worldly power. Since the rule of Emperor Constantine the Great, Christianity became the official religion of the Roman Empire and in the Middle Ages bishops often ruled over vast regions of Europe. The caliphs on the Arabic Peninsula who claimed succession from Muhammad, merged spiritual and worldly power by conquering vast areas in North Africa, the Middle East, stretching out to Asia and south and Eastern Europe. However, in modernity, with the formation of the nation-states in Europe, Christianity and Islam have taken a different approach.

For the Christian religions, this side-by-side existence of worldly and divine power is not a fundamental problem. In Matthew 22: 12-22 Jesus, in a dispute with the Pharisees about the relation between God and the Emperor, says: 'So give back to Caesar what is Caesar's, and to God what is God's. ${ }^{14}$ Apostle Paul also hints at the acceptance of worldly power as separate from the spiritual world. Perhaps the beginning of Christianity as religion persecuted and oppressed by the Roman Empire is relevant in this respect. For Christians there is no doubt that at the end of time the Kingdom of God will make all earthly kingdoms redundant and that the Kingdom of God is the real future we should care about. For the time being, as pilgrims in this earthly world, Christians can adapt to the rules of the state. The Roman Catholic Church, at the Second Vatican Council in the constitution 
Gaudium et Spes formulated its position towards the state and the worldly authorities as follows: 'Christ, to be sure, gave His Church no proper mission in the political, economic or social order. The purpose which He set before her is a religious one. (...) But out of this religious mission itself comes a function, a light and an energy which can serve to structure and consolidate the human community according to the divine law. ${ }^{\prime 15}$ Nonetheless, many Christians have the ambition to let their faith be the source of inspiration in their social and political engagement. They do not accept the position of religion as confined to the private domain. The criticism of Pope John Paul II on communism in Eastern Europe and the active engagement of Pope Francis in the refugee crisis in the Mediterranean and the climate change debate are signs of this ambition.

In Islam, accepting a system of stately rulers parallel to the rules of Allah is more contested. Strict interpreters and Islamic fundamentalists repel the state as the rule-setting entity. ${ }^{16}$ Only the rules set by Allah and handed down through the Prophet, peace be upon him, can organize society. In this perspective there is an unbridgeable divide between 'dar al-Islam' (the world of Islam) and 'dar al-harb' (the world of hate). This antagonistic approach was mirrored in Samuel Huntington's Clash of Civilizations and Benjamin Barber's Jihad vs McWorld. Both authors see the confrontation between Islam and the Western democratic political system as the defining struggle of the 21st century.

More moderate Muslims are developing a new discourse that disentangles the religious, the cultural and the political in Islam. It creates space for the acceptance of diversity of civilizations as the basis for acceptance of a political realm that does not coincide with Islam. ${ }^{17}$ Especially for Muslims living in (European) countries, where they find themselves in a minority position, such a new discourse could create the space to live as true believers and as loyal citizens at the same time.

\section{The theocracy of the Islamic State}

In the debate on religion and state it is interesting to look more in depth at Iran. The Islamic State of Iran has adopted religion as the defining identity for the state. The revolution in Iran that took place in the second half of the 1970 s brought a theocratic regime to power; the Council of religious leaders 
is the supreme authority to assess rules and legislation of parliament against the Islamic religion and rules as set by the Prophet. The judiciary is not independent but subordinated to this Council. Iran tried to harmonize the Islamic concept of the state with the modern concept of the nation-state: It accepted the nation-state with its borders and limited territory as the framework even though the political concept of Islam is universal and disregards borders and distinct territories. It is the same step the Bolsheviks took when, despite the universal claim of the Marxist ideology, they decided to build communism within the borders of the state. In contrast, the new phenomenon of the Islamic State (IS) proclaimed in 2014 in Iraq and Syria disregards national borders and does not recognize nation-states as legitimate entities.

\section{Nationhood and cultural identity}

The third element of national identity is cultural identity. Part of who we are as a nation is shaped by our culture: The amalgamation of our habits, the way we celebrate, the way we mourn, the stories we share, the heroes we adore, the holy places we visit.

Language is a strong carrier of identity. It is our main instrument to express who we are, what we feel, what we think and what we aim for. As Anderson shows, the print technology, combined with the use of vernacular to replace traditional Latin, has had an enormous impact in Europe on the formation of national identities. ${ }^{18}$ Language is a natural cleavage between 'them' and 'us': 'We' can't even understand 'them'. By creating a common vernacular that was increasingly the preferred mode of expression for rulers and religious leaders, a feeling of togetherness was created and strengthened. In the course of this process, many vernaculars were downplayed to the status of dialects. In Spain, the Catalan and Basque languages remain very important identity markers, driving the agenda for autonomy or even independence. ${ }^{19}$

In Africa, where territorial borders were drawn disconnected from any cultural or anthropological logic, the language of the colonial power became the official language until independence. The missionaries played an important role in setting language standards because they chose certain oral languages to become the written language for their translations of the 
Bible. ${ }^{20}$ They thus saved languages that would otherwise have been lost, but at the same time sentenced other oral languages to disappear (see also chapter 8 on nation-building as nation-destroying). Some countries have been successful in creating a unifying language (e.g. Kiswahili in Tanzania), but in many other former colonies people have become experienced polyglots. Many Kenyans for instance speak English and Kiswahili for official and professional purposes, learn one or more neighboring languages to be able to communicate within their regions, but favor their ethnic language as the vehicle to express their emotions.

If language is the verbal expression of our identities, convictions and beliefs, traditions express the same in a non-verbal manner. Through traditions we show how the social relations in our society organized: Especially initiation rites (entering puberty, wedding ceremonies, burials) are strong markers of social relations and social positions. Rituals are also often imbued with religious significance in terms of relating ourselves to the world of the invisible, and through them we build the bridge between past and future.

While tradition is a strong marker of identity, traditions are never absolute: There are always members of the community or the nation-state who do not participate, and certain traditions are shared with other communities or nation-states. The same goes for language. Although English is an international language, the differences between the English spoken by Australians, Scottish people, the Irish, Indians or Canadians create distinctions that are recognized as part of distinct national identities.

\section{Nationhood and ethnicity}

The international community often considers ethnicity the main spoiler of orderly processes of nation-building in fragile states. Ethnic identity is seen as a dysfunctional competitor of national identity. Ethnicity is one of those concepts that is fiercely debated and lacks a definition that is widely agreed on. I follow the definition of Schermerhorn (in the history of Weber's definition), as cited by Cornell \& Hartmann: An ethnic group is 'a collectivity within a larger society having real or putative common ancestry, memories of a shared past, and a cultural focus on one or more symbolic elements defined as the epitome of their peoplehood'. ${ }^{21}$ Ethnicity is about 
historical roots in bloodlines and memories, it is about self-identification where objectivity is not the yardstick (but instead: Selecting, forgetting and inventing) and ethnic identity becomes relevant in relationship to others within the larger society.

Ethnicity is seen as an important factor in the building of a national identity. For those who adhere to a primordial theory of the nation, it represents the decisive historic roots of the nation: The lineage of blood and ancestry ultimately defines who belongs to the nation and who does not. But also researchers with a constructivist outlook consider ethnicity an important part of identity, be it that they consider ethnicity the result of a deliberate process of selecting and forgetting and sometimes even of inventing the defining features of the group's identity. Ethnicity, like religion, is a powerful aspect in identity discourses. A political entrepreneur who knows to strike the right chord, will resound a whole set of notions and feelings that are dear to people's hearts and able to evoke their commitment. The power of ethnicity is deepened in contexts of fragility, where people often heavily depend on the reliability of their ethnic community for both physical security and economic survival. Distrust towards other ethnic groups is often part and parcel of this. Fragile states looking for stability are confronted with an even stronger presence of ethnicity.

I will look at the role of ethnicity from the 'social boundaries' approach developed by Katherine Verdery and Andreas Wimmer. According to Verdery, ${ }^{22}$ ethnicity is a function of organizing society rather than a structure to preserve a certain fixed cultural content. She stresses the importance of situationalism in our approach to ethnicity in order to rid ourselves of a determinist perspective and allow for the logic of difference. The model of ethnicity as social boundaries does away with ethnicity as a 'once and for all' static and timeless identity. Instead, it promotes a much more dynamic perspective of identity and the role identity plays in societies, as argued by the sociologist Andreas Wimmer. ${ }^{23}$

It is not difficult to see how important a dynamic approach to ethnicity is for fragile states, where people often organize themselves politically along these social-ethnic boundaries, and where social closure is high. At the same time, we should realize that these realities are situational, i.e. a response to the circumstances of fragility, the brokenness of society and the lack of trust. Because they are situational, the boundaries can always be changed. 
A situational approach could be seen to suggest that only if the situation of fragility is changed for the better, this will automatically lead to making ethnic cleavages redundant. Most state-building strategies are based on this instrumental and consequential perspective: By building an effective state and just institutions the need for social boundaries based on ethnicity will vanish. Such a strategy is based on the assumption that it is possible and recommendable to make ethnicity redundant in the public life of the nation-state. If this were to be true then we should be able to define at which point in the process of state-building the circumstances are conducive enough to make the social boundaries of ethnicity redundant. And even if such a moment could be defined, the question remains how to tackle the ethnic divisions in the meantime. In fragile states, that 'meantime' can take a very long time. There is thus no other option than to actively engage with the issue of ethnicity as social boundaries.

Verdery adds another important element to the discourse about ethnicity and nationalism by defining both as: '... names for two closely related forms of social ideology. Both are means of social classification, classifying on the assumption that certain types of differences are significant'. ${ }^{24}$ The social boundaries of ethnicity can easily be translated to physical borders, defining the territory and the polity anew as belonging to the ones who share the same characteristics. In a fragile context, where distrust and increased in-group cohesion can be observed, the connection between ethnicity and nationalism is easily made: The only future we believe in, is based on the social boundaries that have proven to be our best shield against the vicissitudes of life.

Equating ethnicity with social boundaries means creating an 'us' versus 'them' divide, which can have severe divisive consequences for a society. Marking ethnic identity as a social boundary means attributing a label of 'otherness' to those who do not belong to the ethnic group - and in the same act labeling one's own ethnic group as different, special, distinct. ${ }^{25}$ It is in this 'us' versus 'them' scheme that the fuse of ethnic conflict lies: It invites all sorts of enemy imagery and accusations and offers the perfect opportunity for political entrepreneurs to mobilize the ethnic groups behind claims of power and superiority. The Peace Research Institute in Oslo in a study on international conflicts between 1946 and 2008 found that 90 of the 174 were ethnically motivated. ${ }^{26}$ The combination of strict social borders, the 
competition over limited resources, lack of trust and the temptation to strengthen the group's position in a messy situation, are bound to provoke violent conflicts.

This dynamic is reinforced by the ethnicization ${ }^{27}$ of political power structures: Government officials are appointed based on their ethnic identity, partly to defend the own ethnic group against rivals and partly for channeling resources to the 'us' community. Ethnicization of political power directly influences the state-building agenda and undermines the agenda for fair and equal distribution. In this problem of ethnicity the institutional and the identity components of the nation-/state-building agenda come together.

Our program on nation-building presented in chapter 10 does not pretend that it can rid societies of the problems of ethnic divides. Ethnic identities define social relations and social belonging and do not cease to exist. Our program of nation-building is in line with Horowitz' statement: 'It is, as I shall suggest, both fruitless and undesirable to attempt to abolish ethnic affiliation, but not at all fruitless to attempt to limit their impact. ${ }^{28}$ By constructing a layer of national identity, which serves as an overarching sense of belonging and responsibility for the nation-state, I believe we can reduce the negative impacts of ethnic affiliation and processes of exclusion.

Ethnicity as an element of national identity has two components.

Ancestry relates to the primordial orientation within the body of literature on the nation: The nation is born out of a historic presence and our national identity therefore is based on a lineage with our ancestors. It is the ius sanguis approach to national identity: The bloodline that connects us through history defines our national identity. The issue of ancestry plays a role in both non-Western and Western countries. In Europe, for instance, ancestry continues to play an important role in defining the national identity of Germans. German ancestry gives access to German citizenship, even if it relates to ancestors who moved to Russia or the Ukraine over a century ago. ${ }^{29}$ Following the same logic, Hungarian minorities in Slovakia and Rumania were offered Hungarian citizenship based on their ancestral roots.

In fragile states, plagued by internal conflicts and civil wars, the ancestry issue is paramount and relevant from a loyalty-perspective: Ancestry defines to which group you belong. It also serves as the basis for two-way loyalty claims: Ethnic leaders call for loyalty in times of conflict to gather 
support (military, logistic, emotional) and ordinary people in turn may call upon their leaders' loyalty (protection, food and care). In many cases, this loyalty is based on ancestry functions as the replacement of an absent state that has relinquished its people.

Race, the second component of ethnicity, is a sensitive category in social relations. It originates in the $15^{\text {th }}$ and 16 th century, when the European explorers for the first time were confronted with people so different in physiognomy. The definition and categorization of race throughout history is not consistent.$^{30} \mathrm{~A}$ telling example are the very diverse categories used for race in the censuses of different countries. We now know that there is no biological basis for race. The differences in human DNA fall short to explain the differences labeled as racial. What remains is race as a social category that serves to define and highlight distinctions between groups. This is why ethnicity and race sometimes overlap, e.g. African-Americans can be labeled as a race as well as an ethnic group. The main differences between race and ethnicity as social constructs are that ethnicity is based on descent and history, race is based on physical differences; race typically originates in the assignment by others, ethnicity is often based on self-identification; and race always refers to intrinsic differences in human worth, ethnicity can but does not need to do so. ${ }^{31}$

Race is a very powerful notion and racial categories when applied have a profound impact on social relations. In Rwanda, the history of the HutuTutsi conflict is partly due to the racial labels introduced by the Belgian colonial authorities. While defining the difference between the two groups as an ethnic difference would have meant labeling the others as different but familiar, defining the difference as a racial one meant that the other group became labeled as strangers, aliens, from outside, and not worthy of loyalty or compassion.

\section{From open to ascribed identity}

The adjusted Shulman model presented in this chapter which discerns four elements of national identity (civic, religious, cultural, ethnic) is useful because it comprises both open and ascribed aspects of identity. The four elements and their nine components can be placed on a continuum from open to ascribed: 'Citizenship' and 'will and consent' at the one end, 
'ethnicity' and 'race' at the other end, and the other components somewhere in between (e.g. territory more towards the ascribed end and language more towards the open end).

The civic element of identity is the most open. People can access the civic community by embracing citizenship, the political institutions and political ideology of the state. It requires will and consent, one has to respond explicitly and positively to the civic identity, but the hurdles to take are mostly in the mindset, convictions and values of the person, not so much in the rules and regulations of the state.

The cultural element of identity is in theory accessible to anyone living within the borders of the state, but acquiring new languages and traditions is not necessarily easy. Time plays an important role. Often, first-generation migrants have lasting difficulties in mastering a new language, while their children and grandchildren will much more easily become fluent speakers. Language is an important, but at the same time often an impeding factor in facilitating participation in society; migrants who do not speak their host country's language are at a disadvantage and will experience limited access to the economic, cultural and political life. The same goes for traditions. Immigrants from Islamic countries can adopt the typical Christian feasts like Christmas or St Nicholas, but really engaging in these is more difficult. But also in the aspect of tradition the divide will be bridged over time.

The religious element of identity is open for change and personal choice, even though religion is often part of the social fabric, which makes change having potentially important consequences for the social network of people. In Islam changing your religion can be threatening as some Islamic groups see apostasy as unacceptable. For scheduled casts in India changing religion is sometimes seen as a possibility to escape the oppressive and denigrating structure of the caste system. Christian missionaries have shown capacities to create a mixture of their Christian message with traditional religious symbols and rituals, thereby making it easier for people to change religion. The rapid spread of autonomous churches in Africa and Latin America has created a crowded 'market' where people are selecting their favorites and are easily changing their religion. Migration of Muslims to (dominantly) Christian Europe has lead to a narrative of the familiarity of Christianity and Islam, creating a joint platform for religiousness for the existing different religions.

The ethnic element of identity is the most difficult to get access to, with race being more difficult than ancestry. African-Americans, whose ancestors came to the country in the 17th and 18th century, remain blacks in racial terms. For most migrants in Western Europe it is almost impossible 
to identify themselves in ancestral terms with the host nation. Also here, time is an important factor. After generations, migrants can rightly claim to have ancestral roots. Another increasingly important factor is intermarriage, which in a very poignant way makes society aware that the strict boundaries we tend to draw between groups can in fact become much more fluid. On personal and family level homogeneity in ethnic or racial terms is increasingly contested.

National identity is a composite of elements, some of which are more open and others more closed. Addressing the issue of national identity in fragile states requires taking all these different elements into account. A real awareness of the different constituting elements of national identity, both open and closed, and an understanding of identity as social construct to define social boundaries in response to changing social contexts create entry points to tackle the challenge of nation-building. National identity is not a mysterious, thick, reified reality - it is fluid and malleable and a most significant part of building stable, secure, inclusive and fair states. When Fukuyama and US-based think tanks, like the Rand Corporation, claim that nation-building is not doable for the international community, it is because they have not taken the time to really deconstruct what national identity entails. 


\section{Case}

\section{Bangsamoro nation}

Since 1971, a low-intensity conflict is raging on Mindanao, an island of the Philippines where most of the country's five million Muslims, belonging to the Moro ethnic groups, live among a majority of Christians. The Islamic Moro community started an armed struggle for independence in response to the systemic discrimination and marginalization they were facing. Regional marginalization (the Mindanao periphery vis-à-vis the Manila-Luzon center) as well as religious and cultural discrimination (the Islamic Moro community as a minority in a dominant catholic country) created the basis for this conflict.

The conflict between the Moro Islamic Liberation Front (MILF), the main movement for Moro self-determination, and the government is quite different from the other low-intensity conflict in the Philippines, the one between the communist New People's Army and the government. While the New People's Army attempts to overthrow the government to establish a socialist regime, the Moro liberation movement focuses on self-determination. It does so in response to the unwillingness of the government and the dominant culture to be inclusive towards the Moro community in all aspects (religion, culture, socioeconomic position).

Since 1971, between 120,000 and 150,000 people died and more than two million people were internally uprooted. The economic costs of the conflict are estimated between US\$2 and US\$ 3 billion..$^{32}$ Although the Philippines does not appear on any of the fragile states lists, the conflict has made Mindanao a pocket of fragility in a stable low middle-income country.

In March 2014, after seventeen years of negotiations, a peace accord was signed between the government of the Philippines and the MILF. The 2014 peace deal orders the creation of an autonomous political entity in western Mindanao, called Bangsamoro. Bangsamoro will receive a fairer share of revenues from the region's natural resources, as well as having budgetary autonomy, a parliamentary form of governance and shariah courts. In exchange, the MILF agreed to give up arms as well as its demand for a separate state.

Although a proper nation-building strategy has not yet been developed, the case of Bangsamoro underlines several issues that are at stake in the nationbuilding agenda. 
Firstly, the political agenda of identity is dominant over the socioeconomic agenda. The leadership of the MILF has repeated time and again that the problems of religious and cultural discrimination and regional marginalization cannot be solved by socioeconomic development. They deem socioeconomic development outside a framework of political recognition of identity and selfdetermination and even interpret it as a counter-insurgent strategy to undermine the legitimate aspirations of the Moro community. There is no underestimation of the urgent socioeconomic needs of the Moro (part of Bangsamoro would rank very low in the Human Development Index), but they are convinced that socioeconomic development without political autonomy and recognition of the Moro-identity will not bring sustainable solutions.

Secondly, the Moro movement is the result of the failure of the Philippine government to create a national identity that includes the Islamic Moro community as an equal group within the nation-state. The Americans at the beginning of the 2oth century after the Paris Treaty with Spain, by which the US bought the Philippines) defined the Moro problem as a question of 'method or form of administration by which the Moros (...) can be governed to their best interest (...) for their gradual advancement in culture and civilization, so that in the course of a reasonable time they can be admitted into the general government of the Philippine islands as qualified members of a republican national organization.'33 This patronizing attitude based on the notion of the Moro as backward, has remained dominant since. The Philippine Human Development Report in 2005 added that 'One might say that the post-colonial Philippine government's definition of the Moro problem remains essentially the same including its corresponding policy solution of national integration.'34 The fact that the Philippine government has allowed the discrimination and marginalization of the Moro population and not spoken or acted against their portrayal as second-class citizens and an insignificant minority in the country, has made the struggle for self-determination unavoidable. It is telling that the government never tried to develop a comprehensive and inclusive answer to the legitimate grievances of the Moro. From the beginning of the peace negotiations (Tripoli agreement $\left.1976^{35}\right)$, the government took the autonomy path as the way out of the conflict.

Thirdly, the autonomy agreed upon by the government and the MILF is, from the Moro perspective, accepted as the next-best solution if independence is

33 http://hdn.org.ph/wp-content/uploads/2005_PHDR/Chapter\%202\%2oEvolution\%20of\%2o the\%2oArmed\%20Confict\%200n\%2othe\%2oMoro\%2oFront.pdf (accessed 11 October 2015) 34 Ibidem.

35 The first peace agreement of 1976 (the Tripoli agreement) states as first agreed outcome of the negotiations: 'First: The establishment of Autonomy in the Southern Philippines within the realm of the sovereignty and territorial integrity of the Republic of the Philippines.' (my italics) 
not possible by negotiations nor by a military victory. This autonomy was the basis of the Framework Agreement on Bangsamoro (FAB, 2012) and the Comprehensive Agreement on the Bangsamoro (CAB). ${ }^{36}$ As an autonomous territory with a parliament and a cabinet, with the responsibility to collect taxes and have its own police and shariah law institutions, autonomy was maximized. The peace agreement clearly acknowledges: 'Underlying the CAB is the recognition of the justness and legitimacy of the cause of the Bangsamoro people and their aspiration to chart their political future through a democratic process that will secure their identity and posterity and allow for meaningful self-governance'.

Fourthly, the ambition of the Bangsamoro can be characterized as building a nation-state in the modern sense. The Moro people took the position that a national identity without a state structure would not solve the problem. And like all nation-states they trace back their history and existence to the precolonial times. The notion of the Bangsamoro Homeland is connected to that. To create space for the Moro identity and culture and for their Islamic values, the connection to state-building is deemed necessary. The intertwined reality of nation and state is the basis of the Bangsamoro.

Fifthly, for both the Bangsamoro nation and for the Philippine government the issue of nation-building will remain on the agenda: For autonomy as political and institutional solution is not the final answer. For the autonomous Bangsamoro government the challenge will be to create an inclusive national identity. The reality of demographic changes, due to internal migration, has led to diversity of the people in the Bangsamoro territory: Settlers and indigenous people have to be included in the nation-building process to avoid new majority and minority issues. For the government of the Philippines the challenge remains to make Bangsamoro an integral part of the republic. If they do ignore this challenge, the process of autonomy and nation-building will undoubtedly lead to new secessionist dynamics.

The government and the future autonomous Bangsamoro government will have to jointly deal with the issue of the Moros and indigenous communities that are not included in the autonomy process. These communities can use an opt-in provision in the autonomy agreement if a majority in a plebiscite will decide so. This could lead to scattered communities being officially part of the Bangsamoro without being physically connected to it. The government of the Philippines has promised that it 'shall ensure the protection of the rights of the Bangsamoro people residing outside the territory (...). And undertake programs for the rehabilitation and development of their communities'. Even the new 
Bangsamoro government may provide assistance to these communities in their economic, social and cultural development. Which could lead to programs by the Bangsamoro government outside their territory. It will be of interest to see whether the Philippine society will be more aware of the Moro/Muslim community as part of their national identity that deserves space or whether the implementation of an autonomous Bangsamoro will be seen as a solution of the problem 'outside', no longer affecting the Philippine identity. 



\section{A program for nation-building in fragile states}

In the previous chapters we gathered the building blocks for nationbuilding: The nation and the state, the contested concept of fragility, the citizen as the fundamental principle of sovereignty, the different elements of national identity. Can a coherent program for nation-building that is relevant for fragile states be designed based on these elements? Yes it can. Nation-building in fragile states is doable as long as we start from a constructivist viewpoint and do not expect to achieve a log-frame, lineair model. Nation-building is a complex and open-ended process, but that does not mean we should shy away from embracing the challenge. This final chapter presents some building blocks for nation-building without pretending to offer a straightforward intervention scheme: Every context is specific and requires a tailor-made approach. The first part of this chapter discusses the content of nation-building: What are the elements of national identity that need to be worked on? We have argued that homogeneity is not an achievable goal, nor a desirable one. Out of respect for the diversity of identities present in fragile states, we have to build a sense of national belonging that is overarching and which leaves room for group-identities to exist alongside the national identity. Secondly, I will focus on the processes that are necessary to make nation-building a successful undertaking. A consistent, carefully designed and inclusive multistakeholder approach is the core of this process.

Thirdly and fourthly, we will look at the institutions and actors that must be involved to make nation-building work. Although there is no doubt that domestic actors should lead the process, I do see a facilitating and supportive role for international actors.

Subsequently, we will reflect on the program of nation-building in relation to the three modes of fragility that were identified in chapter 3 , based on the triangle of fragility by authority, legitimacy and capacity (or the lack thereof). The chapter will close with an answer to the possibility of nation-building given the reality of oppressive regimes that are unwilling to share power and be inclusive.

This chapter is a walk into unchartered territory. There is hardly any literature available on a comprehensive nation-building agenda that could be used as reference or on which results I could build my proposed program. 


\section{Content: The elements that make up national identity}

In the previous chapters I defended that diversity of identities is the reality of national sovereignty. This reality defines the space for any meaningful debate about nationhood and national identity. Nation-building is not a zero-sum power game in which competing identities fight for dominance and where the winner takes it all, at the expenses of all the other identities. I ruled out that homogeneity is an achievable objective in our globalizing, interconnected world. I do not exclude the possibility of a process of convergence, which will result in some common elements in a national identity as happened in Europe, but this is not something that can be planned. Nation-building must be programmed from the perspective that a national identity will exist alongside various subnational identities. That is not a problematic idea. There is a large body of sociological and psychological literature on the concept of multiple identities in individuals: We all have and live many identities, including our sexual, professional, linguistic, cultural, religious, ethnic and physical identities. And we constantly arrange and rearrange these according to the contexts and the circumstances. When I am a Pashtun in Afghanistan and I speak the Dari language and I am a Sunni Muslim, then there is a coherent pattern as most of my fellow Pashtuns share these features. But if at the same time I am a well-educated woman working as a consultant for an international agency or company, I do no longer seamlessly fit into the dominant Pashtun pattern. Most likely I will draw on these identities differently when attending a company management team meeting than when together with my extended family I am celebrating Eid al-Fitr at the end of Ramadan. There is no need to erase or deny certain identities in order to let others be prominent at times. Although in principle rearranging multiple identities is possible, whether people are willing to manage their different identities in a flexible way will depend on the context.

The question whether national and subnational identities can exist side by side was part of the 2008 Afrobarometer survey program carried out in 16 countries in sub-Sahara Africa. ${ }^{1}$ The results presented in the working paper titled National versus ethnic identity in Africa: State group and individual level correlates of national identification ${ }^{2}$ show that only $5 \%$ of all respondents identified themselves in purely ethnic terms. $31 \%$

1 http://www.afrobarometer.org (accessed 29 June 2015)

2 http://afrobarometer.org/sites/default/files/publications/Working\%2opaper/AfropaperNo112.pdf (accessed 29-06-2015) 
identified themselves exclusively in terms of their national identity. The majority $64 \%$ identified themselves with both their ethnic and national identity (ethnic dominant over national $11 \%$, national and ethnic equal $42 \%$, and national over ethnic $11 \%$ ). In other words, for two thirds of the African citizens participating in the survey both identities were real and relevant. They held their ethnic and national identities in parallel, even if probably assigning different values to both in different contexts. ${ }^{3}$ We must note that fragile states like the DRC, Somalia, Sudan and the Central African Republic were not included in this research. Mali and Nigeria were included, but the research was conducted before the crises in both countries broke out.

The way I conceptualize national identity is that it is the overarching identity, shared by people from different ethnic, linguistic and religious groups, like a layer or skin that covers or holds together their group identities. That does not mean that national identity is merely a lowest common denominator identity, a narrow identity of minor issues that nobody objects to like the national anthem, flag, the national soccer or cricket team, or independence day. These symbols of national identity are important, but especially in a fragmented country one cannot expect them to be strong enough to generate a deep emotional commitment. Such a minimal identity will not create the sense of belonging that we aspire to. The process of exchange and sharing by different groups (see below under process) should lead to a richer bouquet of issues that people adopt as features of their national identity. A selection of historic heroes and founding stories of different ethnic groups, celebrations or sacred places of religious communities can all be integrated into the national identity.

The four different elements of national identity (civic, religious, cultural and ethnic) that we identified in the previous chapter do not carry the same weight on a national and subnational level.

Civic identity/citizenship. Building on what we described in chapter 4 about citizenship as being able to overcome class differences and therefore being able to create a foundation of equality in an (from class perspective) unequal society, I advocate to make citizenship, i.e. civic identity, the basis of the national identity we want to build. Ideally, citizenship - the first and central component of civic identity - is more than just a formal identity: A

3 The balance of ethnic and national identification is not stable. Benn Eifert, Edward Miguel \& Daniel N. Posner published research that found that ethnic identity becomes more salient in the run-up to elections and that this salience increases when the competiveness of the elections is higher: Eifert, Miguel \& Posner 2010, p. 494-510. 
deeply-felt and rich notion of citizenship can serve as a strong foundation to bear and hold together the diversity of society. It is important that citizenship should be disconnected from ethnic, religious, linguistic or any other subnational identity, i.e. being a citizen can never be dependent on being part of a specific ethnic, religious or linguistic group. Mamdani (2005), in an analysis of the troubling colonial heritage of citizenship, ethnicity and race, clearly shows the problems that arise if citizenship, membership of the polity, becomes part of ethnic identity. ${ }^{4}$ The same would be the case if citizenship was made part of religious identity. Because citizenship in the modern nation-state is the foundation of sovereignty, being a citizen of the state should not depend on one's other identifications. The political community is distinct from the cultural, ethnic or religious community.

This principle still leaves a lot of questions unanswered about who is eligible for citizenship, for bearing the civic identity of the nation-state. If we decide that living on the territory of the nation-state (ius solis) is the most appropriate way to define citizenship, fragile states will have tricky questions to answer about what to do with those people who left the country involuntarily due to civil war or other forms of violence. Another issue faced in many fragile states is that of kinship ties in cross-border regions.

Ethnicity. If civic identity must be considered the foundation of the national identity, ethnicity and race are features too complex to accommodate in a national identity. Making ethnic identity or race part of the national identity will enshrine exclusionist features in the national identity, which will threaten minorities and will make migrants second-class citizens - or refuse in-migration altogether. Ethnicity and race as ascribed identities cannot and should not be part of the national-identity discourse. Traces of ethnic history (heroes, places, stories) can become part of the national identity, but it is only by transferring them from the ethnic realm to the national realm that they offer the possibility for identification for all of the people. Ethnic identity can be part of a parallel subnational identity (see above) that is lived by communities who nourish their ethnic traditions.

Religious identity. In almost any given nation-state, the diversity of religions and denominations within religions is far too great to justify making a specific religion part of the national identity. The examples of Iran and

4 http://scholar.google.nl/scholar_url?url=https://xa.yimg.com/kq/groups/20674633/ 1245888392/name/revisedMamdani.pdf\&hl=nl\&sa=X\&scisig=AAGBfmılS2dD3mgGoiwK2VX oA93Rhpf_xg\&nossl=1\&oi=scholarr (accessed 29 June 2015) 
Israel show that making a specific religion part of the national identity is rife with problems. That does not exclude that at a more general level the nation-state identifies religion as an important part of its identity: The spiritual world may be part of its reference in the perspective on its existence. The nation-states does not by definition need to be a secular state that bans religion from the public and political discourse. The 'God bless America' phrase is widely accepted as part of the American identity and the annual State of the Nation Address in the Philippines is opened with prayers by a Roman Catholic, a Protestant and a Muslim representative. But it firmly goes against any effort at building nationhood to capture the state for a specific religious belief or practice. The nation-state accepts the diversity of religions and religious practices without expressing a preference and privilege. At the subnational level, all sorts of religious beliefs and practices can be present and expressed as part of group identities as long as this happens within the framework of the national law.

Cultural identity. The inclusion of cultural identities within the national identity asks for a similar approach as to religion. People often share cultural beliefs and practices across ethnic and religious divides, even if these are not national in terms of being shared by everyone. Many nation-states have a national culture in food, music, celebrations, clothing styles, etc. Identifying and celebrating these shared cultural features is an important first step in building nationhood. These are the important quick wins, the low-hanging fruit, in a complex and sensitive process. Widely shared cultural practices help to emphasize the similarities in a reality of diversity. More specific and idiosyncratic cultural identity features should remain part of subnational identities, where people should be given ample space to identify with and live these cultural traditions.

There is one cultural component that merits specific attention: Language. It will be difficult to create a national sense of belonging without a common language. To execute citizenship, the membership of the political community, communication and mutual understanding in a language that is shared by the population of the nation-state is a prerequisite. Without this, there will be no level playing field in political deliberations about the common interests and the sharing of resources. Without a common language, those who speak the dominant language are at a clear advantage when it comes to political decision-making. It is in the interest of all subnational identity groups to have a shared language in order to create a level playing field. This does not rule out the possibility of more than one official language, but in 
order to create the basis for communication and decision-making a nation needs clarity about what the common language(s) is (or are).

The battle over language is a hard-fought battle and seen by some as proof that nation-building is impossible: Making language part of nation-building by definition results in nation-destroying. ${ }^{5}$ As we discussed in chapters 8 and 9, language is extremely important in people's identities as it is our primary avenue for giving meaning to our thoughts and feelings. We also saw that many people in former colonies (the whole of Latin America, large parts of Africa and Asia) are polyglots: They speak the official state language (often the colonial language), another vernacular as alternative national language, and one or more tribal languages. This polyglot reality offers opportunities to solve the problem of language, but it is unavoidable that the result will be one or a limited number of official national languages and many dialects. If a nation wants to avoid entering into a shallow horsetrading process and approaches the process of building a national identity from the perspective of diversity as richness, then there is space to offer 'compensation' to those language traditions that are not chosen as the national vernacular. These linguistic traditions can provide stories, songs and heroes to include into the national identity.

Nation-states are embedded in the ongoing process of globalization - and so is national identity. In the nation-building discourse globalization is usually considered a threat to national identity. I believe that globalization may instead prove conducive for national identities to develop and even flourish. Until globalization became a dominant feature of today's world, nation-states were considered all-encompassing: Who we are and how we feel about ourselves was strongly defined by the language, food, history, stories, music, etc. of our nation-state. Even religion (with Catholicism as a possible exception) has a very national face. Although the essence of religion (Christianity, Islam) was not confined to nation-states, its sociological features often were nationally defined: The mainstream Protestant churches in Europe had a strong national identity with the monarch as the head of the church and Islam has a very decentralized structure with no central authority.

The previous all-encompassing character of the nation-state did put a strain on the national identity, which had to ensure that all citizens could identify with it and at the same time that this national identity was markedly different from that of other nation-states. I believe that globalization is easing this strain: The nation-state does no longer need to load all the 
aspects of our identity with specific national content. It is okay if we feel Italians in terms of our culinary identity, Indians in religion, Africans in music, Anglo-Saxons in language - this does not make us traitors of our national identity. This process is not only happening in Western Europe, where this diversity of identifications has become well-accepted. In all African countries one can find pizza on the menu of local restaurants, music and film have become international and the MBA is a coveted certificate for young university students. Medical standards are increasingly globally accepted and traditional healers are blending their traditional knowledge with new foreign insights.

Such an international approach offers a new perspective for the problem of the artificial boundaries of the colonized states that have divided ethnic groups and sometimes even dispersed them over more than two countries. Instead of trying to create homogeneous homelands by redrawing borders, we should take globalization and internationalization as a helpful framework for living part of our identity in a cross-border relationship. Nation-states have to accept that these cross-border identity relations exist without accusing people who adhere to them of being disloyal citizens of their nation-state. In a globalizing world, national identity can never be a zero-sum game. Migration is part of and reinforces this process. Large diaspora groups spread over different continents often maintain strong ties with their country of origin. They bring in new ideas and practices, influence the national identity of the country and create a reference to identities foreign to the nation-state. In Europe, several political parties stress that this process of migration threatens to undermine the national identity. But even those who are critical of the influence of migration and are anxious about the future of their national identity, are selective and do embrace parts of the international influence.

\section{Process: Nation-building is a learning process}

Nation-building is not only content, it is also and to a large extend process as Brubaker and Cooper in their notion of identification have stated. If we know which components eventually will have to be included in a national identity, and which features need to be left out, the question remains: Through what process can this national identity be created? Here we focus on the first phase of nation-building in fragile states, when fragility is still lingering and the process of nation-building, complementary to state-building, is at its very early start. The most important rule is that nation-building needs 
to be an inclusive process, which offers opportunities for all groups to participate and to contribute to define the features of a national identity. All identity groups and communities within the country are stakeholders in the process, with each of them contributing from their own reservoir of identity components. A national identity that emerges in fragile states as the result of a conscious design process will be different from a national identity that emerged after a centuries-long process. For one thing, it still needs to stand the test of practice: Will this national identity be offering identification to people, will it be seen and felt as complementary rather than competitive or even incompatible with subnational identities? This means that a long-standing commitment to monitor the process of building national identity should be present as well as a mechanism for making modifications. National identity as a social construct is ever evolving and therefore nation-building is a continuous, open-ended process in which there will always be room for change.

\section{Multistakeholder process}

To be inclusive, the process of constructing a national identity should be consciously set up as a multistakeholder process in which all groups are invited to participate. There is no criterion for exclusion. Group size or geographic spreading should not be an issue, if only because in fragmented countries the application of such criteria is bound to be arbitrary. Organizing this process in a non-exclusionary way is anything but easy, but it should be decided on a case-to-case basis who are the stakeholders with vital representational interests. Perhaps professional unions like shoemakers, bakers and hairdressers will register, only to be decided later that as a group they do not have a relevant stake in the nation-building process. Pastoralists, on the other hand, do have a real stake in the process because their 'profession' rather is a way of life with a specific culture. The selection will happen as the process goes along. Eventually, something in the way of a citizen forum (see below) will be established and given responsibility for the weighty task of defining the national identity.

It is important that there is a clear mandate for the process of nationbuilding as complementary to state-building. The mandate is, like the process of nation-building, self-referential. In the spirit of the sovereignty of people, it is the people - by willing to participate - that together build the legitimacy if the process. As intertwined with state-building, the state should acknowledge this legitimacy and accept the representatives of the multistakeholder process as their counterparts. The nation-building 
process is not meant to attract those groups that have mainly economic or political interest and want to secure these in laws and regulations. It is not a 'second-chance' project for those who did not manage to push through their interest in the state institutions.

Regarding the four elements of national identity, the meaning and content given to civic identity or citizenship, which is fundamentally equal to all, is by definition an issue for all. No specific group representatives are needed because everyone is entitled to speak about the desired civic identity of their country. The elements of religion, ethnicity and culture, including language, on the other hand, should each have their own representatives. Religious leaders can be at the same time members of an ethnic or a linguistic community, but as the chosen representatives of religion they should focus on that aspect of the national identity. It is important to create richness and diversity in the process, and to avoid lumping together different identities in order to rush to conclusions and limit the options. Specific attention is needed for the identity groups of women and youth. In any country, around half of the population is female and in many fragile states nowadays nearly half of the population is below the age of 25 . Although being female or being young are as such not part of the national identity discourse, these groups deserve a place at the table.

What the role of the diaspora should be in the process of nation-building remains an open question. Research shows that the relationship between people who stayed in the country of origin and the diaspora is complicated. People from the diaspora provide financial support to families, communities and possibly political groups, they play a role in the country's social and political development, and they are active in international advocacy. They serve as bridges between the country and the global world, offering opportunities and connections people would not otherwise have had. But people from the diaspora did not share the experience of those who stayed behind. They are often considered outsiders who give their opinions and advice from an outsider's perspective.

\section{Practicing citizenship}

The process of nation-building should be seen as a process of learning and practicing citizenship in the republican way, as was discussed in chapter 4 . It is a training ground for what should be the prevailing culture of civic engagement with the nation-state. Republican citizenship has three aspects that are important success factors for the process of nation-building: 
1 Citizenship is the capacity to make judgments and take decisions from the perspective of the common good. Citizenship as an office makes a citizen responsible for the well-being of the community at large. It pulls him/her out of the particular and parochial realm of the group and puts him/her in the realm of the public, where all people's interests have to be taken into account. Building the national identity is an excellent practice for citizenship as all citizens bear responsibility for the flourishing of the nation-state.

2 Citizenship is the competence to engage in exchange and conversations. In the process of nation-building, more is required than putting opinions, convictions and experiences on the table. The process requires 'deep listening' to all the others around the table. It should be a real conversation in which every group has something valuable to offer and has a legitimate right to be heard.

3 Being a citizen of the nation-state automatically puts all people in a framework that is broader than the nation-state because part of the legitimacy of the nation-state as institution is derived from its position in the international community of nation-states. Processes of nationbuilding do not happen in isolation. And citizens are themselves increasingly engaged in webs of international connections and relations.

Citizenship as an office requires practicing and learning. Although most people are citizens of a nation-state purely by birth - only migrants sometimes need to pass an exam to be bestowed this status - the competence to act as a citizen is not an innate capacity. In fragile states where civil war and distrust have trained people in self-interest, the competences of citizenship have to be learned and deepened through training. The process of nation-building is an excellent framework for this learning process and will be 'leadership by example'. If the chosen representatives of the communities show the behavior of republican citizenship, their message will gain credibility.

\section{Knowledge}

There is an important role to play for researchers and scholars in the process of nation-building. Even though representatives of communities and identity groups are the ones to take decisions and to create a solid base, the contribution of scholars can open up windows that are overlooked. Historians, linguistic experts, cultural anthropologists, experts in religious studies can bring in aspects that are outside the scope of community representatives. 
And these scholars also have a role to play in questioning opinions and convictions that are put forward without a solid credibility. Sound research is needed to verify or falsify claims of certain identity beliefs and practices as unique or being part of an ancestral heritage. More than once they are shared by fellow citizens or are the social constructs of a (recent) past.

\section{Institutions: Nation-building requires an institutional setup}

If nation-building is a complementary effort to state-building, it also needs an institutional framework parallel to state institutions. I propose that at the very center of the nation-building process is a citizen forum, which brings together the chosen or elected representatives of the subnational identity groups for deliberations and decisions. The citizen forum acts in parallel to the parliament, but has no legislative power. It has the right to submit proposals to the legislature in so far as these proposals are within the mandate of the forum. It has a long-term time horizon. A citizen forum should not be a one-off process. If nation-building is a design process, the results will not immediately have the same robustness as that of national identities that were formed and refined in a continuously iterative process, shaped and tested by reality, over decades or even centuries of time. The design process of fragile states will require subsequent processes of monitoring and refinement and this requires a constant and ongoing dialogue on issues of nation-building and national identity.

One might think that organizing an all-inclusive citizen forum that welcomes representatives of all subnational identity groups is bound to end up being unmanageable. The examples of the Loya Jirga in Afghanistan and the Lekgotla in Southern Africa tell a different story.

The Loya Jirga, which could be translated as 'grand assembly', is the gathering of representatives of the Afghan ethnic communities and is called together for important issues at national level. ${ }^{6}$ Its history dates back to the 18 th century and the institution has played a role in the transition after the ousting of the Taliban in 2001. In 2002, the Loya Jirga approved Hamid Karzai as the interim president of Afghanistan as well as his provisional administration, and in 2003 they gathered to discuss and finally adopt

6 Wardak.http://www.institute-for-afghan-studies.roashan.com/AFGHAN\%2oCONFLICT/ LOYA\%20JIRGA/Jirgabywardak.pdf (accessed 21 October 2015) link doesn't work, try: http:// unpanı.un.org/intradoc/groups/public/documents/apcity/unpano17434.pdf (accessed 8 June 2016) 
the constitution of Afghanistan. The Afghan constitution has a provision for the Loya Jirga 'the highest manifestation of the [will of the] people of Afghanistan' (Art. 110). In 2010, Karzai called the Loya Jirga together once again to get a mandate for his negotiations with the Taliban. This is interesting: Although the Afghan parliament is the legitimate representation of the Afghan people, the Loya Jirga was considered important to give a legitimate mandate for the sensitive negotiations with the Taliban. The Loya Jirga is a large gathering: In 2002/2003 and in 2010 some 1,500 representatives, not organized in political parties with party discipline and a party platform of policies came together for the deliberations and decision-making process. The Loya Jirga is an institution of consultation and decision-making. In essence it is consultative but the results of the Loya Jirga are seen as guiding. And although it seems a large, unstructured process, the Loya Jirga works with smaller groups that build decisions from the bottom upwards.

In Southern Africa, the Lekgotla is a similar model of deliberations and decision-making. In a Lekgotla all members of the community come together to discuss issues that are vital for the community. Broad consultations create an atmosphere of exchange and listening and they are important to enrich the discussions: By bringing in the different perspectives and interests all members of the community are heard and new perspectives are opened that facilitate the decision-making processes. The Lekgotla model has also been put in practice in large firms where all employees (sometimes 1,00o and more) are brought together.

In Liberia, a process runs of national dialogue 'Liberia Rising 2030'. It is a nationwide process to develop a long-term vision for the future of this country. It is a state-building and nation-building process in one. It develops policies that should make Liberia a middle-income country by 2030, while at the same timing aiming to build social cohesion. ${ }^{7}$

Countries can build on the examples and experiences of such communal practices for setting up a citizen forum that fits their context. Of course the Internet and new media will change the reality of a Loya Jirga and a Lekgotla and will require new organizational processes and procedures, but they will also facilitate the inclusiveness of the process. A citizen forum should (without being exhaustive) deal with issues like: ${ }^{8}$

7 http://www.pambazuka.net/en/category.php/features/87998 (accessed 15 September 2015)

8 Dealing with grievances and injustices of the past is always a sensitive issue in fragile countries. Transitional justice and truth and reconciliation processes are important mechanisms. Whether dealing with the past should be part of a nation-building process is open for further 
- the national languages and the role of dialects in communication and education;

- national holidays, national memorial places;

- dual citizenship and the issue of (forced) migrants: How to maintain a relationship with nationals outside the territory;

- the design of a curriculum on national history in the education system;

- the religious identity of the nation-state: Religious symbols, religious practices and national celebrations;

- the space for religion and traditional practices in law (shariah, indigenous decision-making and representation);

- the identification of traditions that deserve to be included in a national heritage list.

The citizen forum should not have a legislative power, to avoid unhealthy competition with the political institutions of the nation-state. Proposals by the citizen forum should be translated into legislation by these political institutions. However, like the Loya Jirga in Afghanistan as a representative body, the citizen forum should have a legal status to strengthen its position.

The citizen forum does not have to be limited to the national level. The model is perfectly fit for application at other levels to create a regional or local sense of belonging. Regional and local citizen forums are the place to discuss the results of the national forum and they serve as a platform to discuss regional issues of identity. Not all regional and local issues are relevant for the national level, and therefore a regional/local structure creates the space where identity groups can address identity issues that are pertinent and urgent to them whilst keeping the national citizen forum free of too many regional and local issues.

Organizing groups along different agenda-issues of the forum could be a way of organizing the process and keeping it manageable. Representatives of these different streams could form a steering group to coordinate and aggregate.

\section{Formal and non-formal education}

Nation-building requires not only a design and definition process led by chosen representatives of identity communities, it also requires the spreading

reflection. There is a risk to put too much burden on the process of nation-building, but there is also the opportunity to create synergy between processes of nation-building and transitional justice as both contribute to social cohesion in society. 
of the results and conclusions to the population. Bringing nation-building into the curriculum of primary and secondary education is an important instrument in this.

Many scholars consider Tanzania a successful example of nation-building in post-colonial Africa. After independence, a national curriculum for nation-building was developed and implemented in the country. Although there were other important factors (the visionary leadership of Julius Nyerere and the equal distribution of the ethnic groups), education is seen as an important pillar for Tanzania's success in nation-building.

However, those outside the education system should also be reached and this can be achieved by working with civil society organizations that are deeply rooted in the communities: Religious communities, women's groups, and neighborhood groups. There is an important role for the representatives of the identity communities, members of the citizen forums, to engage their communities in the process.

When developing educational material, it should be kept in mind that due to civil war and conflict at times large parts of the population had no access to the formal education system.

\section{Media}

The citizen forum should have access to the people through a broadcasting station that reaches out to all people. As a public service, which is not by definition a state-run service, it should serve the need to get people everywhere in the country involved. Radio has proven to have a wide coverage and it is essential for information and participation. But also the new opportunities of Internet and social media should be part of the instruments a citizen forum has at its disposal for disseminating its work and the results.

\section{Actors: Nation-building is a national endeavor}

Nation-building is a process led by domestic actors. As part of the social capital of the country, those who are supposed to feel the national sense of belonging are the ones to define what it is and what it means. ${ }^{9}$ International actors, who are around only temporarily and whose nationhood lies elsewhere, are outsiders. 
Citizenship defines the fundamental eligibility to be part of the nationbuilding process. Because citizens are the key actors in the nation-building process, defining citizenship is important, but in fragile states it is complex due to the processes of (forced) migration and the lack of registration systems. In chapter 4 we referred to the ius solis and ius sanguis principles and the reality that both are difficult to apply in a pure way. Fragile states are confronted with substantial numbers of people who live outside the country, but who still are citizens and many of whom want to be part of the process of nation-building. An exclusive ius-solis criterion for citizenship could exclude all these involuntary migrants and should therefore be complemented by ius-sanguis elements to give access to participation to those who have roots of descent, language or culture.

\section{The role of civil society}

Civil society is a key player in the process of nation-building. Nation-building is a bottom-up process to build an overarching identity at the national level out of the diversity of identities that exist at the grassroots level of nation-states. It tries to organize the social capital that exists at grassroots level and lift it up to national level. Too often the idea exists that fragile states are blank sheets without valuable systems and structures and where every process has to start from scratch. The reality is that there is a lot of social capital in these societies. It is exactly this social capital that made people survive the crisis of violence and civil war. The social capital kept rudimentary systems of food provision, healthcare, spiritual care going. The challenge of nation-building is to make this social capital relevant for the building of a national sense of belonging. Here the distinction between the bridging and bonding of social capital is important. In times of crisis and war social capital works in favor of bonding: It strengthens the ties between people based on kinship or religion or local presence. Because people are in survival mood and other relevant actors such as state institutions are absent, the social relations become crucial and often the only reliable source of support. Relations of trust with neighboring groups have disappeared, cleavages have become deeper: ${ }^{10}$ The bridging part of social capital, the capacity to reach out to people outside the community, has decreased. The process of nation-building is a process of restoring the bridging quality of social capital.

10 Weijer \& Kilnes 2012. http://ecdpm.org/wp-content/uploads/2013/10/DP-135-Civil-SocietyInternational-Engagement-Fragile-States-2012.pdf (accessed 10 July 2015) 
Civil society is the space where people organize themselves through diverse structures. It is not the straightjacket of representative democratic systems where people are represented along political party lines. Among civil society there are NGOs with a clear governance structure and juridical institutional provisions. Interest groups like trade unions are part of civil society. More market-oriented organizations like cooperatives are part of it too. Religious groups are important actors in civil society. ${ }^{11}$ Ethnic and tribal organizations are important actors in this domain, even if their role is sometimes seen as exacerbating conflict. And there are numerous informal groups that organize themselves in neighborhoods, communities, credit and saving groups. Civil society is a vibrant reality, even in fragile states, although most of the time unnoticed by international actors and donors who select their partners based on institutional and formal criteria. ${ }^{12}$ While the lack of a formal and institutional setup of civil society is seen as a problem for state-building, because organizations cannot comply with donor standards for organizing and reporting and are not able to operate in log-frame models, this is not a problem for nation-building, where the basic condition for participation is not effectiveness or efficiency, but legitimacy: Does the civil society organization represent a constituency in the nation-state that rightly claims a role as participant in the process of nation-building?

\section{The role of elites}

In nation-building elites play a pivotal role. They are the ones who stage civil war and conflict by mobilizing their communities and claiming to defend their rights and interests. They are crucial in peacemaking processes too, because peace agreements depend heavily on the capacity of the political elites of the warring parties to forge a deal that is acceptable for all. As leaders of identity groups, elites subsequently also play a significant role in creating a national sense of belonging, which may include promoting a shared identity with former rivaling groups. Research on violence and social order has revealed the crucial role of elites, the strategies that they employ to remain in power, and their willingness or reluctance to share power and resources. ${ }^{13}$ There is little reason to be optimistic about the willingness of elites to engage in processes of nation-building, unless they 
see the opportunities this provides for strengthening their position and power base. However, it would also be too cynical to accept the role of elites as de facto obstructing a process of nation-building. In all conflict-affected countries, the presence of elites is a reality that cannot be denied and it does not make sense to a priori deny them a role in nation-building, or state-building for that matter. But it would also be too pessimistic too assume that the role of elites is the only relevant factor in building a nationstate. After peace-making, tensions will decrease, strict loyalty will be less important, there will be more space for diversity of people and groups. After pace-making in all conflict countries we see the emergence of new social initiatives and civil society organizations for voice in the public debate, even if their social, political and economic power is limited, compared to the vested elites.

\section{The role of the state}

Out of the principle of complementarity between nation-building and state-building follows that the institutions of the state have a role to play in the process of nation-building. The legitimacy of the nation-state lies with its citizens and nation-building processes can be successfully implemented only in the intertwined relation between nation and state. The state has to provide the political legitimacy to the process of nationbuilding: The citizen forum should be based on the legal provisions issued by the state. It is important to avoid a competitive relationship between the political institutions of the state and the citizen forum as the main institution for the nation-building process. As contended earlier, the citizen forum is therefore not part of the legislature. It needs the political institutions of the state to adopt its results and proposals into laws and regulations. The state in turn should open its education system to integrate the outcomes of the nation-building process into the curricula and for the same purpose the state has to provide the citizen forum with access to public media.

The state should accept the citizen forum as an independent body with space to maneuver and to act on its own behalf. A strong political mandate that creates independence for the citizen forum is necessary to avoid regular political interventions and instrumentalizing of the nation-building process by political actors. Of course such interventions will happen and politicians will try to use the citizen forum for their own power struggle, but a strong mandate and sufficient support by the state can maximize a balanced relationship between the state and the citizen forum. 


\section{The role of international actors}

If nation-building is a national process, led and defined by national actors, what role do international actors play? International actors are often the indispensable brokers of a peace agreement to bring civil war and conflict to an end (see chapter 6). And they are important actors in state-building by providing expertise and financial resources. In the process of nationbuilding their role is much more modest. This may not be easy for them to accept. In fragile states, international actors are used to making themselves appear very important, bringing in huge amounts of money and regiments of consultants and advisors. Their footprint is rarely modest and it remains to be seen whether international actors are able to leave the national actors in the driver's seat of the nation-building process. There are two ways in which international actors can contribute:

First, they can play a role as facilitators in the complex multistakeholder process. But different from the peacemaking process, where they take the lead in getting warring parties around the table, drafting agreements, proposing compromises and holding out the prospect of resources and support, they will serve the national citizen forum only as facilitators and only on request. This role of facilitator may include financial support for the citizen forum to meet in plenaries, to get a secretariat running, to organize working groups and to finance scholars and experts to advise on specific issues. They cannot apply the traditional log-frame methodology and SMART indicators to these financial contributions. As a process-based instead of a result-based approach, different forms of accountability are needed, like participation rate, change in legitimacy, polling of constituencies.

Second, being connected to the international community, international actors play a role in keeping the process of nation-building within the framework of international law. Even if nation-building is a national process, in our globalizing world nation-states cannot isolate themselves from the international community and its standards. Here is important what I contended earlier about international values and norms. If the international (Western) community will use this role to try and put a straightjacket on these nation-states by imposing its social and cultural norms and forms, it will put the nation-building under stress. It requires deep listening to make the conversation about international values, norms and forms relevant for the nation-building process. There is no doubt need for embedding the nation-building process in the international community, but there is also need for restraint and sensitivity on the part of the international community. 
The role of international civil society deserves specific attention. International civil society organizations often have good connections to national civil society organizations in fragile countries as well as to communities at grassroots level. They are accustomed to bottom-up processes and can offer national civil society the opportunity to connect to their international networks. This makes them valuable as contributors to the nation-building process. However, international civil society has to be cautious about two pitfalls. They have to look beyond the usual suspects of NGOs that have organized themselves in conformity to organizational standards of international civil society. Most of the identity-based communities, which are very relevant for the nation-building process, are not organized according to these standards. Secondly, international civil society has to make a comprehensive analysis of the identity issues at stake in fragile states. Identifying with just one of the identity groups and their cause is helpful and often necessary in order to support their role and contribution in the national process, but should be seen as part of the larger picture of building a national sense of belonging. Understanding the layered framework for nation-building is important in the process of claiming space for the identities of communities.

\section{Internal and external brokers}

The presence of internal and external (international) brokers is vital for the nation-building. But this brokering is fundamentally different from brokering in the peace-making phase. At the outset of the process, there is often a lack of trust between groups and many competing interests. Identifying internal brokers who are willing and able to bridge the divides and who are credible in the eyes of the different communities is essential. In the first phase these honest brokers must be found in the second tier of communities. Community leaders have identified themselves too much with the specific interests of the community. Among all parties engaged in conflicts there are 'hard-liners' and 'soft-liners'. And although both are needed to get sustainable outcomes, the soft-liners are necessary to build the bridges and create the space for dialogue and understanding. For external brokers it is important that they are not perceived as the representatives of international actors with clear geopolitical interests. Brokers are important to build relationships between parties, to translate positions and find common ground, to mediate in order to understand the different positions. Although they are supporters, not leaders of 
the process of nation-building, they can help to foster an open problem

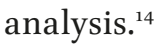

\section{The possibility of nation-building for different modes of state fragility}

In chapter 3, we identified three different forms of state fragility, based on the presence or absence of legitimacy, capacity and authority. This distinction is relevant for answering the question whether nation-building is possible in fragile states. An important cautionary note is that national contexts and patterns of power must be taken into account before one can make any final assessment on whether a state offers a conducive environment for processes of nation-building. Part of this is the realization, discussed earlier, that fragile states are no monolithic entities. There are differences between and among governments and political power holders in fragile states. Whereas the inner circle of power (presidency, ministers of defense and interior, military) are usually entrenched obstacles for change and inclusion, others in the system may be much more open to these processes. High-ranking civil servants are frequently much more susceptible for the need to start processes of inclusion and provincial/regional politicians are different in their power politics than those on the national level.

\section{States that are legitimate and have authority but lack the capacities}

When capacity is the biggest problem, we have a rather conducive environment for nation-building. In these countries the state lacks financial resources to function, its institutions are debilitated by war and conflict and the human resources are scarce due to years of non-functioning educational systems and the out-migration of the best and brightest who had the opportunity to escape conflict and war. The legitimacy is the most valuable asset of the state: It is able to mobilize the people and in general its policies will be seen as legitimate. In such a fragile situation different identity groups feel themselves represented and accepted as part of the new nation-state. That offers a context that is conducive for a nation-building program as a complementary effort in the state-building process: By explicitly acknowledging the different ethnic, religious and language groups as part of the nation-state, these identity groups could become more willing 
to bring in their resources (human, social) in the state-building process. Sierra Leone, Liberia and Timor-Leste are examples of states that can be characterized as legitimate but with limited capacities and resources. Most challenging in these states that lack capacity is to pay tribute to the principle that nation-building is a domestic program, led by national communities and their leaders. Lack of capacity easily becomes a motive for bringing in foreign expertise and marginalizing local actors.

\section{States that have legitimacy and capacity but lack control over their territory}

In fragile states that are legitimate and capable but that lack control, security is a dominant issue. The process of peacemaking is not yet finished. Although one can fundamentally question the legitimacy of a state that has no control over its entire territory (apparently people in part of the territory do not acknowledge the state), the overall situation can be seen as legitimate. This is the situation in many fragile countries, often with very limited levels of legitimacy and capacity. The DRC is an example, with the eastern part of the country frequently plagued by the violence of different rebel groups that seize part of the territory, so are Mali and Afghanistan. In all these countries the state has legitimacy - albeit limited. Democratic elections have brought governments to power and there is a limited capacity to perform, with the support from the international community, the basic stately functions (security, justice, basic social services). Nation-building in a state that lacks full control is a delicate process. It may result in deepening the cleavage with the insurgent groups. A process of nation-building including the different identity groups living in the territory under control, can be seen as further marginalizing the rebel movement and labeling them as outsiders. Leaving a symbolic seat at the table, being transparent in the process to avoid the image of secret deals, and actively expressing the need to make the process of nation-building more inclusive, can be strategies to show that there is space for every group in the of nation-building. The role of internal and external brokers as go-between for these not-yet included groups is crucial to find ways for reaching out to them.

The fact that the process of building a sense of national belonging and nationhood is never finished, underlines this openness for future inclusion. Those leading the process of nation-building play a crucial role in presenting it as really open and inclusive. Such leaders often have relations with those as yet outside of the process and could reach out to them to convey the 
message of inclusiveness. If this happens, the process of nation-building can contribute to alleviating the tensions and easing the conflict.

Included in this category can be certain countries that are not labeled as fragile in international overviews, ${ }^{15}$ but which face similar problems, like Colombia and the Philippines. In both cases there is a legitimate and capable government that has no full control over its territory due to the presence of revolutionary movements and insurgents (FARC in Colombia, MILF in the Philippines). ${ }^{16}$ Both movements control part of the territory of the nation-state. In these countries a process of nation-building can be relevant to deconstruct the image of a majority that forms a monolithic bloc against the revolutionary/insurgent movement: The nation-building process shows that also the supposed majority is made up of a large diversity of the groups, communities an identities.

\section{States that have authority and power, but lack legitimacy}

When legitimacy is the key problem, nation-building as a complementary process of state-building seems counter-productive and impossible. A state that lacks legitimacy, will not allow an open and inclusive process of nation-building to start with. A nation-building process that pretends to be inclusive but is in fact complementary to an illegitimate state will easily get tainted. Sudan can be taken as an example: The state is powerful and controls the territory but has no legitimacy, even though president Bashir was elected in the 2015 elections (boycotted by other political parties) with $94 \%$ of the votes. The secession of South Sudan has not created a coherent Sudan, the problem with the regions of Darfur, Blue Nile and Nuba Mountains are not solved. But the Bashir government lacks the legitimacy to start a process of nation-building that could build a stronger basis for the Sudan nation-state. Too many groups (Darfur, Blue Nile State, Kordofan) do not see the Bashir government as a legitimate representative to lead such a process. Zimbabwe presents a similar situation. President Mugabe still controls the country but there is no basis for an inclusive nation-building process.

15 Harmonized list of fragile situations FY 15 of the World Bank: http://pubdocs.worldbank. org/pubdocs/publicdoc/2014/7/425731404933583114/FY15FragileSituationList.pdf (accessed 21 August 2015)

16 In both Colombia and the Philippines peace processes are on the threshold of providing agreements that could end a decades-long war. 
Is nation-building outside the state a possibility in these situations? Could one design a nation-building process led by civil-society actors, all the more since we concluded that the leadership of this process lies with the leadership of identity groups and communities, not with the state. I see at least two obstacles to such an approach. First, if the power and authority of the state is non-inclusive, which most of the time means that an ethnicitization of politics and power is happening, it is hardly possible to create an equal basis for a nation-building process for all identity groups. The ethnic exclusivity of the existing power structure is bound to influence the nation-building process. Second, we defined nation-building as a complementary process to state-building. The sense of belonging we want to achieve through a nation-building process, should be accompanied by rules and regulations by the state that are inclusive and lend credibility to the process of nation-building. Nation-building in isolation, without the support of practical policies that underpin the creating of a sense of belonging, will not be successful. The efforts by civil society actors to create inclusion, to overcome barriers between identity groups and to prevent conflict are certainly relevant and useful, but should be considered as preparatory for a nation-building process. When legitimacy is the biggest problem, at best forms of multistakeholder processes could be started at a second-track leadership-level, finding internal brokers within the different identity group who are willing to create bridging social capital. Strong external brokering support and facilitation will be needed. These processes could function as preparatory stages for proper nation-building whenever political changes on the national level will happen.

\section{Oppressive states are not for eternity}

Policymakers, peace and human rights activists, and NGO-practitioners working to solve the issue of fragility often question whether it is at all possible to work on nation-building, in terms of creating a sense of belonging, in states that function very badly. And we all know examples of such states, where a small group clings to power, where politics are ethnicitized and where a deeply entrenched zero-sum thinking leaves no room for inclusivity. The good news is that dysfunctional, brutal regimes do not stay in power. Looking back at the four decades since, as a student, I became active in international solidarity, I witnessed several change-strategies (designed or spontaneously emerged) that proved to be effective in toppling autocratic regimes, even if not all of these yielded stability and human dignity. 
First, revolutions are a way to solve the problem of brutal or autocratic regimes. Examples include the people of the Philippines who ousted president Marcos, the Portuguese revolution of 1975 that overthrew the fascist dictatorship, the fall of Suharto after a three-decades-long presidency in 1998, the Orange Revolution in the Ukraine in 2004 and the Arab Spring of 2011. All of these popular uprisings were domestic in nature, and sometimes not expected by analysts and political strategists. But not all of these revolutions proved to be sustainable solutions for the problem of unequal and exclusionary power.

Second, there have been internal liberation movements that launched a civil war to get rid of dictators. The Nicaragua uprising of the Sandinistas against dictator Somoza was effective, as was the civil war of the South Sudanese to free themselves of the oppressive regime in Khartoum. But neither of those two managed to bring a regime into power that was able to realize peace and prosperity for the people. However, history has seen many more armed revolutionary movements that did not succeed: The Tupamaros in Uruquay, Sendero Luminoso in Peru and the Tamil secessionist movement in Sri Lanka.

Third, the democratic processes that drove the military dictators out of Latin America (e.g. Chili, Argentina, Brazil) are a clear example of social movements that are able to bring about political change and create the basis for a stable and inclusive government. There are more examples of democratic transitions: The transition in Ghana after the military leadership of Jeremy Rawlings, the process in Kenya after the Arap Moi regime.

Lastly, we have witnessed external military interventions to bring about regime change with very different outcomes. The UN-led interventions in Liberia and Sierra Leone proved to be effective in toppling a criminal regime and creating the basis for post-conflict reconstruction. The interventions in Uganda against Idi Amin led by Tanzania in 1990 and the Vietnam intervention in Cambodia against Pol Pot in 1991 could be considered rather successful, however, the subsequent regimes in both countries led by Museveni and Hun Sen quickly transformed themselves from solutions to new autocracies. We have seen military interventions in Libya and Iraq, which cannot be labeled successful. The Afghanistan intervention is still hanging in the balance with the unsolved problem of the Taliban insurgency making life for Afghans unstable and insecure. It also means that a lot of resources are diverted to the problem of insurgency instead of being available for reconstruction and development. The embarrassing presidential elections in Afghanistan of 2008 and 2014 were not a convincing sign that the international ISAF intervention has created political stability. 
The list is definitely incomplete and it would require much more in-depth comparative research of these different modalities of regime change to analyze whether there is a pattern of successful interventions and whether we could identify success and failure factors in these transitions. But what is clear is that there are always opportunities for change. Nation-building is not a solution for dysfunctional power holders, it is not a strategy for toppling dictators. Nation-building can, however, contribute to make regime change more stable and more sustainable, it can in a preventive way contribute to more inclusive policies and contribute to conditions that are conducive for such policies. 


\section{Vignette}

\section{Legitimacy for development organizations in Uruzgan}

When the Dutch government decided to take the role of lead agent in the ISAFmission in the province of Uruzgan, the debate on the role and position of Dutch NGOs started. Cordaid was, at that time, one of the few international NGOs active in Uruzgan. Via the Afghan NGO AHDS (Afghan Health and Development Services), Cordaid was supporting the healthcare in the province. In addition, Cordaid supported small community-building programs of Afghan NGOs.

In the Netherlands the main message to the Dutch public was: We are not going to fight, we are going to rebuild the country. With that message the tone was set for the relationship between the ISAF-mission and development cooperation and the challenge for development organizations was there how to relate to the ISAF-mission. There was a lot of political pressure to build a close cooperation: The popular 3D approach stipulated an integral approach of defense, development and diplomacy. Dutch members of parliament moreover bluntly stated that it was all about taxpayer's money, so development agencies, financed by the government, had to be part of a coherent and integrated strategy in Uruzgan. Some agencies based themselves on the strict interpretation of the humanitarian principles of neutrality and impartiality: Development NGOs cannot cooperate with the military without jeopardizing their position.

I took a different position for Cordaid. We made a distinction between operational cooperation, which we decided against, and a cooperation of exchange: Sharing information, exchange of analyses on what was happening in the reality of Afghanistan, trying to understand the dynamics of the different actors in the province of Uruzgan. We always maintained our strategy of inclusiveness. While the Dutch military made a distinction between the 'clean' areas under control of ISAF and ANA, Cordaid supported programs in all of the areas of Uruzgan, including in Taliban-controlled areas. Cordaid did not act differently from its Afghan partner organizations who frequently visited Camp Holland for conversations with the Dutch PRT and who explicitly had the same inclusive approach.

In my opinion the most sensitive and decisive issue in the cooperation between the military and development agencies was the legitimacy on the ground. Too much of the debate was nurtured from the perspective of the donor countries and the political debates in their capitals. To me the essence of the debate was whether the legitimacy of Cordaid as a development agency in Uruzgan was jeopardized. We had been in Uruzgan before the Dutch ORT deployed its mission and we would stay there after the Dutch mission finished. Therefore the central question was whether Cordaid's profile in Uruzgan and Afghanistan 
would be tainted by our relationship with the Dutch PRT mission, whether our legitimacy was undermined by the relationship.

The deputy country representative of the United Nations Assistance Mission in Afghanistan (UNAMA) in Kabul once fiercely criticized me for being far too cooperative with ISAF: 'You are sleeping with the devil'. I personally believe we managed to draw fine but consistent lines. After the withdrawal of the Dutch PRT mission in Uruzgan, Cordaid managed to continue its programs in the province in collaboration with its Afghan NGO partners. 


\section{Case}

\section{Rwanda: Nation-building in mildly authoritarian regimes}

Special attention is due to the problem of nation-building in what I characterize as 'mildly authoritarian regimes', most of which are not seen as outright failed states. In Africa, I would label Ethiopia (Meles Zenawi and his successor Hailemariam Desalegn governing since 1991), Uganda (Yoweri Museveni in power since 1986) and Rwanda (Paul Kagame in power since 1994) as examples. In Latin America another example is Venezuela (Hugo Chávez since 1998 and his successor Nicolás Maduro). In these mildly authoritarian states the space for political opposition is limited and the incumbent powers dominate the political landscape. Recurrent stories about violations of human rights indicate that these regimes, even though there is an electoral legitimacy, operate with tight control over their citizens. CNN journalist Fareed Zakaria dubbed these countries 'illiberal democracies':17 Countries with regularly held elections but without a culture of political freedom and space for diversity. What makes these illiberal democracies interesting from the perspective of nation-building, is the nationalist politics of their leaders, who very much stress the national identity and try to create a joint commitment to the political and socioeconomic challenges of the country. They do so sometimes by formulating a joint development challenge (Rwanda wants to be the technological hub for central Africa, Ethiopia wants to be food secure), sometimes by invoking en external enemy (Venezuela against the US, Museveni against the Western human rights activists that will impose gay rights).

Rwanda after the genocide of 1994 is an interesting example. After those unspeakable 100 days, the new government started a clear nation-building program by strictly forbidding everyone (individuals and institutions) to refer to ethnic distinctions: Everyone is Rwandese and your ethnic background (Hutu or Tutsi) does not matter. Simply referring to ethnic identity makes one guilty of inciting ethnic hatred..$^{18}$ The nation-building strategy takes citizenship as the basic principle over and above any other distinction. The country has a shared vernacular (Kinyarwanda), which together with English and French is one of the three official languages. President Paul Kagame also invested in a strong pro-

17 https://www.foreignaffairs.com/articles/1997-11-01/rise-illiberal-democracy (accessed 27 August 2015)

18 See the Oppenheimer lecture of Paul Kagame in 2010 about nation-building in Africa, which is more marketing than critical reflection (http://www.iiss.org/en/events/events/archive/2010c61c/september-cbd6/oppenheimer-lecture-paul-kagame-5co9 (accessed 27 August 2015). 
gram of state-building, by creating institutions, maintaining law and order and providing security and basic services to the population.

The Rwanda strategy has evoked a lot of articles, op-eds and papers about the pros and cons of this approach. While some commentators support this approach as paving new ways for solving the ethnic divide in African countries, others are critical because of the poor human rights record of the Kagame regime. Others again challenge Kagame's strict development-without-politics approach arguing that denying the existence of social tensions may well result in an explosion of such tensions in the future. ${ }^{19}$ However, no critical research has been conducted on Kagame's approach to nation-building that really digs deeper into the sustainability of his approach. It would be interesting to find out whether the Rwandan national identity has taken up cultural traditions, stories or heroes that are derived from the different identity groups. The nationwide application of the traditional gacaca system (community courts) to build grassroots reconciliation is a sign of a shared tradition accepted by all different identity groups. Are there more of these shared traditions that build on a shared past and are used to shape a shared national identity?

19 http://csis.org/files/publication/110623_Cooke_Rwanda_Web.pdf(accessed 27 August 2015) It resembles the problems in former Yugoslavia, where a shallow national Yugoslavian identity was not able to contain the different underlying identities that exploded when the Yugoslavian national structure was unraveling. 



\section{Epilogue: The challenges of fragility - and the beginning of an answer}

The challenges posed by fragility are extremely urgent in the world of today and tomorrow. First of all, because of the large-scale human suffering caused by fragility: Women are unsafe and exploited, children are malnourished and not in school, youth lack opportunities to build their own future, and communities are divided and insecure. The ability of people in fragile states to live dignified lives is severely compromised. The refugee crisis in the Middle East and the Mediterranean, which has been going on for years but only became painfully visible to most people in Europe in 2015 , is not the only sign of this unacceptable human suffering. Millions of people suffer from fragility outside of the purview of international media cameras. The challenges posed by fragility are also urgent because in a world of global interdependencies, unstable countries and contexts with increasing inequalities between countries undermine global peace and security. Thirdly, fragility undermines the efforts of the international community to eradicate poverty. Fragile and conflict-affected countries have consistently lagged behind other developing countries in achieving the targets of the Millennium Development Goals (see also chapter 3). This trend is likely to continue with the even more ambitious and inclusive agenda of the Social Development Goals (SDGs) that the world's governments agreed on at the UN Special Summit in September 2015. Poverty is increasingly concentrated in fragile and conflict-affected states: By 2030, two thirds of all poor people are expected to live in fragile situations. For the next decade the fragile states will be home to the increasing majority of the people living below the poverty line. The OECD expects that $62 \%$ of all poor people may be living in fragile states by 2030 , compared to $43 \%$ in $2015 .{ }^{1}$ Without an effective strategy to address the issue of fragility, the ambitious SDG agenda of zero poverty in 2030 will be extremely difficult to realize.

The fragile-states challenge is aggravated by the increase in the development gap between these fragile states and the stable low- and middleincome countries, which increasingly manage to benefit from processes of development that connect them to the globalizing world. The widening gap will create more tensions: If Rwanda continues to progress and Burundi and the DRC remain stuck in their fragile condition, regional tensions are bound 
to reignite. The urgency of the problem of fragility is clear. The international community should generously provide all the necessary resources (human, intellectual, financial, technical) to address this problem as soon as possible. But here we stumble on the reality of fragility: There is no silver bullet, no magic wand to solve this problem. ${ }^{2}$ The enormous efforts by the international community in Afghanistan and South Sudan have not been able to make these countries stable or even to prevent new or ongoing conflict. That failure is partly due to limitations on the part of the international community. The Dutch chief commander Dick Berlijn stated in 2007, one year into the Uruzgan mission, that the Dutch government and public should reckon with a time frame of 20 years of presence in Afghanistan. According to his analysis, this was the time realistically needed to stabilize the country and to realize the goals as set by the ISAF-mission. ${ }^{3}$ Three years later, however, the Dutch withdrew from Uruzgan due to domestic political conflicts between the two coalition parties (Social Democrats and Christian Democrats). Four years later, in December 2014, the international ISAF mission came to an end. Lack of political and electoral support in the donor countries and unwillingness to bear the ongoing financial burden were the main reasons to end the ISAF mission long before its target of stability was achieved. Or was it the realization that solving the problem of fragility in Afghanistan proved so much more complex than the architects of the $3 \mathrm{D}$ approach and instruments had ever imagined? Dick Berlijn was perhaps right with his assessment of a 20 -year time frame: Deep cleavages in society that are a result of decades of war and mistrust cannot possibly be resolved by means of a rapid international 'therapy'. There is no overnight solution for the extremely tricky reality of societies where people who were used to living in rather homogeneous identity groups were suddenly uprooted by war and conflict, and that now face the challenge of becoming a 'decent' nationstate in the international family of nation-states. Overcoming decades of war and internal conflict and finding a response for the new challenges of these countries is not something that can be planned or managed through a 'tick-the-boxes' process of defining output and outcomes. However, I

2 Grindle 2007 concludes: 'Thus, particularly for those engaged in efforts to improve governance in fragile states, there are no magic bullets, no easy answers, and no obvious shortcuts towards conditions of governance that can result in faster and more effective development and poverty reduction. The task of research and practice is to find opportunities, short of magic bullets, for moving in a positive direction, yet recognizing that this is not always possible.' (p. 572)

3 http://vorige.nrc.nl/binnenland/article1826976.ece/Dick_Berlijn_blijf_in_Afghanistan (accessed 3 September 2015, in Dutch) 
do see a few challenges ahead that can be turned into opportunities for formulating better answers to the dilemma of fragility.

\section{Broaden the policy scope}

The complex reality of fragility calls for a broadening of the current scope of our policies and interventions. Given the prevalent discourse on fragility this is no easy call. The OECD 2015 States of Fragility report sticks to the same model that has guided interventions for the last two decades; at the heart of the analysis are still the weak institutions of fragile states that need to be strengthened. The OECD signals 'new approaches to fragility' but this only entails welcoming the inclusion of security and peace within the new SDG Agenda. The mainstream discourse on fragility continues to be dominated by the political economy domain: By building strong political institutions (government, judiciary, military, police) and by investing in the economy, the problem of fragility will be solved. Referring back to the triangle model of basic competences of the state presented in chapter 3 , current efforts and innovation are focused on the axis of authority and capacity, with effectiveness as the anticipated outcome. I am convinced this current recipe is not enough.

We need to broaden the scope of strategies, meaning that we must start to include also the third component of the fragility-triangle into our policies: Legitimacy. And this should not be done in a flawed manner of assuming that legitimacy is the automatic result of effectiveness; the importance of legitimacy should be judged for what it is: The missing pillar for comprehensive policies.

Strengthening institutions and capacities is not irrelevant, far from it. People in Afghanistan, the DRC and the Central African Republic want state institutions that function well, take citizens seriously, deliver in an effective and efficient way, and spend the scarce resources properly and fairly. The ideal of good governance is not alien to the aspirations of people in fragile states - there is no need for 'us' to convince them of its importance. However, I believe that people in fragile states want to see that this institution building is embedded in a cultural, social and spiritual understanding that they relate to. Moreover, they want acknowledgement of the fact that during war and conflict people survived not thanks to the state but in spite of the state. It is offensive to people in fragile states to ask them to transfer their loyalty from the institutions and communities that 
helped them survive to the state, which proved to be unreliable. According to many people, the state is based not on the sovereignty of the people, but on the support of the international community. It is therefore only reasonable that they want to see a connection between the institutions that helped them survive and the new institutions that claim to be the solution to their country's fragility. Only if we can link the trust that people have towards the existing, often customary, institutions and the new official institutions, can we begin to find a solution for the problem of fragile states. Bringing in legitimacy as a focal point will put our efforts in a new light. It opens our mind for connections between old and new systems, it brings in the legitimacy of traditional institutions as a basis (not the end stage) for creating stability. In a study of the justice system in Mali researchers concluded: 'Accepting that the Malian state does not have, will not have and should not aspire to have a monopoly on the provision of justice for the next few decades is a critical starting point for making improvements to how justice is provided in matters that affect Malians in their daily lives. ${ }^{5}$ Building on the customary laws of the country should be regarded as an option to build a justice system that delivers to the people and that has a strong legitimacy. The same goes for healthcare: Is it useful to follow a replacement strategy by which traditional healing institutions are marginalized and blamed as outdated and dangerous, or can we build on these systems as a building block for a professional and well-functioning health system? The madrassah school system in Pakistan poses the same challenge for the debate on the education system. ${ }^{6}$ Such an approach would value existing systems of ethnic, religious and other identity communities as valuable contributions to the process of building a functioning state. Bridging the gap between old and new becomes a possibility when taking serious the pillar of legitimacy in all efforts to reduce fragility. In this bridging we see the connection between nation-building and state-building, between identity and institutions.

5 http://www.clingendael.nl/sites/default/files/beyond_dichotomy.pdf(accessed 15 November 2015)

6 http://www.iiu.edu.pk/wp-content/uploads/downloads/ird/downloads/madrassaeducation-in-pakistan-and-bangladesh.pdf (accessed 15 November 2015), and also: http://www. netreed.uio.no/articles/Papers_final/Karlsson_Mansory.pdf (accessed 15 November 2015) 


\section{Commit to interdisciplinarity}

Tackling the problem of fragility requires a strong alliance between researchers, policymakers and practitioners. I have argued that the central concepts of the fragility discourse (nation, fragility, identity) show a certain fluidity. Combining three more-or-less fluid concepts makes the challenge even more volatile and changeable. The academic concepts need contexts and reality: The proof of the pudding is in the eating. Academia will not solve the conceptual dilemmas any time soon, and the same goes for policymakers and practitioners: In isolation none will find the answer. Working in isolation means accepting an endless process of trial and error: People in fragile states deserve better. They deserve that policymakers, scholars and practitioners do the difficult work of understanding each other, their different frameworks, conceptual approaches, methodologies, time frames and pressures. With this book I call on all of them to start that laborious effort of bridging the gaps to find better answers. It will require 'deep listening' and honest conversations. There is an urgent need for such an interdisciplinary approach, which will demand of all - researchers, policymakers and practitioners - an equal dose of continuous, smart and stubborn dedication.

I distinguish three lines of research that should be tackled as much as possible in an interdisciplinary way, involving the knowledge and experience of all actors. On top of that, researchers have their own challenges of multidisciplinarity. Departments of international relations and international politics should eagerly look for their colleagues in other departments like cultural anthropology, social psychology, history, religion and sociology in order to understand the social-cultural and religious dynamics in fragile societies. Based on such an interdisciplinary approach, research is needed about how people understand their national identity: What do people in Afghanistan, Sudan and the DRC understand as the components that make up their national identity? What is their 'imagined community'? Can they formulate what are essential elements of being an Afghan, a South Sudanese or a Congolese citizen? Are there national historical events, heroes or sacred places that they see as crossing ethnic and religious borders? How do they look at emigrants who fled the country? Without a predefined normative frame of national identity, research should start to understand the elements and components of national identity.

A second line of research could be a series of case studies from a nationbuilding perspective. What happened in South Sudan between the Naivasha peace agreements of 2005 that brought so much hope and the outbreak of 
ethnic violence in 2013? What made the hard-won independence unravel so easily? Why did the unity felt in the struggle against North Sudan dissipate and where were opportunities missed to create a stronger national identity as a bulwark against ethnic conflict? A similar analysis could be made in Mali. The Libya crisis and the pouring of militants and military equipment into Mali after the fall of Khadafy have contributed to the crisis in Mali, but what was missed in the years prior to that? A very relevant case study would be Rwanda and its nation-building strategy after the genocide. Does it work to weed out all references to ethnicity? How strong and how deeply felt is the national identity created by the Kagame regime?

A third line of research could study the relationship between peacemaking, state-building and nation-building as distinct but complementary efforts. What are the points of connection, where do the different processes meet and what are the opportunities to use progress in one (nation-building) as a stepping stone in the other (state-building) and vice versa? Such research could help to maximize the synergy between the different processes.

Policymakers should question the self-evidence of the models they apply for supposedly solving the problems of fragile states. Applying the institutional models of the Western world is not going to build legitimate institutions. Based on the distinction between values, norms and forms, policymakers should open the conversation with their colleagues in fragile states on how values like democracy and accountability are interpreted in their culture and tradition, and which norms and forms are connected to these values. The interplay of democracy and leadership is different in Islamic tradition. Institutions like shariah law and madrassah education should be taken seriously as contributions to the development of justice and education. The Ubuntu tradition can be a valuable contribution to building an inclusive political community. Humility is an important virtue policymakers have to acquire in order to understand what is happening in fragile contexts. Policymakers should also develop their networks beyond the power centers of the political circles in the capital. Second- and third-track diplomacy, connecting to leaders of ethnic groups, religious communities and leadership in regions should be developed more deeply in order to understand and give content to the need for inclusiveness.

International practitioners in multilateral, bilateral and NGO programs can play an important role in this. Their involvement in daily practice makes them well-positioned to translate these practices to the policy level and advocate for them. They can serve as a countervailing power, taking responsibility for challenging the taken-for-granted policies of multilateral institutions. Practitioners should do more in linking their practices on local 
and regional levels to national policies. They are often engaged in specific issues of minority communities that need to be connected to the process of nation-building. The process of nation-building requires new intervention logics that find a middle ground between the reality that nation-building escapes the time-bound and result-based models so common in development work, but at the same time requires serious and carefully designed work. Nation-building challenges policymakers and practitioners alike to be, as William Easterly phrased it, searchers, not planners.

\section{Build the nation-state on solid soil}

The nation-state is not the end of history. Like the Roman Empire, the Caliphate and the Princedoms of the Middle Ages and the Renaissance, it is a social and historical construct. We see the change happening. The interconnected, globalizing world will have consequences for the nation-state. The establishment of regional multilateral agencies (EU, AU, Mercosur, ASEAN) will have its influence on the mandate of nation-states in the international arena. The increasing power of cities and urban conglomerates will affect from below the role of the nation-state. There is a growing global elite which is not connected to one physical place and has the means and the capital (financial, intellectual, cultural) to live independently from nation-states. All these developments will affect the nation-state.

And yet. Communities and societies need a house to live in. The nationstate is our current house. It needs structures and systems that make us feel at home and comfortable with our fellow citizens. Even though these houses are being constructed differently in time and place, they all should minimally provide us with security, justice, basic social services and a viable infrastructure. We all constantly restructure and refurbish our houses to make them fit for new internal and external developments. This refurbishment does not come without tensions, misunderstanding and differences. But we can manage them if every house is built on solid soil and on solid fundaments - to make sure it is sustainable and will not to crumble under our tensions and different designs. Nation-building, creating this imagined community of belonging, is the solid soil and fundament that we cannot do without. The poor and vulnerable of this world need a solid house on solid soil where they can live and flourish. They have nowhere else to go. 



\section{Acknowledgements}

This book emerged out of my ten years as Executive Director of the Catholic development organization Cordaid. As Cordaid focuses its work in fragile and conflict-affected states, I increasingly felt the need for a deeper reflection on the challenges these countries are facing - and the possible solutions. Through my extensive traveling in fragile and conflict-ridden countries, I had the privilege to meet many outstanding, brave and dedicated women and men. Most of them were staff members of Cordaid's partner organizations. Knowing that there were many more, I wish to mention here: Doctor Fareed of AHDS in Afghanistan, Jesuit Father Francesco (Pacho) de Roux in Colombia, and Jacky and Jan Willemsen in Gaza. Many staff members of Cordaid have accompanied and guided me during my visits to these countries. They helped me understand the realities that we came across and connect with the people we met. The commitment and the inspiration of Albert van Hal, Hetty Burgman, Akinyi Wallender and many others have been invaluable. The conversations with Paul van den Berg and Karen Mol, who were my advisers for the - sometimes tough - discussions in the Netherlands about Afghanistan and South Sudan, always challenged me to take on new ideas and a wider perspective.

Georg Frerks was my mainstay during the process of research and writing. With his academic quality and his commitment to the practice of conflict resolution, he was the right person to guide me in keeping a balance between my ambition to build my work on sound research and to produce something relevant for policymakers and practitioners. His colleagues at the Centre for Conflict Studies at Utrecht University as well as Lucien van Liere at the Department of Philosophy and Religious Studies provided helpful feedback to complete the picture.

I owe a lot to Bas van Bavel who offered me the opportunity to be part of his multidisciplinary team of researchers engaged with the strategic theme 'Institutions for an Open Society' at Utrecht University. His dedication to realize an interdisciplinary culture at the University inspired me in my endeavor.

Dirk-Jan Koch, Jan Gruiters, Willem van de Put, Ronald Wormgoor, Arjen de Wolff and Kees Zevenbergen provided me with critical feedback from the perspective of policymakers and practitioners, supporting my ambition to be relevant for both. 
Besides for the countless moments of inspiration and sharing that Cordaid provided for ten years, I am grateful to the organization for its financial support that created the material conditions to complete this study.

Roeland Muskens and Ellen Lammers have greatly contributed to sharpen the message of this book and to make sure that the message comes across. Like with my previous publications, their knowledge about conflict and development and their distance as editors have proven to be an excellent mix of competences.

During my research for this book, I had many conversations, at the kitchen table or in our shared study, with my wife Inge. Time and again she, a teacher in social work at the University of Applied Sciences in Utrecht, and I discovered common ground in our global and local work for participation and social inclusion. Without the joy of sharing our commitment, this book would have missed its deepest source of inspiration. 


\section{Bibliography}

Acemoğlu, Daron \& James A. Robinson (2013). Why Nations fail. New York: Crown Publishers.

Alesina, Alberto, Reza Baqir \& William Easterly (1999). Public goods and ethnic divisions.

Quarterly Journal of Economics 114(4), p. 1243-1284.

Anderson, Benedict (2006). Imagined communities. New York: Verso.

Ayoob, Mohammed (1995). The New-Old disorder in the Third World. Global Governance 1(1), p. 59-79.

Ayoob Mohammed (2007). State Making, State Breaking and State Failure. In: Crocker, Chester A., Fen Osler Hampson \& Pamela All (eds.) Leashing the dogs of War. Washington, DC: United States Institute of Peace Press.

Barkin, J. Samuel \& Bruce Cronin (1994). The state and the nation: changing norms and rules of sovereignty in international relations.: International organization 48(1), p. 107-130.

Bertram, Eva (1995). Reinventing governments, the promise and perils of United Nations peace building. The Journal of Conflict Resolution 39 (3), p. 387-418.

Blagojevic, Bojana (2007). Peace Building in ethnically divided societies. Peace Review: AJournal of Social Justice 19(4), p. 555-562.

Boege, Volker M., Anne Brown \& Kevin P. Clement (2009). Hybrid Political Orders, not fragile States. Peace Review: A Journal of Social Justice 21(1), p. 13-21.

Bourdieu, Pierre \& John B. Thompson (1991). Language and Symbolic Power: Identity and Representation. Cambridge, MA: Harvard University Press.

Brubaker, Rogers (1999). The Manichean Myth. In Kreisi Hanspeter, Klaus Armingeon, Hannes Slegrist \& Andreas Wimmer (eds.), Nation and National Identity: The European Experience in Perspective. Rügger Verlag.

Brubaker, Rogers (2009). Ethnicity, Race and Nationalism. Annual Review of Sociology 35(2), p. 125-151.

Brubaker, Rogers \& Frederick Cooper (2000). Beyond Identity. Theory and Society 20(1), p. 1-47.

Bryant, Christopher G.A. (1997). Citizenship, national identity and the accommodation of difference: reflections on the German, French and British cases.Journal of Ethnic and Migration Studies 23, p. 157-172.

Calhoun, Craig (1993). Nationalism and Civil Society. International Sociology 8(4), p. 378-411.

Carment, David, Yiagadeesen Samy \& John Landry (2013). Transitioning fragile states, a sequencing approach. The Fletcher Forum of World Affairs 37(2), p. 125-151.

Carment, David, Yiagadeesen Samy \& Stewart Prest (2008). State fragility and the implications for aid allocation: an empirical analysis. Conflict Management and Peace Sciences 25, p. 349-373.

Castells, Manuel (2010). The Power of Identity. Wiley-Blackwell.

Cavanaugh, William T. (2007). Does Religion Cause Violence. Harvard Divinity Bulletin 35, p. 2-3.

Cavanaugh, William T. (2009). The Myth of Religious Violence: Secular Ideology and the Roots of Modern Conflicts. Oxford: Oxford University Press.

Connor, Walker (1972). Nation-building or Nation-destroying. World Politics 24(3), p. 319-355.

Connor, Walker (2004). The Timelessness of Nations. Nations and Nationalism 10(1-2), p. 35-47.

Conversi, Daniele (2012). Modernism and Nationalism. Journal of Political Ideologies 17(1), p. 13-34.

Cornell, Stephen \& Douglas Hartmann (2007). Ethnicity and Race: Making Identities in a Changing World. Sage Publications. 
Cusack, Igor (2000). African Cuisines, Recipes for Nation-building? Journal of African Cultural Studies 13(2), p. 207-225.

Debiel, Thomas \& Daniel Lambach (2009). How State-Building Strategies Miss Local Realities. A Journal of Social Justice 21(1), p. 22-28.

Doornbos, Martin (1990). The African State in academic debate: retrospect and prospect. The Journal of Modern African Studies 28(2), p. 179-198.

Doyle, Michael \& Nicholas Sambani (2006). Making War and Building Peace. Princeton: Princeton University Press.

Earle, Lucy (2011). Citizenship: The Right to the City and State Fragility, LSE/Destion working paper no. 87 .

Easterly, William \& Ross Levine (1997). Africa's Growth Tragedy: Policies and Ethnic Divisions. The Quarterly Journal of Economics 112(4), p. 1203-1250.

Eifert, Benn, Edward Miguel \& Daniel N. Posner (2010). Political competition and ethnic identification in Africa. American Journal of Political Sciences 54(2), p. 494-510.

Engberg-Pedersen, Lars, Louise Andersen, Finn Stepputat \& Dietrich Jung (2008). Fragile Situations, Background Papers. Danish Institute for International Studies.

Englebert, Pierre \& Denis M. Tull (2008). Post-conflict Reconstruction in Africa: Flawed Ideas about Failed States. International Security 32(4), p. 106-139.

Etzioni, Amitai (2004). A Self-restrained Approach to Nation-building by Foreign Powers. International Affairs 8o(1), p. 1-17.

Evans, Gareth (2009). The Responsibility to Protect: Ending Mass Atrocities Crimes Once and For All. Irish Studies in International Affairs 20, p. 1-13.

Falk, Richard (2000). The Decline of Citizenship in an Era of Globalization. Citizenship Studies $4(1)$, p. 5-17.

Fischer, Martina \& Beatrix Schmelzle (2009). Building Peace in the Absence of States: Challenging the Discourse on State Failure. Berghof Handbook Dialogue Series no. 8.

Freeman, Mark A. (2003). Mapping Multiple Identities within the Self-Concept: Psychological Constructions of Sri Lanka's Ethnic Conflict. Selfand Identity 2(1), p. 61-83.

Fukuyama, Francis (2006). Nation Building beyond Afghanistan and Iraq. John Hopkins University Press.

Gellner, Ernest (2006). Nations and Nationalism. Cornell University Press.

Ghani, Ahsraf \& Claire Lockhart (2008). Fixing Failed States: A Framework for Rebuilding a Fractured World. Oxford: Oxford University Press.

Giddens, Anthony (1990). The Consequences of Modernity. Polity Press.

Goetze, Catherine \& Dejan Guzina (2008). Peace-building State-building nation-building: Turtles All the Way Down? Civil Wars 21(4), p. 319-347.

Gomberg, Paul (1990). Patriotism is Like Racism. Ethics 101(1), p. 144-150.

Greenfield, Liah (1993). Trancending the Nation's Worth. Daedalus 122(3), p. 47-62.

Greenfield, Liah (2003). Nationalism and the Mind. Nations and Nationalism 11(3), p. 325-341.

Grimm, Sonja (2008). External Democratization After War: Success and Failure. Democratization $15(2)$, p. 525-549.

Grindle, Merilee S. (2007). Good Enough Governance Revisited. Development Policy Review 25(5), p. 553-574. 
Gubler, Joshua R. \& Joel Salwat Selway (2012). Horizontal Inequality: Crosscutting Cleavages and Civil War.Journal of Conflict Resolution 56(6), p. 206-232.

Gunsteren, Herman van (1994). Four Concepts of Citizenship In Steenbergen, Bart van (ed.) The Conditions of Citizenship. Sage Publications.

Habermas, Jürgen (1998). The European Nation-state: On the Past and Future of Sovereignty and Citizenship. Public Culture 10(2), p. 397-416.

Haider Naqvi, Imran, Shazia Ahziz, Syed Abbas Haider Zaidi \& Kashir-Ur Rehman (2011). The Model of Good Governance in Islam. African Journal of Business Management 5, p. 10984-10992.

Hastings, Adrian (1999). The Construction of Nationhood. Cambridge: Cambridge University Press. Haynes, Jeff (2001). Transnational Religious Actors and International Politics. Third World Quarterly 22(2), p. 143-158.

Helling, Dominik (2009). Analysis of a 'Political Chameleon': Re-examining Fluid Shapes and Solid Constants of Nationalism and Nation-building. LSE Crisis States Research Centre working paper no. 17 .

Hesselbein, Gabi, Frederick Golooba-Mutebi \& James Putzel (2006). Economic and Political Foundations of State-making in Africa: Understanding State Reconstruction. LSE Crisis State Research Centre working paper no. 3 .

Hippler, Jochen (2004). Nation-building, ein Schlüsselkonzept für friedliche Konfliktbearbeitung? Hobsbawn, Eric J. (1992). Nations and Nationalism since 1780. Cambridge University Press. Horowitz, Donald (1985). Ethnic Groups in Conflict. University of California Press.

Institute of Development Studies (2010). An Upside down view of Governance.

Jackson-Preece, Jennifer (2010). Origins of Nation. Routledge Handbook of Ethnicity. Routledge. Jeronimo, Patricia (2011). Pacific Rim Law and Policy Journal 1, p. 28-44.

Jung, Dietrich (2008). State Formation and State-building: There is a Lesson to Learn from Sociology. DIIS report.

Kaplan, Seth (2008). Fixing Fragile States: A New Paradigm for Development. Preager Security International.

Kaplan, Seth (2009). Identity in Fragile States: Social Cohesion and State Building. Development $52(4)$, p. 466-472.

Kellsall, Tim (2008). Going with the Grain in Africa? African Power and Politics Program of ODI. Discussion paper.

Kertzer, David I. \& Dominique Ariel (2002). Census and Identity: The Politics of Race, Ethnicity and Language National Censuses. Cambridge: Cambridge University Press.

Kronenberg, Clemens \& Andreas Wimmer (2012) Struggling over Boundaries of Belonging: A Formal Model of Nation Building. Ethnic Closure and Populism. American Journal of Sociology 118(1), p. 176-230.

Kymlicka, Will (2001). Politics in the Vernacular. Oxford: Oxford University Press.

Le Vine, Victor T. (1997). Conceptualizing Ethnicity and Ethnic Conflict: A Controversy Revisited. Studies in Comparative International Development 32(2), p. 45-75.

Lehning, Percy B. (1998). Towards a Multicultural Civil Society: The Role of Social Capital and Democratic Citizenship. Government and Opposition 33(2), p. 221-242. 
Lemay-Herbert, Nicolas (2009). State-building Without Nation-building? Legitimacy, State Failure and the Limits of the Institutional Approach. Journal of Intervention and Statebuilding $3(1)$, p. 21-45.

Lewis, David (2001). Civil Society in Non-western Contexts: The Usefulness of a Concept. LSE Centre for Civil Society working paper no. 13 .

Linklater, Andrew (1990). The Problem of Community in International Relations. Alternatives 15(2), p. 135-153.

Linklater, Andrew (1998). Cosmopolitan Citizenship. Citizenship Studies 2(1), p. 23-41.

Logan, Carolyn (2009). Selected Chiefs, Elected Councilors and Hybrid Democrats: Popular Perspectives on Co-existence of Democracy and Traditional authority. Journal of Modern African Studies 47(1), p. 101-128.

Lotz, Christian (2010). International Norms in State-building: Finding a Pragmatic Approach. Global Governance 16, p. 219-236.

Lun, Mary Thida (2009). Reconnecting Joined up Approaches: Nation-building through Statebuilding? ODI, SPIRU working paper no. 25.

Luttwak, Edward (1999). Give War a Chance. Foreign Affairs 78(4).

MacIntyre, Alisdair (1984). Is Patriotism a Virtue? Liley lecture at Kansas University.

Mandami, Mahmood (2005). Political Identity, Citizenship and Ethnicity in Post-colonial Africa. Lecture at conference New Frontiers in Social Policy.

Mann, Michael (1993). Nation-states in Europe and Other Continents: Diversifying, Developing, not Dying. Daedalus 122(3), p. 115-140.

Marshall, Thomas H. (1996). Citizenship and Social Class. In Marshall, Thomas H. \& Tom Bottomore, Citizenship and Social Class. Pluto Press.

Melber, Henning (2002). From Liberation Movements to Governments: On Political Culture in Southern Africa. African Sociological Review 6(1), p. 161-172.

Metz, Thaddeus (2011). Ubuntu as a Moral Theory and Human Rights in South Africa. African Human Rights Law Journal 11(2), p. 523-559.

Miguel, Edward (2004). Tribe or Nation? Public Goods and Nation-building in Kenya versus Tanzania. World Politics 56(3), p. 328-362.

Moisi, Dominique (2009). The Geopolitics of Emotions. Random House.

Nairn, Tom (1993). Internationalism and the Second Coming. Daedalus 122(3), p. 155-170.

Nash, Kate (2009). Between Citizenship and Human Rights. Sociology 43(6), p. 1076-1083.

Natanson, Stephan (1989). Moderate Patriotism. Ethics 99, p. 535-552.

Nimni, Ephraim (2007). Stateless Nations in a World of Nation-states. In Cordell, Karl \& Stefan Wolff (eds.), Routledge handbook of Ethnic conflict. Routledge.

North, Douglas, John Joseph Wallis \& Barry R. Weingast (2012). Violence and Social Order. Cambridge: Cambridge University Press.

Nussbaum, Martha (2013). Political Emotions: Why Love Matters for Justice. Cambridge, MA: Harvard University Press.

OECD (2009). Concepts and Dilemmas of State Building in Fragile Situations: From Fragility to Resilience. Discussion paper.

OECD (2015). States of Fragility. Meeting post-2015 Ambitions.

Olukishi, Adebayo O. \& Liisa Laakso (1996). Challenges to the Nation-State in Africa. Nordiska Afrikainstitutet.

Osagahae, Egosha E. (2007). Fragile States. Development in Practice 17(4-5), p. 691-699. 
Paffenholz, Thania. Civil Society and Peace-building, CCDP working paper no. 4.

Pandian, Matthias (2009). Nation Impossible. Economic and Political Weekly 44 (10).

Patterson, Orlando (2014). Making Sense of Culture. Annual Review of Sociology 40, p. 1-30.

Pearce, Jenny (2007). Violence Power and Participation: Building Citizenship in Contexts ofChronic Violence, IDS working paper no. 274.

Pouligny, Beatrice (2005). Civil Society and Post-conflict Peace-building: Ambiguities of International Programs, Aimed at Building 'New' Societies. Security Dialogue 36(4), p. 495-510.

Putnam, Robert (2006). E pluribus Unum: Diversity and Community in the Twenty-First Century. John Skytte Price lecture.

Rawls, John (1989). The Domain of Political and Overlapping Consensus. New York University Law Review 64(2), p. 233-255.

Robinson, Amanda Lea (2009). National versus Ethnic Identity in Africa: State, Group and IndividualLevel Correlations of National Identification. Afrobarometer working paper no. 112.

Rodrik, Dani (2011). The Globalization Paradox: Democracy and the Future of the World Economy. W.W. Norton.

Rousseau, Jean-Jacques (1762). Du contrat social ou Principes du droit Politique, electronic version on http://classiques.uqac.ca/classiques/Rousseau_jj/contrat_social/Contrat_social.pdf

Ruane, Joseph \& Jennifer Todd. Ethnicity and Religion: Redefining the Research Agenda. Ethnopolitics 9(1), p. 1-8.

Santiso, Carlos (2001). God Governance and Aid Effectiveness, the World Bank and Conditionality. The Georgetown Public Policy Review 7(1), p. 1-22.

Sassen, Saskia (2002). The Repositioning of Citizenship: Emergent Subjects and Spaces for Politics. Berkeley Journal of Sociology 46, p. 4-25.

Shils, Edward (1995). Nation, Nationality and Nationalism and Civil Society. Nations and Nationalism 1(1), p. 93-118.

Shulman, Stephen (2002). Challenging the Civic-ethnic and East-West Dichotomies in the Study of Nationalism. Comparative Political Studies 35(5), p. 554-585.

Smith, Anthony D. (1991). National Identity. University of Nevada Press.

Somers, Margaret R. (1994). The Narrative Constitution of Identity: A Relational and Network Approach. Theory and Society 23(5), p. 605-649.

Stewart, Francis (2002). Horizontal Inequalities: A Neglected Dimension of Development. QEH/ University of Oxford, working paper no. 81.

Stewart, Francis (2009). Horizontal Inequalities: Two Types of Trap. Journal of Human Development and Capabilities 10(3), p. 315-340.

Stewart, Francis \& Graham Brown (2009). Fragile States, CRISE working paper no. 51.

Tamir, Yael (1995). The Enigma of Nationalism. World Politics 47(3), p. 418-440.

Tibi, Bassam (1998). Europa ohne Identität? Die Krise der multikulturellen Gesellschaft. Bertelsmann.

Tibi, Bassam (2012). Islam in Global Politics. Routledge.

Tilly, Charles (1985). War Making and State Making as Organized Crime. In Evans, Peter, Dietrich Rueschemeyer \& Theda Skocpol (eds.) From Bringing the State Back. Cambridge University Press, p. 169-191.

Tilly, Charles (2002). Self-determination as a Problem for All of Us. Daedalus 122(3), p. 29-33. 
UNDP (1994). Human Development Report.

Uvin, Peter (1999). Ethnicity and Power in Burundi and Rwanda: Different Paths to Massviolence. Comparative Politics 31(3), p. 253-271.

Varshney, Ashutosh (2001). Ethnic Conflict and Civil Society, India and Beyond. World Politics 53(3), p. 362-398.

Verdery, Katherine (1993). Whither Nation and Nationalism? Daedalus 122(3), p. 37-46.

Verdery, Katherine (1994). Ethnicity, Nationalism and State Making: Ethnic Groups and Boundaries, Past and Future. In Vermeulen, Hans \& Cora Govers, The Anthropology of Ethnicity.

Verkoren, Willemijn \& Bertine Kamphuis (2013). State Building in a Rentier State: How Development Policies Fail to Promote Democracy in Afghanistan. Development and Change 44(3), p. 501-526.

Vogelsang-Coombs, Vera D. \& Larry Bakken (2003). Dynamic Interpretations of Civic Duty: Implications for Governance. International Journal of Organizational Theory and Behavior 6(3), p. 442-46o.

Weber, Eugen (2013). Politik als Beruf. Das Elektronische Antiquariat.

Weijer, Frauke de \& Ulrika Kilnes (2012). Strengthening Civil Society? Reflections on International Engagement in Fragile States. ECDPM discussion paper no. 135.

Weiss, Thomas G. (2000). Governance, Good Governance and Global Governance: Conceptual and Actual Challenges. Third World Quarterly 21(5), p. 795-814.

Williams, Brackette F. (1989). A Class Act: Anthropology and the Race to Nation across Ethnic Terrain. Annual Review of Anthropology 18, p. 401-444.

Wimmer, Andreas (2002). Nationalist Exclusion and Ethnic Conflict: Shadows of Modernity. Cambridge: Cambridge University Press.

Wimmer, Andreas (2008). The Making and Unmaking of Ethnic Boundaries: A Multilevel Process Theory. American Journal of Sociology 113(4), p. 970-1022.

Wimmer, Andreas \& Nina Glick Schiller (2002). Methodological Nationalism and Beyond: Nation-state, Migration and Social Sciences. Global Networks 2(4), p. 301-334.

World Bank (2011). World Bank Development Report 2011: Conflict Security Development.

World Bank (2012). Guidance for Supporting State Building in Fragile and Conflict Affected States: A Tool Kit.

WRR (2007). Identificatie met Nederland. Amsterdam: Amsterdam University Press.

Young, Crawford (1994). Ethnic Diversity and Public Policy: An Overview. UNRISD occasional paper World Summit for Social Development.

Young, Crawford (2004). The End of the Post-colonial State in Africa? Reflections on Changing African Political Dynamics. African Affairs 103, p. 23-49.

Zajda, Joseph (2009). Nation Building and Cultural Identity: The Role of Intercultural Dialogue. Zajda, Joseph, Holder Daun \& Lawrence J. Saha (eds.), Nation-Building, Identity and Citizenship building. Springer.

Žižek, Slavoj (1990). Eastern European Republics of Gilead. New Left Review 1(183), p. 50-62.

Žižek, Slavoj (1997). Multiculturalism or the Cultural Logic of Multinational Capitalism. New Left Review 1(225), p. 28-51.

Zwart, Tom (2012). Using Local Culture to Further the Implementation of International Human Rights. Human Rights Quarterly 34(2), p. 546-569. 


\section{Index}

Afghanistan $10-12,15,18,22-23,35-36,45,47$, $5^{0}, 54,64-65,71,74-76,79,81,83-85,87,92$, 94-95, 103, 115-117, 125-126, 129-132, 138, 154, $163-165,173,178-179,184-187$

Agenda for Peace 93-94

Ancestry $122,127-128,132,134,144-146$

ASEAN $37-38,122,189$

Authority $27,29,33,38,41,49,59,64-65$, $69,75,82-83,86,93,130,137,140,153,15^{8}$, $172-175,185$

Bangsamoro $120,148-152$

Basic social services $12,15,26,36,38,41,47$, $64,81,92,134,173,189$

Berlijn, Dick 184

British Overseas Development Institute (ODI) $\quad 11,53$

Burundi $51,107,183$

Capacity $13,25,46,48-49,53,63,65,73-75$, $153,172-173$

Catalonia $\quad 23,31,38$

Christianity $132,137-138,146,158$

Citizen Forum 103, 163-166, 169

Citizenship $\quad 59-70,75,102,127,129,132$, 134-135, 144-146, 156-157, 161-162, 167, 180 Communitarian perspective $\quad 62$ Global citizenship 70 Ius sanguis $\quad 67-68,144,167$ Ius solis $\quad 67-68,156,167$ Republican citizenship $\quad 61-64,161-162$ Utilitarian perspective 62

Civil Society $\quad 51,53,65,73,110,166,168-171,175$

Colombia 11, 49, 100, 116, 174, 191

Conflict trap 96

Cordaid $9-10,43,52,65,71,92,95,107,178-179$, 191

Democratic Republic of Congo (DRC) 11, $5^{2}$, $56,76,85,118,129-132,155,173,183,185,187$

Diversity 13-14, 29-30, 39-40, 51, 61, 66, 70, 91, 101, 104-105, 110-111, 114-116, 119-122, 132, 139, $150,152,156-161,169,174,180$ Ethnic diversity 111

Ecowas 37

Effectiveness $11,48,65,70,75^{-7} 76,83,168,185$ Effective government 36

Elite $19,41,76,90-91,168-169,189$

Ethnicity $10,12,21,54,62,77,84,113,125$, $127-128,134-135,141-146,156,161,188$

European Union (EU) 37-38, 68-69, 104
Globalization $\quad 18,25,37,41,62,69,78,91$, $101-104,126,133,137,158-159$

Good governance $35-37,56,83,107,185$

Heterogeneity $115^{-117}$

Homogeneity 14, 90-91, 109-111, 115-116

Homogeneous societies 39, 101

Human Rights $\quad 30,36,45-46,69,94,107,110$, 175,180

Human security 54, 94

Hybrid Political order $\quad 5^{0-51}$

Identification $14,20,22,26,28,30,73,76,80$, $84,109,111-113,115,126,128,132,134-136,138$, $142,155^{-1} 5^{6}, 159^{-160}, 165$

Identity

Civic identity $\quad 127-130,13^{2-135}, 146,155^{-15} 6$, 161

Cross-border identity 159

Cultural identity $12,127-128,131-133,140$, 157

Ethnic identity $9,81,114,125,141-144,154$, 156

Religious identity $\quad 29,103,125,136,156,165$ Sub-national identity $\quad 156-157,163$

Illiberal democracies 49,180

Inclusiveness $47,164,174,178$

Institution-building $12,75-78,185$

Integrity $48,65,70,75$

Interconnectedness 91, 101

International Dialogue on Peace-Building and State-Building (IDPS) 11, 46, 54

Dili declaration 54

International law $\quad 25,38,80,98,115,170$

Iraq $10,12,16,18,22-23,31,74,83-84,115,117$, $130,140,176$

ISAF $\quad 15,64,71,92,94,115,176,178-179,184$

Islam 21, 131, 138-140, 146, 158

Kagame, Paul $\quad$ 180-181, 188

Kenya $9-10,50,63,68,116,118,125,176$

Legitimacy $\quad 13,20,30,33-35,40,48-49,54$, 59-6o, 65, 70, 75-76, 80, 83, 86, 129, 137, 150, $153,160,162,168-170,172-175,178-179,185-186$ Leitkultur 30, 110-111

Lekgotla 163-164

Liberal democracy 130

Liberia $\quad 11,17-18,48,164,173,176$

Loya Jirga $\quad 131,163-165$

Loyalty $\quad 30-32,73,86-89,144-145,169,185$ 
Mali $10,35,49-50,118,126,135,155,173,186$, 188

Mercosur $\quad 37,189$

Migration $29-30,36,39,68-70,77,91,101,104$, $110,115-116,122,126,129,132,137,146,150,159$, 167,172

Millennium Development Goals (MDG's) 11, $18,5^{2}, 183$

Minorities 39, 81, 90, 114, 116-119, 144, 156

Moderate patriotism 105-106

Modernity $\quad 23,28,32,59,91,101,110,128,138$

Montevideo (convention) 25, 27, 29, 32

Moral universalism 102,105

Multiculturalism 77,110

Multiple identities $117,128,154$

Multistakeholder process $\quad 153,160,170,175$

Nationalism $\quad 13,89,101-106,109,127,143$

Nationhood $26,29-32,41,46-47,51,67,73-75$, $79,83,85-86,91,109,113-117,120,125,134-136$, $140,141,154,157,166,173$

Sense of belonging $\quad 29-33,79-84,86-87$, $98,101,111-118,121,126,136,144,155,157$, $165^{-168,171, ~} 175$

Organization for Economic Cooperation and Development (OECD) 11, 46, 50, 56, 73-74, 183

Paris Declaration on Aid Effectiveness 11

Peace-building $\quad 46,73,79,86,95-99$

Peacekeeping $18,46,93$

Peacemaking $13,34,84,93-99,168,170,173$ Philippines 21, 103, 105, 120, 148-150, 154, 174

Quebec 23,120
Race $61,112,132,134,145-146,156$

Religion 10, 12, 33, 54, 61-62, 81, 91, 94, 111-112, 127-128, 131-139, 142, 146, 148, 156-159, 161, 165,167

Responsibility to Protect $(\mathrm{R} 2 \mathrm{P}) 34,54,94$

Rwanda 50, 94, 102, 131, 133, 145, 180-181

Scotland 23, 31, 38, 68-69

Secession $17,21,39-41,135,15^{0}, 174,176$

Self-determination $\quad 21,90,148-149$

Sierra Leone $17-18,48,50,173,176$

Social capital $\quad 51,97,166-167,175$

Bonding $51,97,167$

Bridging $51,97,167,175$

Social cohesion $\quad 39,79-80,95,114,164-165$

Social contract $\quad 63,79$

Somalia $21,38,54,81,99,138$

South Sudan 9-11, 16-17, 22-23, 34, 39, 41, 43, $5^{0}, 68,83-84,99,116-117,125,130,174,176$

Sovereignty $13,20-23,32-33,59-65,67-68,70$, $75,91,135,153-154,160$

Sustainable Development Goals (SDG's) 11, 183,185

Timor-Leste $\quad 38,48,54,99,116,173$

Tribal $84,95,114,117-118,125,158,168$

Ubuntu 36, 130-131, 188

United Nations $\quad 15,19,34-35,90,93,179$

Universal Declaration of Human Rights 69 , 90

Unrepresented Nations and Peoples Organization (UNPO) 35

Westphalian Peace Treaties $\quad$ 29, 33-34, 90, 137 World Bank $45-46,49,52,73,75,83$ 